Article

\title{
New $\alpha$-Methylene- $\gamma$-Butyrolactone Derivatives as Potential Fungicidal Agents: Design, Synthesis and Antifungal Activities
}

\author{
Yongling Wu, Delong Wang, Yanqing Gao, Juntao Feng * and Xing Zhang
}

Research \& Development Center of Biorational Pesticide, Key Laboratory of Plant Protection Resources and Pest Management of Ministry of Education, Northwest A \& F University, Xinong Road 22, Yangling 712100, Shaanxi, China; wuyongling39@126.com (Y.W.); rizhaoalong@163.com (D.W.); gaoyanqinggc@nwsuaf.edu.cn (Y.G.); zhxing1952@126.com (X.Z.)

* Correspondence: fengjt67@hotmail.com; Tel./Fax: +86-29-8709-2122

Academic Editor: Thomas J. Schmidt

Received: 10 December 2015 ; Accepted: 19 January 2016 ; Published: 22 January 2016

\begin{abstract}
In consideration of the fact that the $\alpha$-methylene- $\gamma$-butyrolactone moiety is a major bio-functional group in the structure of carabrone and possesses some agricultural biological activity, forty-six new ester and six new ether derivatives containing $\alpha$-methylene- $\gamma$-butyrolactone moieties were synthesized, and their fungicidal activities against Colletotrichum lagenarium and Botrytis cinerea were investigated. Most of the synthesized compounds showed moderate to significant fungicidal activity. Among them, halogen atom-containing derivatives showed better activity than others, especially compounds $\mathbf{6 a}, \mathbf{d}$ which exhibited excellent fungicidal activity against $C$. lagenarium, with $\mathrm{IC}_{50}$ values of 7.68 and $8.17 \mu \mathrm{M}$. The structure-activity relationship (SAR) analysis indicated that ester derivatives with electron-withdrawing groups on the benzene ring showed better fungicidal activity than those with electron-donating groups. A quantitative structure-activity relationship (QSAR) model $\left(R^{2}=0.9824, F=203.01, S^{2}=0.0083\right)$ was obtained through the heuristic method. The built model revealed a strong correlation of fungicidal activity against $C$. lagenarium with the molecular structures of these compounds. These results are expected to prove helpful in the design and exploration of low toxicity and high efficiency $\alpha$-methylene- $\gamma$-butyrolactone-based fungicides.
\end{abstract}

Keywords: $\alpha$-methylene- $\gamma$-butyrolactone; ester and ether derivatives; antifungal activity; quantitative structure-activity relationships (QSAR); heuristic method

\section{Introduction}

Plant pathogenic fungi remain a main cause of plant diseases, which can infect any tissue of a plant and cause severe yield agricultural product losses [1-3]. Moreover, the presence of some phyto-fungal mycotoxins can be harmful to animal and human health [4]. Colletotrichum lagenarium and Botrytis cinerea are the most common plant pathogenic fungi, and can cause cross-infections between diseased and healthy plants [5-7]. In addition, they cause significant reductions of crop yield and quality [8]. Traditional chemical fungicides play an important role in killing or controlling target fungi directly, but sometimes cause adverse effects to the environment and food, and often create fungicide resistance [9]. Therefore, it is urgent to develop novel and effective fungicidal agents to protect plants.

The $\alpha$-methylene- $\gamma$-butyrolactone ring can be found as a key substructural unit in many sesquiterpenoids (Figure 1). It exhibits multiple biological properties, including antibacterial, cytotoxic, antiinflammatory, antioxidant, allergenic and antimicrobial activity [10-16]. In our previous research, we found that carabrone (which is isolated from fruits of Carpesium macrocephalum) and its derivatives 
exhibited potent antifungal activity against C. lagenarium, and the structure-activity relationship (SAR) analysis of these compounds indicated that the $\alpha$-methylene- $\gamma$-butyrolactone ring was a major biofunctional group in the carabrone structure [17-20]. Besides, $\gamma$-monosubstituted compounds of the $\alpha$-methylene- $\gamma$-lactone ring have also been synthesized, and we concluded that aromatic substituents directly fused to the $\gamma$-position improved the potency more effectively than alkyl groups. Meanwhile, the cytotoxicity was tested to ensure the selectivity of the fungicidal effects [21].

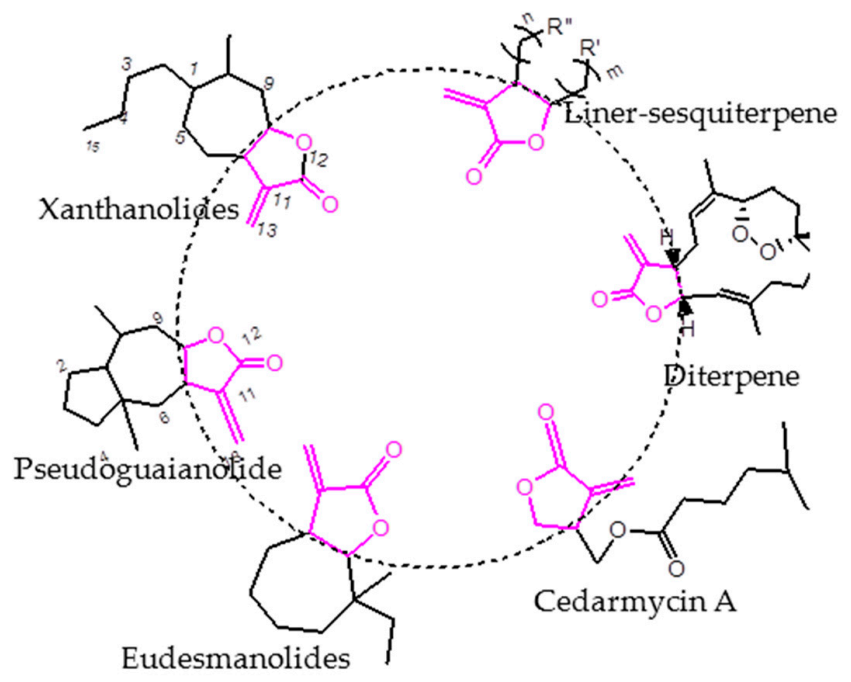

Figure 1. Some representative sesquiterpenoid structures.

It is virtually and economically impossible to develop and screen candidates with fungicidal activity from among numberless compounds. The development of new quantitative structure-activity relationship (QSAR) methods, with simple molecular indexes, is a promising shortcut to resolve the cost and time issues [22]. The QSAR method enables the calculation of numerous quantitative descriptors on the basis of molecular structural information and is very useful to optimize important aspects such as fungicidal activity or toxicity. Meanwhile, QSAR is useful in provide further guidance for the design and development of potential new fungicides [23,24].

In order to obtain novel natural product-based fungicides, two series of derivatives based on $\gamma$-monosubstituted $\alpha$-methylene- $\gamma$-butyrolactone rings were synthesized on the basis of their molecular similarity. The fungicidal activities of these compounds against $C$. lagenarium and B. cinerea were investigated and their structures were characterized by ${ }^{1} \mathrm{H}-\mathrm{NMR},{ }^{13} \mathrm{C}-\mathrm{NMR}$, and HRMS spectrometric analysis. Meanwhile, the cytotoxicity was tested to ensure selectivity of the antifungal effects. Moreover, a QSAR study was also performed on all of the derivatives using the Gaussian and CODESSA software packages, which can correlate their structural features with their fungicidal activity.

\section{Results and Discussion}

\subsection{Synthesis}

Three kinds of intermediate compounds 4-6 were prepared by the cyclization of $\gamma$-hydroxy$\alpha$-methylene esters, which were obtained under mild aqueous reaction conditions through indium-mediated Barbier allyl addition to aldehydes [25]. In order to investigate the structure-activity relationships, different acids were reacted with the three kinds of intermediate compounds to obtain the corresponding ester compounds. Then, six new ether compounds were obtained by reacting with them with brominated alkanes. The structures of all the derivatives were characterized by ${ }^{1} \mathrm{H}-\mathrm{NMR}$, ${ }^{13} \mathrm{C}-\mathrm{NMR}$ and high-resolution electrospray ionization mass spectrometry (HR-ESI-MS). The synthetic routes are shown in Scheme 1. 


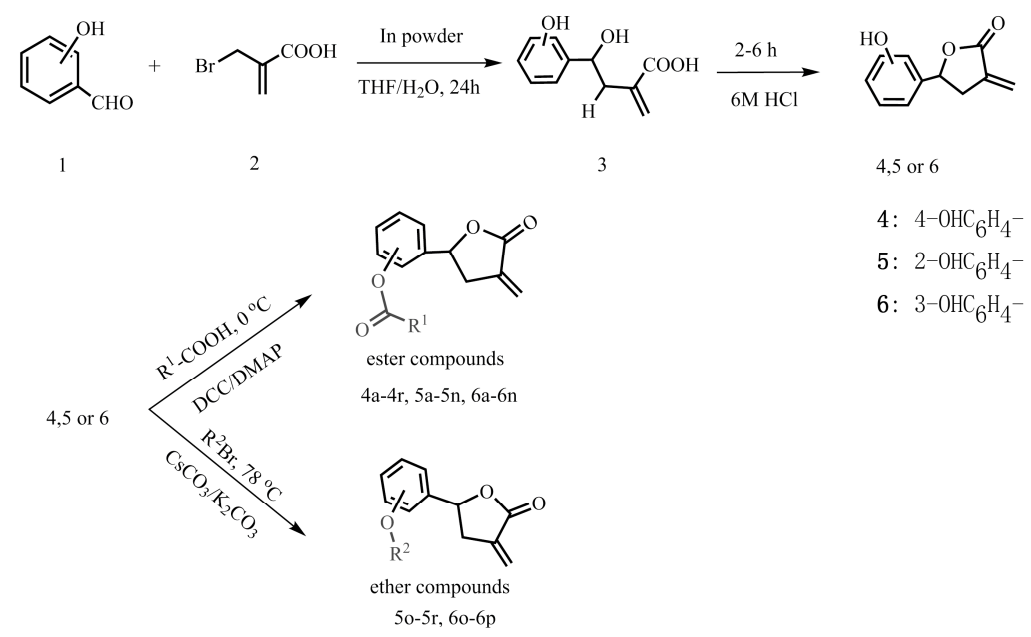

\begin{tabular}{|c|c|c|c|}
\hline 4a: $\mathrm{R}^{1}=2-\mathrm{ClC}_{6} \mathrm{H}_{4}-$ & $40: \mathrm{R}^{1}=4-\mathrm{OCH}_{3} \mathrm{C}_{6} \mathrm{H}_{4}-$ & $5 \mathrm{j}: \mathrm{R}^{1}=4-\mathrm{CH}_{3} \mathrm{C}_{6} \mathrm{H}_{4}-$ & 6e: $\mathrm{R}^{1}=4-\mathrm{BrC}_{6} \mathrm{H}_{4-}^{-}$ \\
\hline $4 b: \mathrm{R}^{1}=3-\mathrm{ClC}_{6} \mathrm{H}_{4}-$ & $4 \mathrm{p}: \mathrm{R}^{1}=\mathrm{CH}_{3} \mathrm{CH}_{2}-$ & $5 \mathrm{k}: \mathrm{R}^{1}=2-\mathrm{OCH}_{3} \mathrm{C}_{6} \mathrm{H}_{4}-$ & 6f: $\mathrm{R}^{1}=\mathrm{C}_{6} \mathrm{H}_{5-}$ \\
\hline $4 \mathrm{c}: \mathrm{R}^{1}=4-\mathrm{ClC}_{6} \mathrm{H}_{4-}$ & $4 q: \mathrm{R}^{1}=4-\mathrm{OH}-3-\mathrm{OCH}_{3}$ & 51: $\mathrm{R}^{1}=3-\mathrm{OCH}_{3} \mathrm{C}_{6} \mathrm{H}_{4-}$ & 6g: $\mathrm{R}^{1}=2-\mathrm{CH}_{3} \mathrm{C}_{6} \mathrm{H}_{4-}$ \\
\hline $4 \mathrm{~d}: \mathrm{R}^{1}=2-\mathrm{BrC}_{6} \mathrm{H}_{4}-$ & $\mathrm{C}_{6} \mathrm{H}_{4}-\mathrm{CH}=\mathrm{CH}-$ & $5 \mathrm{~m}: \mathrm{R}^{1}=n-\mathrm{C}_{3} \mathrm{H}_{7-}$ & $6 \mathbf{h}: \mathrm{R}^{1}=3-\mathrm{CH}_{3} \mathrm{C}_{6} \mathrm{H}_{4-}$ \\
\hline 4e: $\mathrm{R}^{1}=3-\mathrm{BrC}_{6} \mathrm{H}_{4}-$ & $4 \mathrm{r}: \mathrm{R}^{1}=\mathrm{C}_{6} \mathrm{H}_{5} \mathrm{CH}=\mathrm{CH}-$ & $5 \mathrm{n}: \mathrm{R}^{1}=4-\mathrm{OH}-3-\mathrm{OCH}_{3}$ & $6 \mathbf{i}: \mathrm{R}^{1}=4-\mathrm{CH}_{3} \mathrm{C}_{6} \mathrm{H}_{4-}$ \\
\hline 4f: $\mathrm{R}^{1}=4-\mathrm{BrC}_{6} \mathrm{H}_{4-}$ & $5 \mathrm{a}: \mathrm{R}^{1}=3-\mathrm{ClC}_{6} \mathrm{H}_{4}-$ & $\mathrm{C}_{6} \mathrm{H}_{4}-\mathrm{CH}=\mathrm{CH}-$ & $6 \mathbf{j}: \mathrm{R}^{1}=2-\mathrm{OCH}_{3} \mathrm{C}_{6} \mathrm{H}_{4}-$ \\
\hline $4 \mathrm{~g}: \mathrm{R}^{1}=3-\mathrm{CNC}_{6} \mathrm{H}_{4-}$ & $5 b: \mathrm{R}^{1}=4-\mathrm{ClC}_{6} \mathrm{H}_{4}-$ & 5o: $\mathrm{R}^{2}=n$-Butyl & 6k: $\mathrm{R}^{1}=3-\mathrm{OCH}_{3} \mathrm{C}_{6} \mathrm{H}_{4}-$ \\
\hline $4 \mathrm{~h}: \mathrm{R}^{1}=4-\mathrm{CNC}_{6} \mathrm{H}_{4-}$ & $5 \mathrm{c}: \mathrm{R}^{1}=2-\mathrm{BrC}_{6} \mathrm{H}_{4-}$ & 5p: $\mathrm{R}^{2}=n$-Propyl & 61: $\mathrm{R}^{1}=4-\mathrm{OCH}_{3} \mathrm{C}_{6} \mathrm{H}_{4-}$ \\
\hline $4 \mathbf{i}: \mathrm{R}^{1}=\mathrm{C}_{6} \mathrm{H}_{5}-$ & $5 \mathrm{~d}: \mathrm{R}^{1}=3-\mathrm{BrC}_{6} \mathrm{H}_{4-}^{-}$ & 5q: $\mathrm{R}^{2}=i$-Propyl & $6 \mathrm{~m}: \mathrm{R}^{1}=\mathrm{CH}_{3} \mathrm{CH}_{2}-$ \\
\hline $4 \mathrm{j}: \mathrm{R}^{1}=2-\mathrm{CH}_{3} \mathrm{C}_{6} \mathrm{H}_{4-}$ & 5e: $\mathrm{R}^{1}=4-\mathrm{BrC}_{6} \mathrm{H}_{4-}$ & 5r: $\mathrm{R}^{2}=$ Ethyl & 6n: $\mathrm{R}^{1}=\mathrm{C}_{6} \mathrm{H}_{5} \mathrm{CH}=\mathrm{CH}-$ \\
\hline $4 \mathbf{k}: \mathrm{R}^{1}=3-\mathrm{CH}_{3} \mathrm{C}_{6} \mathrm{H}_{4-}$ & $5 \mathrm{f}: \mathrm{R}^{1}=4-\mathrm{CNC}_{6} \mathrm{H}_{4}-$ & 6a: $\mathrm{R}^{1}=3-\mathrm{ClC}_{6} \mathrm{H}_{4-}$ & 6o: $\mathrm{R}^{2}=n$-Butyl \\
\hline 4l: $\mathrm{R}^{1}=4-\mathrm{CH}_{3} \mathrm{C}_{6} \mathrm{H}_{4-}$ & $5 \mathrm{~g}: \mathrm{R}^{1}=\mathrm{C}_{6} \mathrm{H}_{5-}$ & 6b: $\mathrm{R}^{1}=4-\mathrm{ClC}_{6} \mathrm{H}_{4-}$ & 6p: $\mathbf{R}^{2}=n$-Propyl \\
\hline $4 \mathrm{~m}: \mathrm{R}^{1}=2-\mathrm{OCH}_{3} \mathrm{C}_{6} \mathrm{H}_{4-}$ & $5 \mathrm{~h}: \mathrm{R}^{1}=2-\mathrm{CH}_{3} \mathrm{C}_{6} \mathrm{H}_{4-}$ & $6 \mathrm{c}: \mathrm{R}^{1}=2-\mathrm{BrC}_{6} \mathrm{H}_{4-}$ & \\
\hline $4 n: \mathrm{R}^{1}=3-\mathrm{OCH}_{3} \mathrm{C}_{6} \mathrm{H}_{4}-$ & $5 \mathrm{i}: \mathrm{R}^{1}=3-\mathrm{CH}_{3} \mathrm{C}_{6} \mathrm{H}_{4-}$ & $6 \mathrm{~d}: \mathrm{R}^{1}=3-\mathrm{BrC}_{6} \mathrm{H}_{4-}$ & \\
\hline
\end{tabular}

Scheme 1. Synthetic route of the title compounds.

\subsection{Fungicidal Activity and Structure-Activity Relationships (SAR)}

\subsubsection{Fungicidal Activity of the Title Compounds against $C$. lagenarium}

The results of the fungicidal activity against $C$. lagenarium are summarized in Table 1, from which it can be seen that the halogen atom-containing derivatives exhibited significant fungicidal activity against this species. The following three main SARs were obtained: first, the introduction of the electron-withdrawing groups $\mathrm{Cl}, \mathrm{Br}$, and $\mathrm{CN}$ onto the benzene ring dramatically increased the potency. Compounds $\mathbf{4 a - f}$, $5 \mathbf{a}-\mathbf{e}$, and $\mathbf{6 a}-\mathbf{e}\left(\mathrm{IC}_{50}<18 \mu \mathrm{M}\right)$ exhibited fungicidal activity approximately ten to twenty fold higher than the intermediate compounds 4-6, respectively. It was notable that the $\mathrm{IC}_{50}$ values of $\mathbf{6 a}, \mathbf{d}$ were approximately two fold lower than those of chlorothalonil, a commercial fungicide. Meanwhile, the electron-donating groups $\mathrm{CH}_{3}$ and $\mathrm{CH}_{3} \mathrm{O}$ introduced onto the benzene ring to give $\mathbf{4 j - 0}, \mathbf{5 h}-\mathbf{l}$ and $\mathbf{6 g}-\mathbf{1}\left(\mathrm{IC}_{50}>126 \mu \mathrm{M}\right)$ greatly weakened the potency, which was similar to that of the fatty acid derivatives $4 p, 5 \mathrm{~m}$ and $6 \mathrm{~m}$. It can be concluded that the electronic effect of the substituent on the benzene ring is important for the fungicidal activity of $\alpha$-methylene- $\gamma$-butyrolactone groups. Second, intermediate compound $\mathbf{6}$ was found to have higher activity than the corresponding intermediate compounds 4 and 5. Meanwhile, meta-substitution on the benzene ring (compounds 6a-p) was found to improve the potency significantly compared with the corresponding ortho- and para-substitution patterns (compounds $4 \mathbf{a}-\mathbf{r}$ and $\mathbf{5 a}-\mathbf{r}$ ). This result suggests that the steric effect should be considered and substitution patterns on the benzene ring have an important influence on the fungicidal activity. Third, all of the synthesized ether compounds exhibited lower fungicidal activity against $C$. lagenarium than the corresponding ester compounds. It was notable that the cinnamic 
acid and fumalic acid derivatives $4 \mathbf{q}-\mathbf{r}, 5 \mathrm{n}$ and $\mathbf{6 n}$ containing an unsaturated bond showed higher fungicidal activity against $C$. lagenarium.

Table 1. In vitro fungicidal activity of compounds against C. lagenarium and B. cinerea.

\begin{tabular}{|c|c|c|c|c|c|c|c|}
\hline \multirow{2}{*}{ Compd. } & \multicolumn{2}{|c|}{ C. lagenarium } & \multirow{2}{*}{$\begin{array}{l}\text { B. cinerea } \\
\mathrm{IC}_{50}{ }^{\mathrm{a}}, \mu \mathrm{M}\end{array}$} & \multirow{2}{*}{ Compd. } & \multicolumn{2}{|c|}{ C. lagenarium } & \multirow{2}{*}{$\begin{array}{l}\text { B. cinerea } \\
\mathrm{IC}_{50}{ }^{\mathrm{a}}, \mu \mathrm{M}\end{array}$} \\
\hline & $\mathrm{IC}_{50}{ }^{\mathrm{a}}, \mu \mathrm{M}$ & $\mathrm{pIC}_{50}$ & & & $\mathrm{IC}_{50}{ }^{\mathrm{a}}, \mu \mathrm{M}$ & $\mathrm{pIC}_{50}$ & \\
\hline $4 a$ & 13.96 & -1.145 & 29.81 & $5 \mathrm{k}$ & 291.95 & -2.465 & 306.85 \\
\hline $4 b$ & 8.99 & -0.954 & 22.13 & 51 & 283.99 & -2.453 & 303.36 \\
\hline $4 c$ & 12.74 & -1.105 & 27.31 & $5 \mathrm{~m}$ & 173.74 & -2.240 & 205.50 \\
\hline $4 d$ & 15.62 & -1.194 & 24.09 & $5 n$ & 10.27 & -1.012 & 20.57 \\
\hline $4 e$ & 8.76 & -0.943 & 30.24 & 50 & 413.72 & -2.617 & 456.91 \\
\hline $4 f$ & 14.38 & -1.158 & 23.01 & $5 p$ & 499.33 & -2.698 & 524.54 \\
\hline $4 g$ & 52.87 & -1.723 & 60.61 & $5 q$ & 428.93 & -2.632 & 446.08 \\
\hline $4 h$ & 65.63 & -1.817 & 77.00 & $5 r$ & 519.42 & -2.716 & 548.63 \\
\hline $4 i$ & 95.38 & -1.979 & 111.77 & $6 a$ & 7.68 & -0.885 & 23.32 \\
\hline $4 j$ & 192.44 & -2.284 & 198.67 & $6 b$ & 9.24 & -0.966 & 29.08 \\
\hline $4 k$ & 177.96 & -2.250 & 193.28 & $6 c$ & 10.27 & -1.012 & 27.45 \\
\hline 41 & 188.93 & -2.276 & 209.12 & $6 d$ & 8.17 & -0.912 & 25.99 \\
\hline $4 \mathrm{~m}$ & 238.97 & -2.378 & 243.35 & $6 e$ & 9.70 & -0.987 & 27.15 \\
\hline $4 n$ & 212.50 & -2.327 & 224.16 & $6 f$ & 73.14 & -1.864 & 101.94 \\
\hline 40 & 219.44 & -2.341 & 230.85 & $6 \mathrm{~g}$ & 159.33 & -2.202 & 179.62 \\
\hline $4 p$ & 206.51 & -2.315 & 236.62 & $6 \mathrm{~h}$ & 125.71 & -2.099 & 147.84 \\
\hline $4 q$ & 8.93 & -0.951 & 21.50 & $6 i$ & 136.55 & -2.135 & 163.84 \\
\hline $4 r$ & 44.51 & -1.648 & 56.32 & $6 j$ & 162.30 & -2.210 & 196.45 \\
\hline $5 a$ & 16.77 & -1.225 & 30.57 & $6 \mathrm{k}$ & 135.95 & -2.133 & 161.43 \\
\hline $5 b$ & 17.74 & -1.249 & 34.51 & 61 & 154.27 & -2.188 & 179.33 \\
\hline $5 c$ & 15.94 & -1.202 & 34.60 & $6 \mathrm{~m}$ & 173.23 & -2.239 & 202.97 \\
\hline $5 d$ & 13.41 & -1.127 & 22.93 & $6 n$ & 24.25 & -1.385 & 40.26 \\
\hline $5 e$ & 15.35 & -1.186 & 36.10 & 60 & 242.03 & -2.384 & 280.01 \\
\hline $5 f$ & 79.07 & -1.898 & 95.02 & $6 p$ & 266.25 & -2.425 & 298.26 \\
\hline $5 g$ & 170.80 & -2.232 & 193.75 & 4 & 160.63 & -2.206 & 207.99 \\
\hline $5 \mathrm{~h}$ & 215.94 & -2.334 & 229.37 & 5 & 238.61 & -2.378 & 279.96 \\
\hline $5 i$ & 181.69 & -2.259 & 193.87 & 6 & 117.12 & -2.069 & 139.85 \\
\hline $5 \mathbf{j}$ & 207.63 & -2.317 & 259.27 & Chlorothalonil ${ }^{b}$ & 4.21 & -0.624 & 8.31 \\
\hline
\end{tabular}

Note: a All $50 \%$ inhibition concentration $\left(\mathrm{IC}_{50}\right)$ values are presented as the means $\pm \operatorname{SD}(n=3), \mu \mathrm{M} ;{ }^{\mathrm{b}}$ Commercial fungicide, chlorothalonil was used as the positive control.

\subsubsection{Fungicidal Activity of the Title Compounds against B. cinerea}

The results of the fungicidal activity against $B$. cinerea are summarized in Table 1, from which we can see that compounds $\mathbf{4 a - f}, \mathbf{4 q}, \mathbf{5 a}-\mathbf{e}, \mathbf{n}$ and $\mathbf{6 a}-\mathbf{e}$ exhibited moderate fungicidal activity against B. cinerea. All of the test compounds were less effective than against C. lagenarium.

\subsection{QSAR Study on the Fungicidal Activity against C. lagenarium}

In general, descriptors used in QSAR can be categorized as constitutional, topological, geometrical, electrostatic, quantum chemical, and thermodynamic. There are many regression approaches available for the CODESSA 2.7.15 software, such as the best multi-linear, multi-linear regression, principal component analysis, partial least square regression, and heuristic regression [26]. In view of the number of samples and descriptors used in this study, the heuristic regression was selected for developing the QSAR model.

Determining the number of descriptors is an important step. The "breaking point" rule was used in the improvement of the statistical quality of the model, as described in Figure 2, the $R^{2}$ value of the heuristic regression had a dramatic increase before the number of the descriptors reached 5 , descriptors with high $t$ values were accepted and those with low $t$ values were rejected. After the number of the descriptors reached a certain value, the improvement of the regression model became less insignificant 
$\left(\Delta R^{2}<0.02-0.04\right)$ [27]. In addition, the number of the descriptors complies to the linear regressions given by Equation (1):

$$
N \geqslant 3(K+1)
$$

where $N$ is the number of sample compounds and $K$ is the number of descriptors. Thus, the final model with five descriptors was selected as the best model. The values of the five descriptors of compounds can be found in Table 2.

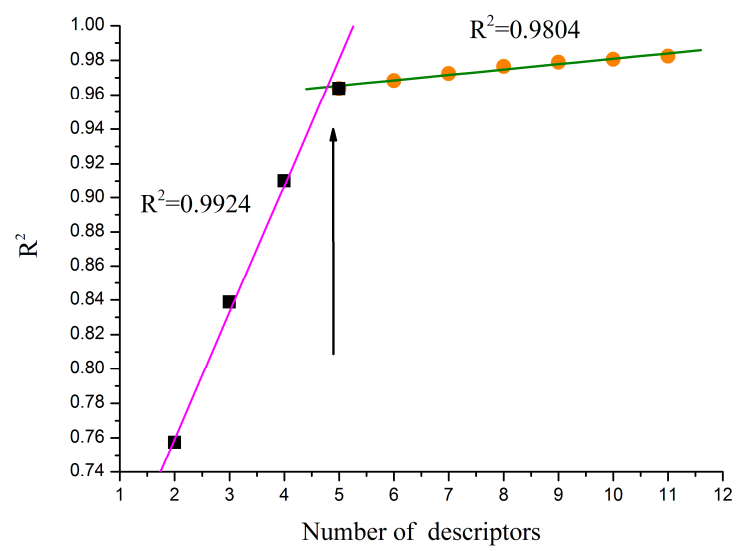

Figure 2. The "breaking point" rule results.

Table 2. Fungicidal activity and structural descriptors of the title compounds.

\begin{tabular}{|c|c|c|c|c|c|c|c|}
\hline \multirow{2}{*}{ No. } & \multirow{2}{*}{ Compd. } & \multirow{2}{*}{$\mathrm{pIC}_{50}$} & \multicolumn{5}{|c|}{ Structural Descriptors } \\
\hline & & & $N_{\mathbf{o}}$ & $q^{\mathrm{C}_{\max }}$ & MAOEP & $q^{\mathrm{H}_{\max }}$ & $q_{\text {min }}^{\mathrm{H}}$ \\
\hline 1 & $4 \mathbf{a}$ & -1.1450 & 1.6111 & 0.3570 & 1.9821 & 0.1606 & 0.1084 \\
\hline 2 & $4 b$ & -0.9540 & 1.6111 & 0.3568 & 1.9820 & 0.1716 & 0.1084 \\
\hline 3 & $4 c$ & -1.1050 & 1.6111 & 0.3571 & 1.9820 & 0.1628 & 0.1084 \\
\hline 4 & $4 d$ & -1.1940 & 1.6111 & 0.3532 & 1.9751 & 0.1613 & 0.1078 \\
\hline 5 & $4 e$ & -0.9430 & 1.6111 & 0.3571 & 1.9851 & 0.1712 & 0.1084 \\
\hline 6 & $4 f$ & -1.1580 & 1.6111 & 0.3555 & 1.9669 & 0.1631 & 0.1085 \\
\hline 7 & $4 \mathrm{~g}$ & -1.7230 & 1.5946 & 0.3558 & 1.9135 & 0.1708 & 0.1088 \\
\hline 8 & $4 \mathrm{~h}$ & -1.8170 & 1.5946 & 0.3533 & 1.9134 & 0.1655 & 0.1088 \\
\hline 9 & $4 \mathbf{i}$ & -1.9790 & 1.5278 & 0.3575 & 1.9133 & 0.1603 & 0.1082 \\
\hline 10 & $4 j$ & -2.2840 & 1.4872 & 0.3595 & 1.9132 & 0.1601 & 0.0821 \\
\hline 11 & $4 k$ & -2.2500 & 1.4872 & 0.3577 & 1.9133 & 0.1602 & 0.0872 \\
\hline 12 & 41 & -2.2760 & 1.4872 & 0.3588 & 1.9133 & 0.1601 & 0.0885 \\
\hline 13 & $4 \mathrm{~m}$ & -2.3780 & 1.5250 & 0.3658 & 1.9138 & 0.1598 & 0.0751 \\
\hline 14 & $4 n$ & -2.3270 & 1.5250 & 0.3558 & 1.9133 & 0.1721 & 0.0735 \\
\hline 15 & 40 & -2.3410 & 1.5250 & 0.3616 & 1.9135 & 0.1608 & 0.0771 \\
\hline 16 & $4 p$ & -2.3150 & 1.4688 & 0.3342 & 1.9125 & 0.1610 & 0.0843 \\
\hline 17 & $4 q$ & -0.9210 & 1.5333 & 0.3441 & 1.9135 & 0.2228 & 0.0668 \\
\hline 18 & $4 r$ & -1.6480 & 1.5000 & 0.3435 & 1.9135 & 0.1607 & 0.1074 \\
\hline 19 & $5 a$ & -1.2250 & 1.6111 & 0.3597 & 1.9820 & 0.1635 & 0.1077 \\
\hline 20 & $5 b$ & -1.2490 & 1.6111 & 0.3598 & 1.9820 & 0.1647 & 0.1078 \\
\hline 21 & $5 c$ & -1.2020 & 1.6111 & 0.3514 & 1.9838 & 0.1594 & 0.1080 \\
\hline 22 & $5 d$ & -1.1270 & 1.6111 & 0.3596 & 1.9667 & 0.1736 & 0.1079 \\
\hline 23 & $5 e$ & -1.1860 & 1.6111 & 0.3581 & 1.9788 & 0.1649 & 0.1081 \\
\hline 24 & $5 f$ & -1.8980 & 1.5946 & 0.3563 & 1.9132 & 0.1670 & 0.1092 \\
\hline 25 & $5 g$ & -2.2320 & 1.5278 & 0.3602 & 1.9131 & 0.1590 & 0.1068 \\
\hline 26 & $5 h$ & -2.3340 & 1.4872 & 0.3643 & 1.9126 & 0.1546 & 0.0871 \\
\hline 27 & $5 i$ & -2.2590 & 1.4872 & 0.3603 & 1.9131 & 0.1587 & 0.0848 \\
\hline 28 & $5 j$ & -2.3170 & 1.4872 & 0.3614 & 1.9131 & 0.1585 & 0.0859 \\
\hline 29 & $5 k$ & -2.4650 & 1.5250 & 0.3741 & 1.9121 & 0.1568 & 0.0710 \\
\hline
\end{tabular}


Table 2. Cont.

\begin{tabular}{cccccccc}
\hline \multirow{2}{*}{ No. } & \multirow{2}{*}{ Compd. } & \multirow{2}{*}{$\mathbf{p I C}_{\mathbf{5 0}}$} & \multicolumn{5}{c}{ Structural Descriptors } \\
\cline { 4 - 8 } & & & $\boldsymbol{N}_{\mathbf{~}}$ & $\boldsymbol{q}^{\mathbf{C}}$ max & MAOEP & $\boldsymbol{q}^{\mathbf{H}}{ }_{\text {max }}$ & $\boldsymbol{q}^{\mathbf{H}}{ }_{\text {min }}$ \\
\hline 30 & $\mathbf{5 l}$ & -2.4530 & 1.5250 & 0.3593 & 1.9131 & 0.1752 & 0.0718 \\
31 & $\mathbf{5 m}$ & -2.2400 & 1.4286 & 0.3432 & 1.9123 & 0.1578 & 0.0713 \\
32 & $\mathbf{5 n}$ & -1.0120 & 1.5333 & 0.3472 & 1.9131 & 0.2218 & 0.0659 \\
33 & $\mathbf{5 o}$ & -2.6170 & 1.3333 & 0.3407 & 1.9117 & 0.1409 & 0.0717 \\
34 & $\mathbf{5 p}$ & -2.6980 & 1.3636 & 0.3408 & 1.9117 & 0.1409 & 0.0687 \\
35 & $\mathbf{5 q}$ & -2.6320 & 1.3636 & 0.3346 & 1.9118 & 0.1471 & 0.0822 \\
36 & $\mathbf{5 r}$ & -2.7160 & 1.4000 & 0.3412 & 1.9117 & 0.1406 & 0.0712 \\
37 & $\mathbf{6 a}$ & -0.8850 & 1.6111 & 0.3569 & 1.9820 & 0.1729 & 0.1084 \\
38 & $\mathbf{6 b}$ & -0.9660 & 1.6111 & 0.3574 & 1.9820 & 0.1703 & 0.1085 \\
39 & $\mathbf{6 c}$ & -1.0120 & 1.6111 & 0.3547 & 1.9817 & 0.1736 & 0.1085 \\
40 & $\mathbf{6 d}$ & -0.9120 & 1.6111 & 0.3571 & 1.9667 & 0.1726 & 0.1085 \\
41 & $\mathbf{6 e}$ & -0.9870 & 1.6111 & 0.3558 & 1.9669 & 0.1705 & 0.1085 \\
42 & $\mathbf{6 f}$ & -1.8640 & 1.5278 & 0.3577 & 1.9133 & 0.1700 & 0.1082 \\
43 & $\mathbf{6 g}$ & -2.2020 & 1.4872 & 0.3573 & 1.9138 & 0.1690 & 0.0823 \\
44 & $\mathbf{6 h}$ & -2.0990 & 1.4872 & 0.3579 & 1.9133 & 0.1698 & 0.0868 \\
45 & $\mathbf{6 i}$ & -2.1350 & 1.4872 & 0.3590 & 1.9133 & 0.1699 & 0.0884 \\
46 & $\mathbf{6 j}$ & -2.2100 & 1.5250 & 0.3665 & 1.9126 & 0.1701 & 0.0746 \\
47 & $\mathbf{6 k}$ & -2.1330 & 1.5250 & 0.3569 & 1.9133 & 0.1742 & 0.0727 \\
48 & $\mathbf{6 1}$ & -2.1880 & 1.5250 & 0.3632 & 1.9134 & 0.1692 & 0.0769 \\
49 & $\mathbf{6 m}$ & -2.2390 & 1.4688 & 0.3344 & 1.9126 & 0.1702 & 0.0841 \\
50 & $\mathbf{6 n}$ & -1.3850 & 1.5000 & 0.3468 & 1.9133 & 0.1689 & 0.1081 \\
51 & $\mathbf{6 o}$ & -2.3840 & 1.3333 & 0.3340 & 1.9117 & 0.1719 & 0.0700 \\
52 & $\mathbf{6} \mathbf{p}$ & -2.4250 & 1.3636 & 0.3340 & 1.9117 & 0.1720 & 0.0694 \\
\hline & & & & & & &
\end{tabular}

The best statistical model for the $\mathrm{pIC}_{50}$ data had the following statistical characteristics: $R^{2}=0.9824$, $F=203.01, S^{2}=0.0083$. This model included five descriptors in descending order according to their statistical significance ( $t$ values), which is shown in Table 3 , and the regression coefficients $X$ and their standard errors $\Delta X$ are also listed. The comparison between the experimental and predicted $\mathrm{pIC}_{50}$ is listed in Table 4, and the plot of the comparison between the predicted and experimental values is shown in Figure 3. The five descriptor QSAR model equation is described in the following Equation (2) (Figure 4):

$$
\mathrm{pIC}_{50}=-24.230-0.6261 \times N_{\mathrm{o}}-10.225 \times q^{\mathrm{C}}{ }_{\text {max }}+12.075 \times \mathrm{MAOEP}+12.464 \times q^{\mathrm{H}}{ }_{\max }+16.086 \times q^{\mathrm{H}}{ }_{\text {min }}
$$

$N=52, R^{2}=0.9824, F=203.01, S^{2}=0.0083$.

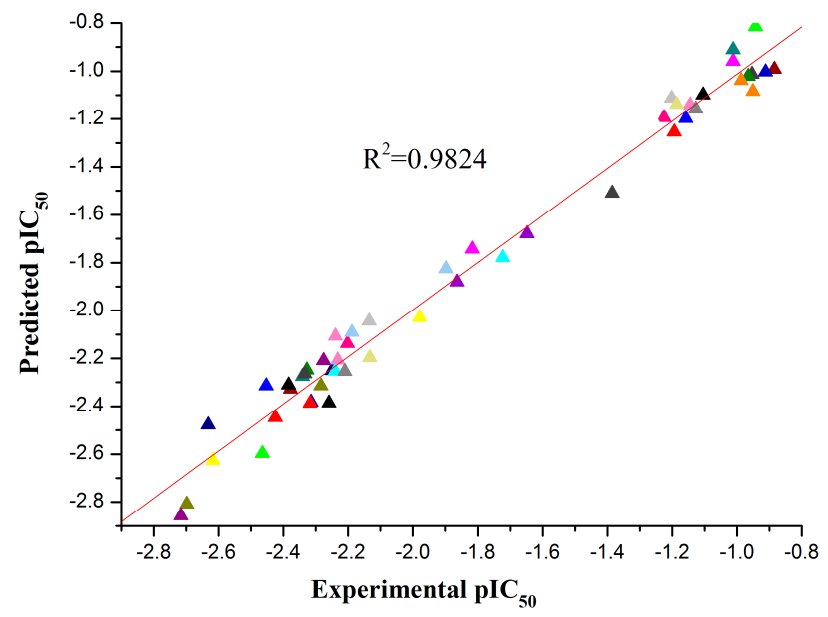

Figure 3. Experimental $\mathrm{pIC}_{50}$ vs. predicted $\mathrm{pIC}_{50}$. 


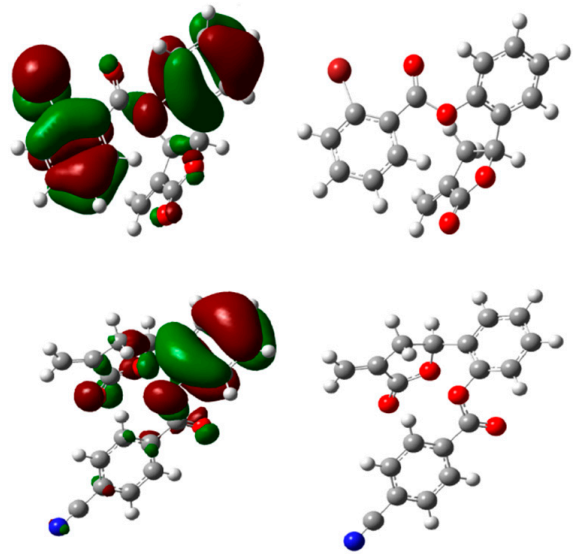

Figure 4. Optimized structures and HOMO energy maps for compounds $\mathbf{5 c}, \mathbf{f}$ from the DFT calculations of Gaussian 03W. The green parts represent positive molecular orbitals, and the red parts represent negative molecular orbitals.

Table 3. The best five-descriptor model.

\begin{tabular}{ccccc}
\hline Descriptor No. & $\boldsymbol{X}$ & $\pm \Delta \boldsymbol{X}$ & $\boldsymbol{t}$-Text & Descriptor \\
\hline 0 & $-2.4230 \times 10$ & 4.1535 & -3.0433 & Intercept $^{\mathrm{a}}$ \\
1 & $-6.2613 \times 10^{-1}$ & $5.2603 \times 10^{-1}$ & -1.1903 & $N_{\mathrm{o}}{ }^{\mathrm{a}}$ \\
2 & $-1.0225 \times 10$ & 2.9561 & -3.4591 & $q^{\mathrm{C}}{ }_{\max } \mathrm{b}$ \\
3 & $1.2075 \times 10$ & $8.0165 \times 10^{-1}$ & 15.0631 & $\mathrm{MAOEP}^{\mathrm{c}}$ \\
4 & $1.2464 \times 10$ & 2.0587 & 6.0544 & $q^{\mathrm{H}}{ }_{\max }^{\mathrm{d}}$ \\
5 & $1.6086 \times 10$ & 1.8059 & 8.9076 & $q^{\mathrm{H}}{ }_{\text {min }}{ }^{\mathrm{e}}$ \\
\hline
\end{tabular}

Note: a Number of occupied electronic levels of atoms; ${ }^{b}$ Max. net atomic charge for a $\mathrm{C}$ atom; ${ }^{\mathrm{c}}$ Max. atomic orbital electronic population; ${ }^{\mathrm{d}}$ Max. net atomic charge for a $\mathrm{H}$ atom; ${ }^{\mathrm{e}}$ Min. net atomic charge for a $\mathrm{C}$ atom.

Table 4. The difference between the experimental $\mathrm{pIC}_{50}$ and predicted $\mathrm{pIC}_{50}$.

\begin{tabular}{|c|c|c|c|c|c|c|c|c|c|}
\hline No. & Compd. & Calc. pIC ${ }_{50}$ & Exp. pIC ${ }_{50}$ & Difference & No. & Compd. & Calc. $\mathrm{pIC}_{50}$ & Exp. pIC ${ }_{50}$ & Difference \\
\hline 1 & $4 a$ & -1.1403 & -1.1450 & 0.0047 & 27 & $5 i$ & -2.3856 & -2.2590 & -0.1266 \\
\hline 2 & $4 b$ & -1.0128 & -0.9540 & -0.0588 & 28 & $5 j$ & -2.3869 & -2.3170 & -0.0699 \\
\hline 3 & $4 c$ & -1.0988 & -1.1050 & 0.0062 & 29 & $5 \mathrm{k}$ & -2.5972 & -2.4650 & -0.1322 \\
\hline 4 & $4 d$ & -1.2533 & -1.1940 & -0.0593 & 30 & 51 & -2.3140 & -2.4530 & 0.1390 \\
\hline 5 & $4 e$ & -0.8153 & -0.9430 & 0.1277 & 31 & $5 \mathrm{~m}$ & -2.2529 & -2.2400 & -0.0129 \\
\hline 6 & $4 \mathrm{f}$ & -1.1974 & -1.1580 & -0.0394 & 32 & $5 n$ & -0.9584 & -1.0120 & 0.0536 \\
\hline 7 & $4 g$ & -1.7783 & -1.7230 & -0.0553 & 33 & 50 & -2.6263 & -2.6170 & -0.0093 \\
\hline 8 & $4 \mathrm{~h}$ & -1.7431 & -1.8170 & 0.0739 & 34 & $5 p$ & -2.8078 & -2.6980 & -0.1098 \\
\hline 9 & $4 \mathbf{i}$ & -2.0285 & -1.9790 & -0.0495 & 35 & $5 q$ & -2.4778 & -2.6320 & 0.1542 \\
\hline 10 & $4 j$ & -2.3147 & -2.2840 & -0.0307 & 36 & $5 r$ & -2.8579 & -2.7160 & -0.1419 \\
\hline 11 & $4 k$ & -2.2508 & -2.2500 & -0.0008 & 37 & $6 a$ & -0.9917 & -0.8850 & -0.1067 \\
\hline 12 & 41 & -2.2089 & -2.2760 & 0.0671 & 38 & $6 b$ & -1.0220 & -0.9660 & -0.0560 \\
\hline 13 & $4 m$ & -2.3273 & -2.3780 & 0.0507 & 39 & $6 c$ & -0.9105 & -1.0120 & 0.1015 \\
\hline 14 & $4 n$ & -2.2477 & -2.3270 & 0.0793 & 40 & $6 d$ & -1.0028 & -0.9120 & -0.0908 \\
\hline 15 & 40 & -2.2751 & -2.3410 & 0.0659 & 41 & $6 e$ & -1.0382 & -0.9870 & -0.0512 \\
\hline 16 & $4 p$ & -2.3821 & -2.3150 & -0.0671 & 42 & $6 f$ & -1.8806 & -1.8640 & -0.0166 \\
\hline 17 & $4 q$ & -1.0839 & -0.9510 & -0.1329 & 43 & $6 \mathrm{~g}$ & -2.1368 & -2.2020 & 0.0652 \\
\hline 18 & $4 r$ & -1.6793 & -1.6480 & -0.0313 & 44 & $6 \mathrm{~h}$ & -2.0781 & -2.0990 & 0.0209 \\
\hline 19 & $5 a$ & -1.1940 & -1.2250 & 0.0310 & 45 & $6 i$ & -2.0438 & -2.1350 & 0.0912 \\
\hline 20 & $5 b$ & -1.2255 & -1.2490 & 0.0235 & 46 & $6 j$ & -2.2545 & -2.2100 & -0.0445 \\
\hline 21 & $5 c$ & -1.1129 & -1.2020 & 0.0891 & 47 & $6 k$ & -2.1958 & -2.1330 & -0.0628 \\
\hline 22 & $5 d$ & -1.1579 & -1.1270 & -0.0309 & 48 & 61 & -2.0901 & -2.1880 & 0.0979 \\
\hline 23 & $5 e$ & -1.1386 & -1.1860 & 0.0474 & 49 & $6 \mathrm{~m}$ & -2.1068 & -2.2390 & 0.1322 \\
\hline 24 & $5 f$ & -1.8257 & -1.8980 & 0.0723 & 50 & $6 n$ & -1.5095 & -1.3850 & -0.1245 \\
\hline 25 & $5 g$ & -2.2060 & -2.2320 & 0.0260 & 51 & 60 & -2.3109 & -2.3840 & 0.0731 \\
\hline 26 & $5 \mathrm{~h}$ & -2.2643 & -2.3340 & 0.0697 & 52 & $6 p$ & -2.4467 & -2.4250 & -0.0217 \\
\hline
\end{tabular}


The internal validation and the "leave-one-out" cross-validation methods were used to validate the developed QSAR model [28]. The internal validation was carried out by dividing the compound data into three subsets A-C, with 17, 17 and 18 compounds respectively. The compounds 1, 4, 7, 10, etc., went into the first subset (A); 2, 5, 8, 11, etc., went into the second subset (B); and 3, 6, 9, 12, etc., went into the third subset $(C)$. Two of the three subsets, (A and B), (A and C), and (B and C), consist the training set while the remaining subset was treated as a test set. The correlation equations were derived from each of the training sets using the same descriptors and then used to predict values for the corresponding test set [29]. Internal validation results are presented in Table 5. The $R_{\text {Training }}{ }^{2}$ and $R_{\text {Test }}{ }^{2}$ are within $5 \%$ for all three sets, and the average values of $R_{\text {Training }}{ }^{2}=0.9833$ and $R_{\text {Test }}{ }^{2}=0.9855$ were close to the overall $R^{2}$ value. Thus, the obtained QSAR model obtained demonstrated the predictive power of 3-fold cross-validation. Meanwhile, the "leave-one-out" method was completed in a similar manner to the internal validation. Every fourth compound $(\mathbf{1}, \mathbf{5}, \mathbf{9}, \mathbf{1 3}$, etc.) was put into an external test set, and the remaining compounds were left in the training set. The QSAR model containing the same five descriptors was obtained with $R^{2}=0.9862$ from the training set. When the same QSAR model was applied on the test set, $R^{2}=0.9789$ was observed. Therefore, the "leave-one out" cross-validation results were also satisfactory.

Table 5. Internal validation of the QSAR model ${ }^{\mathrm{a}}$.

\begin{tabular}{cccccccccc}
\hline Training Set & $\boldsymbol{N}$ & $\boldsymbol{R}^{\mathbf{2}}$ & $\boldsymbol{F}$ & $\boldsymbol{S}^{\mathbf{2}}$ & Test Set & $\boldsymbol{N}$ & $\boldsymbol{R}^{\mathbf{2}}$ & $\boldsymbol{F}$ & $\boldsymbol{S}^{\mathbf{2}}$ \\
\hline A + B & 34 & 0.9862 & 211.53 & 0.0095 & $\mathrm{C}$ & 18 & 0.9896 & 214.65 & 0.0086 \\
B + C & 35 & 0.9797 & 201.69 & 0.0112 & $\mathrm{~A}$ & 17 & 0.9807 & 204.11 & 0.0104 \\
A + C & 35 & 0.9841 & 207.43 & 0.0090 & $\mathrm{~B}$ & 17 & 0.9862 & 209.81 & 0.0092 \\
Average & & 0.9833 & 206.83 & 0.0099 & Average & & 0.9855 & 209.52 & 0.0094 \\
\hline
\end{tabular}

Note: ${ }^{a}$ Compounds A: 1, 4, 7, 10, 13, 16, 19, 22, 25, 28, 31, 34, 37, 40, 43, 46, 49; Compounds B: 2, 5, 8, 11, 14, 17, 20, 23, 26, 29, 32, 35, 38, 41, 44, 47, 50; Compounds C: 3, 6, 9, 12, 15, 18, 21, 24, 27, 30, 33, 36, 39, 42, 45, 48, 51, 52.

Descriptors involved in this model revealed the relationship between the compounds and the fungicidal activity. The 1st and 3rd most important descriptors obtained in the model were the number of occupied electronic levels of atoms and maximum atomic orbital electronic population, which belong to quantum-chemically descriptors and have a significant effect on the fungicidal activity. The number of occupied electronic levels of atoms depends directly on the quantum-chemically calculated charge distribution in the molecules, and therefore describes the polar interactions between molecules [30,31]. This study found that the derivatives with electron-withdrawing groups on the benzene ring showed higher $N_{\mathrm{O}}$ values than those with electron-donating groups. Maximum atomic orbital electronic population for a given atomic species in the molecule is an important index to describe the nucleophilicity of the molecule, which is directly related to molecular nucleophilic capacity and characterizes the susceptibility of the molecule to electrophilic attack [32]. In Equation (2), the maximum atomic orbital electronic population and $\mathrm{pIC}_{50}$ are positively correlated, which suggested that the electron withdrawing substitution groups of the derivatives are beneficial for the fungicidal activity against $C$. lagenarium. In fact, the $\alpha, \beta$-unsaturated carbonyl system (Michael acceptor), which had higher electron deficiency induced by electron-withdrawing groups, can be easily attacked by bionucleophiles $[33,34]$. Therefore, the obtained QSAR study result partially met the above SAR study conclusion.

The 2nd, 4th and 5th descriptors obtained in the model were the maximum net atomic charge for a $\mathrm{C}$ atom, maximum net atomic charge for an $\mathrm{H}$ atom, and minimum net atomic charge for an $\mathrm{H}$ atom. These three descriptors belong to electrostatic descriptors, and they reflect characteristics of the charge distribution of the molecules $[35,36]$. Thus, the electrostatic descriptors play an important role in influencing the fungicidal activity of compounds. In Equation (2), appearance with a positive sign in the model indicated that a molecule with a higher descriptor value had a higher $\mathrm{pIC}_{50}$. On the 
contrary, a negative sign in the model indicated that a molecule with a lower descriptor value had a higher $\mathrm{pIC}_{50}$.

\subsection{Cytotoxic Activity of the Representative Compounds against Human Tumor Cells Line (HepG2)}

As a fact, compounds containing the $\alpha$-methylene- $\gamma$-butyrolactone structure often exhibit a high toxicity potential against mammalian cells $[37,38]$. In order to ensure the selectivity of the fungicidal effects, the cytotoxicity of 24 representative derivatives was tested in a human tumor cells line (HepG2). The result is listed in Table 6, which indicated that the QSAR underlying the fungicidal and cytotoxic effects of these representative compounds are different. For instance, compound $\mathbf{6 a}$ has the highest fungicidal activity with $\mathrm{IC}_{50}=7.68 \mu \mathrm{M}$ (against $C$. lagenarium) but moderate cytotoxic activity with $\mathrm{IC}_{50}=30.2 \mu \mathrm{M}$ (against HepG2 cell line), while, compound $4 \mathbf{i}$ has low fungicidal activity with $\mathrm{IC}_{50}=95.38 \mu \mathrm{M}$ (against $C$. lagenarium) but high cytotoxic activity with $\mathrm{IC}_{50}=5.3 \mu \mathrm{M}$ (against HepG2 cell line). Through QSAR studies on fungicidal and antitumor activity of $\alpha$-methylene- $\gamma$-butyrolactone derivatives, these are important points that need further investigation to seek high activity derivatives with weak cytotoxicity.

Table 6. In vitro fungicidal activity of compounds against $C$. lagenarium and cytotoxic activity against a human tumor cells line (HepG2).

\begin{tabular}{cccc}
\hline No. & Compd. & IC $_{\mathbf{5 0}}(\boldsymbol{\mu M})$ (against C. lagenarium) & IC $_{\mathbf{5 0}}(\boldsymbol{\mu} \mathbf{M})$ (against HepG2 Cell Line) \\
\hline 1 & $\mathbf{4 b}$ & 8.99 & 22.4 \\
2 & $\mathbf{4}$ & 8.76 & 21.7 \\
3 & $\mathbf{4 g}$ & 52.87 & 18.3 \\
4 & $\mathbf{4 i}$ & 95.38 & 5.3 \\
5 & $\mathbf{4}$ & 177.96 & 28.5 \\
6 & $\mathbf{4 o}$ & 219.44 & 25.0 \\
7 & $\mathbf{4 p}$ & 206.51 & 19.5 \\
8 & $\mathbf{4 q}$ & 8.93 & 27.3 \\
9 & $\mathbf{5 a}$ & 16.77 & 28.4 \\
10 & $\mathbf{5 d}$ & 13.41 & 35.6 \\
11 & $\mathbf{5 i}$ & 181.69 & 85.2 \\
12 & $\mathbf{5 l}$ & 283.99 & 29.0 \\
13 & $\mathbf{5 m}$ & 173.74 & 23.8 \\
14 & $\mathbf{5 p}$ & 499.33 & $>131.7$ \\
15 & $\mathbf{5 r}$ & 519.42 & 38.4 \\
16 & $\mathbf{6 a}$ & 7.68 & 30.2 \\
17 & $\mathbf{6 d}$ & 8.17 & 20.9 \\
18 & $\mathbf{6 f}$ & 73.14 & 18.5 \\
19 & $\mathbf{6 g}$ & 159.33 & 22.0 \\
20 & $\mathbf{6 1}$ & 154.27 & 58.6 \\
21 & $\mathbf{6 n}$ & 24.25 & 15.7 \\
22 & $\mathbf{6 0}$ & 242.03 & $>108.2$ \\
23 & $\mathbf{4}$ & 160.63 & 23.3 \\
24 & $\mathbf{6}$ & 117.12 & 17.9 \\
\hline
\end{tabular}

\section{Materials and Methods}

\subsection{General Information}

Chlorothalonil was purchased from Xiangtan Huayuan Fine-Chem Co. Ltd. (Xiangtan, China). 4-Dimethylaminopyridine (DMAP), N,N-dicyclohexylcarbodiimide (DCC) and carboxylic acids were purchased from J \& K Chemical Ltd. (Beijing, China). Other reagents and solvents were obtained locally. All solvents were dried, and redistilled before use. The water used was redistilled and ion-free. Analytical thin-layer chromatography (TLC) was performed on silica gel $\mathrm{GF}_{254}$. Column chromatographic (CC) purification was carried out using silica gel (200-300 mesh). Above silica gel 
was obtained from Qingdao Haiyang Chemical Co., Ltd. (Qingdao, China). The melting points of the synthetic derivatives were determined on an X-6 apparatus (Beijing Tech., Beijing, China) and are uncorrected. Nuclear magnetic resonance (NMR) experiments were performed on an Avance 400/500 MHz instrument (Bruker, Bremerhaven, Germany). HR-MS (ESI) were obtained using a Bruker Apex-Ultra 7.0 T spectrometer. Reaction progress was monitored by thin-layer chromatography on silica gel GF-254 with detection by UV light.

\subsection{Synthetic Procedures}

\subsubsection{General Synthetic Procedure for the Intermediate Compounds}

$\alpha$-(Bromomethyl)acrylic acid was synthesized according to our previous report [21]. Hydroxybenzaldehyde (122.1 mg, $1.0 \mathrm{mmol}), \alpha$-(bromomethyl) acrylic acid (198.0 mg, $1.2 \mathrm{mmol}$ ), and indium powder $(136.0 \mathrm{mg}, 1.2 \mathrm{mmol})$ were added to THF $(10.0 \mathrm{~mL})$ at room temperature. $6.0 \mathrm{M}$ $\mathrm{HCl}$ was added to the above mixture when the starting aldehyde disappeared according to TLC analysis and stirring was continued for 6 hours. Then, the mixture was extracted with ethyl acetate $(3 \times 10 \mathrm{~mL})$ and the organic phase dried over anhydrous $\mathrm{Na}_{2} \mathrm{SO}_{4}$ and evaporated under reduced pressure. The resulting residue was purified using preparative chromatography on silica gel eluting with $0 \%-40 \%$ ethyl acetate in petroleum ether. These intermediate compounds were used to prepare the target compounds.

4-(4-Hydroxyphenyl)-2-methylenebutyrolactone (4). White crystals; mp: 79-81 ${ }^{\circ} \mathrm{C} ; 87 \%$ yield; ${ }^{1} \mathrm{H}-\mathrm{NMR}$ $\left(400 \mathrm{MHz}, \mathrm{CDCl}_{3}\right): \delta 2.88\left(\mathrm{ddt}, 1 \mathrm{H}, J=17.2,6.5,2.6 \mathrm{~Hz}, \mathrm{CHHC}=\mathrm{CH}_{2}\right), 3.30(\mathrm{ddt}, 1 \mathrm{H}, J=17.2,8.0$, $\left.2.0 \mathrm{~Hz}, \mathrm{CHHC}=\mathrm{CH}_{2}\right), 5.43(\mathrm{t}, 1 \mathrm{H}, J=7.1 \mathrm{~Hz}, \mathrm{OCH}), 5.70(\mathrm{t}, 1 \mathrm{H}, J=2.1 \mathrm{~Hz}, \mathrm{C}=\mathrm{CHH}), 6.28(\mathrm{t}, 1 \mathrm{H}$, $J=2.6 \mathrm{~Hz}, \mathrm{C}=\mathrm{CHH}), 6.84-7.11(\mathrm{~m}, 4 \mathrm{H}, \mathrm{ArH}) ;{ }^{13} \mathrm{C}-\mathrm{NMR}\left(100 \mathrm{MHz}, \mathrm{CDCl}_{3}\right): \delta 35.85,79.14,115.86$, $123.05,127.44,130.59,134.54,156.76,171.59$; HR-MS (ESI): $m / z$ calcd for $\mathrm{C}_{11} \mathrm{H}_{11} \mathrm{O}_{3}\left([\mathrm{M}+\mathrm{H}]^{+}\right) 191.0703$, found 191.0703 .

4-(2-Hydroxyphenyl)-2-methylenebutyrolactone (5). Colourless oil; $81 \%$ yield; ${ }^{1} \mathrm{H}-\mathrm{NMR}\left(400 \mathrm{MHz}, \mathrm{CDCl}_{3}\right.$ ): $\delta 2.95\left(\mathrm{ddt}, 1 \mathrm{H}, J=17.4,5.9,2.7 \mathrm{~Hz}, \mathrm{CHHC}=\mathrm{CH}_{2}\right), 3.42\left(\mathrm{ddt}, 1 \mathrm{H}, J=17.4,8.4,2.4 \mathrm{~Hz}, \mathrm{CHHC}=\mathrm{CH}_{2}\right), 5.66$ $(\mathrm{t}, 1 \mathrm{H}, J=2.4 \mathrm{~Hz}, \mathrm{C}=\mathrm{CHH}), 5.79(\mathrm{dd}, 1 \mathrm{H}, J=8.36 .1 \mathrm{~Hz}, \mathrm{OCH}), 6.29(\mathrm{t}, 1 \mathrm{H}, J=2.8 \mathrm{~Hz}, \mathrm{C}=\mathrm{CHH}), 6.86-7.23$ (m, 4H, ArH); ${ }^{13} \mathrm{C}-\mathrm{NMR}\left(100 \mathrm{MHz}, \mathrm{CDCl}_{3}\right): \delta 34.67,76.23,115.93,120.13,122.77,126.04,126.28,129.65$, 134.82, 153.67, 172.26; HR-MS (ESI): $m / z$ calcd for $\mathrm{C}_{11} \mathrm{H}_{11} \mathrm{O}_{3}\left([\mathrm{M}+\mathrm{H}]^{+}\right)$191.0703, found 191.0703.

4-(3-Hydroxyphenyl)-2-methylenebutyrolactone (6). White crystal ; mp: $78-79{ }^{\circ} \mathrm{C} ; 81 \%$ yield; ${ }^{1} \mathrm{H}-\mathrm{NMR}$ $\left(400 \mathrm{MHz}, \mathrm{CDCl}_{3}\right): \delta 2.82\left(\mathrm{ddt}, 1 \mathrm{H}, J=17.2,6.3,2.8 \mathrm{~Hz}, \mathrm{CHHC}=\mathrm{CH}_{2}\right), 3.30(\mathrm{ddt}, 1 \mathrm{H}, J=17.2,8.1,2.3 \mathrm{~Hz}$, $\left.\mathrm{CHHC}=\mathrm{CH}_{2}\right), 5.41(\mathrm{t}, 1 \mathrm{H}, J=7.4 \mathrm{~Hz}, \mathrm{OCH}), 5.66(\mathrm{t}, 1 \mathrm{H}, J=2.3 \mathrm{~Hz}, \mathrm{C}=\mathrm{CHH}), 6.25(\mathrm{t}, 1 \mathrm{H}, J=2.7 \mathrm{~Hz}$, $\mathrm{C}=\mathrm{CHH}), 6.76-7.19(\mathrm{~m}, 4 \mathrm{H}, \mathrm{ArH}) ;{ }^{13} \mathrm{C}-\mathrm{NMR}\left(100 \mathrm{MHz}, \mathrm{CDCl}_{3}\right): \delta 35.91,78.62,112.44,115.87,117.09$, 123.31, 130.16, 134.04, 141.10, 156.71, 171.55; HR-MS (ESI): $m / z$ calcd for $\mathrm{C}_{11} \mathrm{H}_{11} \mathrm{O}_{3}\left([\mathrm{M}+\mathrm{H}]^{+}\right)$191.0703, found 191.0703.

\subsubsection{General Synthetic Procedure for Ester Compounds}

4-Dimethylaminopyridine (DMAP, $30.0 \mathrm{mg}, 0.2 \mathrm{mmol}$ ) and the appropriate intermediate compounds 4,5 or $6(196.0 \mathrm{mg}, 1.1 \mathrm{mmol})$ were added to anhydrous $\mathrm{CH}_{2} \mathrm{Cl}_{2}(15.0 \mathrm{~mL})$ containing the respective carboxylic acid $(1.1 \mathrm{mmol})$. Then the mixture was cooled to $0{ }^{\circ} \mathrm{C}$. $\mathrm{N}, \mathrm{N}$-dicyclohexyl-carbodiimide (DCC, $226.0 \mathrm{mg}, 1.1 \mathrm{mmol}$ ) dissolved in anhydrous $\mathrm{CH}_{2} \mathrm{Cl}_{2}(10.0 \mathrm{~mL})$ was added dropwise into the mixture over a period of $10 \mathrm{~min}$ at $0{ }^{\circ} \mathrm{C}$ and the mixture was then stirred at room temperature until the reaction was complete according to the TLC analysis. Then, the mixture was filtered. Finally, the residual organic layers were extracted by ethyl acetate $(3 \times 30 \mathrm{~mL})$ and dried over anhydrous $\mathrm{Na}_{2} \mathrm{SO}_{4}$. After filtering, the solution was evaporated under vacuum. The target compounds were purified by column chromatography on silica gel eluting with $0 \%-40 \%$ ethyl acetate in petroleum ether. The structures of all ester derivatives were characterized by ${ }^{1} \mathrm{H}-\mathrm{NMR},{ }^{13} \mathrm{C}-\mathrm{NMR}$, and HR-ESI-MS, and the data are listed below. 
4-[4-(2-Chlorobenzoyloxy)phenyl]-2-methylenebutyrolactone (4a) White solid; mp: $187.2-187.9{ }^{\circ} \mathrm{C} ; 40 \%$ yield; ${ }^{1} \mathrm{H}-\mathrm{NMR}\left(400 \mathrm{MHz}, \mathrm{CDCl}_{3}\right): \delta 8.05(\mathrm{dd}, J=7.8,1.1 \mathrm{~Hz}, 1 \mathrm{H}, \operatorname{ArH}), 7.56-7.47(\mathrm{~m}, 3 \mathrm{H}, \mathrm{ArH})$, 7.44-7.37 (m, 4H, ArH), $6.33(\mathrm{t}, J=2.8 \mathrm{~Hz}, 1 \mathrm{H}, \mathrm{C}=\mathrm{CHH}), 5.61-5.52(\mathrm{~m}, 1 \mathrm{H}, \mathrm{OCH}), 5.56(\mathrm{~d}, J=7.7 \mathrm{~Hz}$, $1 \mathrm{H}, \mathrm{C}=\mathrm{CHH}), 3.50-3.37\left(\mathrm{~m}, 1 \mathrm{H}, \mathrm{CHHC}=\mathrm{CH}_{2}\right), 3.04-2.82\left(\mathrm{~m}, 1 \mathrm{H}, \mathrm{CHHC}=\mathrm{CH}_{2}\right) ;{ }^{13} \mathrm{C}-\mathrm{NMR}(125 \mathrm{MHz}$, $\left.\mathrm{CDCl}_{3}\right): \delta 170.06,163.97,150.70,137.72,134.50,133.94,133.41,131.97,131.44,128.99,126.77,122.83$, 122.16, 77.62, 77.05, 76.73, 36.36, 1.05; HR-MS (ESI): $m / z$ calcd for $\mathrm{C}_{18} \mathrm{H}_{13} \mathrm{ClNaO}_{4}\left([\mathrm{M}+\mathrm{Na}]^{+}\right) 351.0394$, found 351.0395 .

4-[4-(3-Chlorobenzoyloxy)phenyl]-2-methylenebutyrolactone (4b) White solid; mp: $168.8-169.2{ }^{\circ} \mathrm{C} ; 54 \%$ yield; ${ }^{1} \mathrm{H}-\mathrm{NMR}\left(500 \mathrm{MHz}, \mathrm{CDCl}_{3}\right): \delta 8.24(\mathrm{~m}, 1 \mathrm{H}, \mathrm{ArH}), 7.69-7.56(\mathrm{~m}, 1 \mathrm{H}, \mathrm{ArH}), 7.54-7.34(\mathrm{~m}, 3 \mathrm{H}$, $\operatorname{ArH}), 7.31-7.19(\mathrm{~m}, 3 \mathrm{H}, \mathrm{ArH}), 6.37(\mathrm{dd}, J=14.9,12.1 \mathrm{~Hz}, 1 \mathrm{H}, \mathrm{C}=\mathrm{CHH}), 5.76(\mathrm{dd}, J=14.6,12.2 \mathrm{~Hz}, 1 \mathrm{H}$, $\mathrm{OCH}), 5.60(\mathrm{dd}, J=20.0,12.6 \mathrm{~Hz}, 1 \mathrm{H}, \mathrm{C}=\mathrm{CHH}), 3.54-3.37\left(\mathrm{~m}, 1 \mathrm{H}, \mathrm{CHHC}=\mathrm{CH}_{2}\right), 3.02-2.88(\mathrm{~m}, 1 \mathrm{H}$, $\left.\mathrm{CHHC}=\mathrm{CH}_{2}\right) ;{ }^{13} \mathrm{C}-\mathrm{NMR}\left(125 \mathrm{MHz}, \mathrm{CDCl}_{3}\right): \delta 150.76,137.71,134.84,133.86,131.05,130.22,129.95$, 128.31, 126.75, 122.74, 122.02, 77.31, 77.01, 76.75, 36.30, 29.70; HR-MS (ESI): $m / z$ calcd for $\mathrm{C}_{18} \mathrm{H}_{13} \mathrm{ClNaO}_{4}$ $\left([\mathrm{M}+\mathrm{Na}]^{+}\right)$351.0394, found 351.0395 .

4-[4-(4-Chlorobenzoyloxy)phenyl]-2-methylenebutyrolactone (4c) White solid; mp: $171.3-171.6{ }^{\circ} \mathrm{C} ; 65 \%$ yield; ${ }^{1} \mathrm{H}-\mathrm{NMR}\left(400 \mathrm{MHz}, \mathrm{CDCl}_{3}\right): \delta 8.30-8.02(\mathrm{~m}, 2 \mathrm{H}, \mathrm{ArH}), 7.68-7.14(\mathrm{~m}, 6 \mathrm{H}, \mathrm{ArH}), 6.33(\mathrm{t}, J=2.8 \mathrm{~Hz}$, $1 \mathrm{H}, \mathrm{C}=\mathrm{CHH}), 5.72(\mathrm{t}, J=2.5 \mathrm{~Hz}, 1 \mathrm{H}, \mathrm{OCH}), 5.60-5.47(\mathrm{~m}, 1 \mathrm{H}, \mathrm{C}=\mathrm{CHH}), 3.43(\mathrm{ddt}, J=17.1,8.0,2.4 \mathrm{~Hz}$, $\left.1 \mathrm{H}, \mathrm{CHHC}=\mathrm{CH}_{2}\right), 2.94\left(\mathrm{ddt}, J=17.1,6.1,2.9 \mathrm{~Hz}, 1 \mathrm{H}, \mathrm{CHHC}=\mathrm{CH}_{2}\right) ;{ }^{13} \mathrm{C}-\mathrm{NMR}\left(125 \mathrm{MHz}, \mathrm{CDCl}_{3}\right)$ : $\delta 170.01,150.82,140.37,137.63,133.95,131.59,129.04,126.73,122.80,122.16,77.39,77.04,76.72,36.31$. HR-MS (ESI): $m / z$ calcd for $\mathrm{C}_{18} \mathrm{H}_{13} \mathrm{ClNaO}_{4}\left([\mathrm{M}+\mathrm{Na}]^{+}\right)$351.0394, found 351.0395.

4-[4-(2-Bromobenzoyloxy)phenyl]-2-methylenebutyrolactone (4d) White crystal; $\mathrm{mp}: 174.5-174.9{ }^{\circ} \mathrm{C} ; 62 \%$ yield; ${ }^{1} \mathrm{H}-\mathrm{NMR}\left(500 \mathrm{MHz}, \mathrm{CDCl}_{3}\right): \delta 8.04(\mathrm{dd}, J=7.5,1.7 \mathrm{~Hz}, 1 \mathrm{H}, \mathrm{ArH}), 7.91-7.68(\mathrm{~m}, 1 \mathrm{H}, \mathrm{ArH})$, 7.56-7.08 (m, 6H, ArH), $6.36(\mathrm{t}, J=2.8 \mathrm{~Hz}, 1 \mathrm{H}, \mathrm{C}=\mathrm{CHH}), 5.74(\mathrm{t}, J=2.4 \mathrm{~Hz}, 1 \mathrm{H}, \mathrm{OCH}), 5.61-5.50(\mathrm{~m}, 1 \mathrm{H}$, $\mathrm{C}=\mathrm{CHH}), 3.56-3.08\left(\mathrm{~m}, 1 \mathrm{H}, \mathrm{CHHC}=\mathrm{CH}_{2}\right), 3.05-2.67\left(\mathrm{~m}, 1 \mathrm{H}, \mathrm{CHHC}=\mathrm{CH}_{2}\right) .{ }^{13} \mathrm{C}-\mathrm{NMR}(125 \mathrm{MHz}$, $\left.\mathrm{CDCl}_{3}\right): \delta 134.69,133.30,131.85,127.36,126.70,122.73,122.03,77.32,77.01,76.75,36.35,29.70$, 14.99.HR-MS (ESI): $m / z$ calcd for $\mathrm{C}_{18} \mathrm{H}_{13} \mathrm{BrNaO}_{4}\left([\mathrm{M}+\mathrm{Na}]^{+}\right)$394.9890, found 394.9889.

4-[4-(3-Bromobenzoyloxy)phenyl]-2-methylenebutyrolactone (4e) White crystal; $\mathrm{mp}: 176.5-176.8^{\circ} \mathrm{C} ; 45 \%$ yield; ${ }^{1} \mathrm{H}-\mathrm{NMR}\left(500 \mathrm{MHz}, \mathrm{CDCl}_{3}\right): \delta 8.37(\mathrm{~s}, 1 \mathrm{H}, \mathrm{ArH}), 8.16(\mathrm{~d}, J=7.7 \mathrm{~Hz}, 1 \mathrm{H}, \mathrm{ArH}), 7.80(\mathrm{~d}, J=7.9 \mathrm{~Hz}$, $1 \mathrm{H}, \mathrm{ArH}), 7.56-7.19(\mathrm{~m}, 4 \mathrm{H}, \mathrm{ArH}), 6.36(\mathrm{t}, J=2.8 \mathrm{~Hz}, 1 \mathrm{H}, \mathrm{C}=\mathrm{CHH}), 5.75(\mathrm{t}, J=2.4 \mathrm{~Hz}, 1 \mathrm{H}, \mathrm{OCH})$, 5.66-5.52 (m, 1H, C=CHH), $5.42(\mathrm{dd}, J=10.6,5.3 \mathrm{~Hz}, 1 \mathrm{H}, \mathrm{ArH}), 3.57-3.37\left(\mathrm{~m}, 1 \mathrm{H}, \mathrm{CHHC}=\mathrm{CH}_{2}\right), 2.95(\mathrm{~s}$, $\left.1 \mathrm{H}, \mathrm{CHHC}=\mathrm{CH}_{2}\right) ;{ }^{13} \mathrm{C}-\mathrm{NMR}\left(125 \mathrm{MHz}, \mathrm{CDCl}_{3}\right): \delta 136.73,133.16,132.05,131.69,130.22,128.79,126.91$, 126.53, 122.77, 122.20, 78.63, 77.34, 77.03, 76.78, 40.03, 36.36, 29.72, 15.00. HR-MS (ESI): $\mathrm{m} / \mathrm{z}$ calcd for $\mathrm{C}_{18} \mathrm{H}_{13} \mathrm{BrNaO}_{4}\left([\mathrm{M}+\mathrm{Na}]^{+}\right)$394.9890, found 394.9889 .

4-[4-(4-Bromobenzoyloxy)phenyl]-2-methylenebutyrolactone (4f) White crystal; $\mathrm{mp}$ : $175.1-175.6{ }^{\circ} \mathrm{C} ; 52 \%$ yield; ${ }^{1} \mathrm{H}-\mathrm{NMR}\left(500 \mathrm{MHz}, \mathrm{CDCl}_{3}\right): \delta 8.10(\mathrm{~d}, J=8.5 \mathrm{~Hz}, 2 \mathrm{H}, \mathrm{ArH}), 7.72(\mathrm{t}, J=12.5 \mathrm{~Hz}, 4 \mathrm{H}, \mathrm{ArH}), 6.38(\mathrm{t}$, $J=2.8 \mathrm{~Hz}, 1 \mathrm{H}, \mathrm{C}=\mathrm{CHH}), 5.76(\mathrm{t}, J=2.4 \mathrm{~Hz}, 1 \mathrm{H}, \mathrm{OCH}), 5.65-5.54(\mathrm{~m}, 1 \mathrm{H}, \mathrm{C}=\mathrm{CHH}), 5.43(\mathrm{dd}, J=10.7$, $5.2 \mathrm{~Hz}, 2 \mathrm{H}, \mathrm{ArH}), 3.55-3.36\left(\mathrm{~m}, 1 \mathrm{H}, \mathrm{CHHC}=\mathrm{CH}_{2}\right), 3.04-2.93\left(\mathrm{~m}, 1 \mathrm{H}, \mathrm{CHHC}=\mathrm{CH}_{2}\right) ;{ }^{13} \mathrm{C}-\mathrm{NMR}(125 \mathrm{MHz}$, $\left.\mathrm{CDCl}_{3}\right): \delta 150.78,136.95,132.05,131.69,129.05,128.28,126.76,122.75,122.08,78.62,77.28,77.03,76.78$, 40.03, 36.36, 15.00. HR-MS (ESI): $m / z$ calcd for $\mathrm{C}_{18} \mathrm{H}_{13} \mathrm{BrNaO}_{4}\left([\mathrm{M}+\mathrm{Na}]^{+}\right) 394.9890$, found 394.9889.

4-[4-(3-Benzonitrile)phenyl]-2-methylenebutyrolactone (4g) Yellow oil; $54 \%$ yield; ${ }^{1} \mathrm{H}-\mathrm{NMR}(500 \mathrm{MHz}$, $\left.\mathrm{CDCl}_{3}\right): \delta 8.52(\mathrm{~s}, 1 \mathrm{H}, \mathrm{ArH}), 8.45(\mathrm{~d}, J=8.0 \mathrm{~Hz}, 1 \mathrm{H}, \mathrm{ArH}), 7.95(\mathrm{~d}, J=7.8 \mathrm{~Hz}, 1 \mathrm{H}, \operatorname{ArH}), 7.70(\mathrm{t}, J=7.9 \mathrm{~Hz}$, $1 \mathrm{H}, \mathrm{ArH}), 7.29(\mathrm{t}, J=4.3 \mathrm{~Hz}, 4 \mathrm{H}, \mathrm{ArH}), 6.36(\mathrm{t}, J=2.8 \mathrm{~Hz}, 1 \mathrm{H}, 1 \mathrm{H}, \mathrm{C}=\mathrm{CHH}), 5.75(\mathrm{t}, J=2.4 \mathrm{~Hz}, 1 \mathrm{H}$, $\mathrm{OCH}), 5.65-5.56(\mathrm{~m}, 1 \mathrm{H}, \mathrm{C}=\mathrm{CHH}), 3.46\left(\mathrm{ddd}, J=10.5,5.7,2.4 \mathrm{~Hz}, 1 \mathrm{H}, \mathrm{CHHC}=\mathrm{CH}_{2}\right), 2.96(\mathrm{ddt}, J=17.0$, $\left.6.1,2.9 \mathrm{~Hz}, 1 \mathrm{H}, \mathrm{CH} H \mathrm{C}=\mathrm{CH}_{2}\right),{ }^{13} \mathrm{C}-\mathrm{NMR}\left(125 \mathrm{MHz}, \mathrm{CDCl}_{3}\right): \delta 163.13,150.51,138.01,136.69,134.16$, $133.82,130.69,129.73,126.83,122.82,121.90,113.36,77.26,77.01,76.76,49.17,36.29,33.95,25.62$. HR-MS (ESI): $m / z$ calcd for $\mathrm{C}_{19} \mathrm{H}_{13} \mathrm{NNaO}_{4}\left([\mathrm{M}+\mathrm{Na}]^{+}\right) 342.0736$, found 342.0740 . 
4-[4-(4-Benzonitrile)phenyl]-2-methylenebutyrolactone (4h) Yellow oil; 57\% yield; ${ }^{1} \mathrm{H}-\mathrm{NMR}(500 \mathrm{MHz}$, $\left.\mathrm{CDCl}_{3}\right): \delta 8.51-8.39(\mathrm{~m}, 1 \mathrm{H}, \mathrm{ArH}), 8.34(\mathrm{t}, J=7.3 \mathrm{~Hz}, 2 \mathrm{H}, \mathrm{ArH}), 7.98(\mathrm{~d}, J=7.8 \mathrm{~Hz}, 1 \mathrm{H}, \mathrm{ArH}), 7.85(\mathrm{~s}$, $2 \mathrm{H}, \mathrm{ArH}), 7.73(\mathrm{t}, J=7.9 \mathrm{~Hz}, 1 \mathrm{H}, \mathrm{ArH}), 6.37(\mathrm{t}, J=2.8 \mathrm{~Hz}, 1 \mathrm{H}, \mathrm{C}=\mathrm{CHH}), 6.25(\mathrm{t}, J=2.9 \mathrm{~Hz}, 1 \mathrm{H}, \mathrm{ArH})$, $5.75(\mathrm{t}, J=2.4 \mathrm{~Hz}, 1 \mathrm{H}, \mathrm{OCH}), 5.71-5.64(\mathrm{~m}, 2 \mathrm{H}, \operatorname{ArH}), 5.61-5.55(\mathrm{~m}, 1 \mathrm{H}, \mathrm{C}=\mathrm{CH} H), 3.49-3.41(\mathrm{~m}, 1 \mathrm{H}$, $\left.\mathrm{CHHC}=\mathrm{CH}_{2}\right), 3.38-3.28\left(\mathrm{~m}, 1 \mathrm{H}, \mathrm{CHHC}=\mathrm{CH}_{2}\right) .{ }^{13} \mathrm{C}-\mathrm{NMR}\left(125 \mathrm{MHz}, \mathrm{CDCl}_{3}\right): \delta 137.00,133.71,132.43$, 130.67, 129.88, 127.05, 126.80, 123.06, 122.84, 121.89, 77.26, 77.01, 76.75, 73.73, 49.17, 36.28, 33.95, 29.69, 25.64. HR-MS (ESI): $m / z$ calcd for $\mathrm{C}_{19} \mathrm{H}_{13} \mathrm{NNaO}_{4}\left([\mathrm{M}+\mathrm{Na}]^{+}\right) 342.0736$, found 342.0740 .

4-(4-Benzoyloxyphenyl)-2-methylenebutyrolactone 4-(4-Benzoyloxyphenyl)-2-methylenebutyrolactone (4i) White solid; mp: $223.3-223.7^{\circ} \mathrm{C}$; $55 \%$ yield; ${ }^{1} \mathrm{H}-\mathrm{NMR}\left(500 \mathrm{MHz}, \mathrm{CDCl}_{3}\right): \delta 8.25(\mathrm{~d}, J=8.3 \mathrm{~Hz}, 5 \mathrm{H}$, $\operatorname{ArH}), 7.70(\mathrm{t}, J=7.4 \mathrm{~Hz}, 4 \mathrm{H}, \mathrm{ArH}), 6.38(\mathrm{~s}, 1 \mathrm{H}, \mathrm{C}=\mathrm{CHH}), 5.76(\mathrm{~d}, J=2.4 \mathrm{~Hz}, 1 \mathrm{H}, \mathrm{OCH}), 5.63-5.55(\mathrm{~m}$, $1 \mathrm{H}, \mathrm{C}=\mathrm{CHH}), 4.11\left(\mathrm{dd}, J=15.3,7.9 \mathrm{~Hz}, 1 \mathrm{H}, \mathrm{CHHC}=\mathrm{CH}_{2}\right), 3.47\left(\mathrm{dd}, J=17.1,8.1 \mathrm{~Hz}, 1 \mathrm{H}, \mathrm{CHHC}=\mathrm{CH}_{2}\right)$; ${ }^{13} \mathrm{C}-\mathrm{NMR}\left(125 \mathrm{MHz}, \mathrm{CDCl}_{3}\right): \delta 133.76,130.21,128.64,126.72,122.12,78.70,77.28,77.03,76.77,40.04$, 36.41, 29.72, 15.00. HR-MS (ESI): $m / z$ calcd for $\mathrm{C}_{18} \mathrm{H}_{14} \mathrm{NaO}_{4}\left([\mathrm{M}+\mathrm{Na}]^{+}\right) 317.0784$, found 317.0788.

4-[4-(2-Methylbenzoyloxy)phenyl]-2-methylenebutyrolactone (4j) White crystals; $\mathrm{mp}$ : $189.6-190.1{ }^{\circ} \mathrm{C} ; 53 \%$ yield; ${ }^{1} \mathrm{H}-\mathrm{NMR}\left(500 \mathrm{MHz}, \mathrm{CDCl}_{3}\right): \delta 8.18(\mathrm{~d}, J=7.8 \mathrm{~Hz}, 1 \mathrm{H}, \mathrm{ArH}), 7.58-7.46(\mathrm{~m}, 1 \mathrm{H}, \mathrm{ArH}), 7.40(\mathrm{t}$, $J=14.7 \mathrm{~Hz}, 2 \mathrm{H}, \operatorname{ArH}), 7.35(\mathrm{t}, J=7.7 \mathrm{~Hz}, 2 \mathrm{H}, \operatorname{ArH}), 7.28(\mathrm{t}, J=6.3 \mathrm{~Hz}, 2 \mathrm{H}, \operatorname{ArH}), 6.35(\mathrm{t}, J=2.8 \mathrm{~Hz}$, $1 \mathrm{H}, \mathrm{C}=\mathrm{CHH}), 5.73(\mathrm{t}, J=2.4 \mathrm{~Hz}, 1 \mathrm{H}, \mathrm{C}=\mathrm{CHH}), 5.64-5.40(\mathrm{~m}, 1 \mathrm{H}, \mathrm{OCH}), 3.45(\mathrm{ddt}, J=17.1,8.0,2.4 \mathrm{~Hz}$, $\left.1 \mathrm{H}, \mathrm{CHHC}=\mathrm{CH}_{2}\right), 3.05-2.85\left(\mathrm{~m}, 1 \mathrm{H}, \mathrm{CHHC}=\mathrm{CH}_{2}\right), 2.70\left(\mathrm{~s}, 3 \mathrm{H}, \mathrm{ArCH}_{3}\right) ;{ }^{13} \mathrm{C}-\mathrm{NMR}\left(125 \mathrm{MHz}, \mathrm{CDCl}_{3}\right)$ : $\delta 170.00,165.67,151.00,141.44,137.39,134.02,132.91,126.65,125.97,125.11,122.96,122.66,122.35$, 77.47, 77.30, 77.05, 76.79, 36.27, 21.95; HR-MS (ESI): $m / z$ calcd for $\mathrm{C}_{19} \mathrm{H}_{16} \mathrm{NaO}_{4}\left([\mathrm{M}+\mathrm{Na}]^{+}\right)$331.0940, found 331.0937 .

4-[4-(3-Methylbenzoyloxy)phenyl]-2-methylenebutyrolactone (4k) White crystals; $\mathrm{mp}: 186.2-186.6{ }^{\circ} \mathrm{C} ; 52 \%$ yield; ${ }^{1} \mathrm{H}-\mathrm{NMR}\left(500 \mathrm{MHz}, \mathrm{CDCl}_{3}\right): \delta 8.00(\mathrm{~d}, J=8.9 \mathrm{~Hz}, 2 \mathrm{H}, \mathrm{ArH}), 7.57-7.14(\mathrm{~m}, 6 \mathrm{H}, \mathrm{ArH}), 6.33(\mathrm{t}$, $J=2.8 \mathrm{~Hz}, 1 \mathrm{H}, \mathrm{C}=\mathrm{CHH}), 5.72(\mathrm{t}, J=2.5 \mathrm{~Hz}, 1 \mathrm{H}, \mathrm{C}=\mathrm{CHH}), 5.58-5.50(\mathrm{~m}, 1 \mathrm{H}, \mathrm{OCH}), 3.43(\mathrm{ddt}, J=17.1,8.0$, $\left.2.4 \mathrm{~Hz}, 1 \mathrm{H}, \mathrm{CHHC}=\mathrm{CH}_{2}\right), 3.05-2.82\left(\mathrm{~m}, 1 \mathrm{H}, \mathrm{CHHC}=\mathrm{CH}_{2}\right), 2.45\left(\mathrm{~s}, 3 \mathrm{H}, \mathrm{ArCH}_{3}\right) ;{ }^{13} \mathrm{C}-\mathrm{NMR}(125 \mathrm{MHz}$, $\left.\mathrm{CDCl}_{3}\right): \delta 170.03,165.28,151.07,138.51,137.37,134.55,134.01,130.71,129.19,128.53,127.37,126.67$, 122.26, 77.48, 77.28, 77.02, 76.77, 36.32, 21.30. HR-MS (ESI): $m / z$ calcd for $\mathrm{C}_{19} \mathrm{H}_{16} \mathrm{NaO}_{4}\left([\mathrm{M}+\mathrm{Na}]^{+}\right)$ 331.0940 , found 331.0937 .

4-[4-(4-Methylbenzoyloxy)phenyl]-2-methylenebutyrolactone (4l) White crystals; $\mathrm{mp}: 184.5-185.1{ }^{\circ} \mathrm{C} ; 60 \%$ yield; ${ }^{1} \mathrm{H}-\mathrm{NMR}\left(500 \mathrm{MHz}, \mathrm{CDCl}_{3}\right): \delta 8.11(\mathrm{~d}, J=8.2 \mathrm{~Hz}, 2 \mathrm{H}, \mathrm{ArH}), 7.56-7.19(\mathrm{~m}, 6 \mathrm{H}, \mathrm{ArH}), 6.35(\mathrm{t}$, $J=2.8 \mathrm{~Hz}, 1 \mathrm{H}, \mathrm{C}=\mathrm{CHH}), 5.74(\mathrm{t}, J=2.5 \mathrm{~Hz}, 1 \mathrm{H}, \mathrm{C}=\mathrm{CHH}), 5.64-5.40(\mathrm{~m}, 1 \mathrm{H}, \mathrm{OCH}), 3.45(\mathrm{ddt}, J=17.1,8.0$, $\left.2.4 \mathrm{~Hz}, 1 \mathrm{H}, \mathrm{CHHC}=\mathrm{CH}_{2}\right), 3.08-2.82\left(\mathrm{~m}, 1 \mathrm{H}, \mathrm{CHHC}=\mathrm{CH}_{2}\right), 2.48\left(\mathrm{~s}, 3 \mathrm{H}, \mathrm{ArCH}_{3}\right) ;{ }^{13} \mathrm{C}-\mathrm{NMR}(125 \mathrm{MHz}$, $\left.\mathrm{CDCl}_{3}\right): \delta 169.99,165.13,151.11,144.63,138.51,137.30,134.03,130.24,129.34,127.37,126.58,122.65$, $122.27,77.48,77.27,77.02,76.76,36.32,21.77$. HR-MS (ESI): $m / z$ calcd for $\mathrm{C}_{19} \mathrm{H}_{16} \mathrm{NaO}_{4}\left([\mathrm{M}+\mathrm{Na}]^{+}\right)$ 331.0940, found 331.0937 .

4-[4-(2-Methoxylbenzoyloxy)phenyl]-2-methylenebutyrolactone (4m) White crystals; mp: $179.8-180.4{ }^{\circ} \mathrm{C}$; $60 \%$ yield; ${ }^{1} \mathrm{H}-\mathrm{NMR}\left(500 \mathrm{MHz}, \mathrm{CDCl}_{3}\right): \delta 8.02(\mathrm{dd}, J=8.0,1.7 \mathrm{~Hz}, 1 \mathrm{H}, \mathrm{ArH}), 7.56(\mathrm{td}, J=8.2,1.8 \mathrm{~Hz}$, $1 \mathrm{H}, \mathrm{ArH}), 7.40-6.97(\mathrm{~m}, 6 \mathrm{H}, \mathrm{ArH}), 6.32(\mathrm{t}, J=2.8 \mathrm{~Hz}, 1 \mathrm{H}, \mathrm{C}=\mathrm{CHH}), 5.71(\mathrm{t}, J=2.5 \mathrm{~Hz}, 1 \mathrm{H}, \mathrm{C}=\mathrm{CH} H)$, 5.59-5.48 (m, 1H, OCH), $3.94\left(\mathrm{~s}, 3 \mathrm{H}, \mathrm{ArOCH}_{3}\right), 3.42\left(\mathrm{ddt}, J=17.1,8.0,2.4 \mathrm{~Hz}, 1 \mathrm{H}, \mathrm{CHHC}=\mathrm{CH}_{2}\right), 2.93$ $\left(\mathrm{ddt}, J=9.3,6.0,2.9 \mathrm{~Hz}, 1 \mathrm{H}, \mathrm{CHHC}=\mathrm{CH}_{2}\right) ;{ }^{13} \mathrm{C}-\mathrm{NMR}\left(125 \mathrm{MHz}, \mathrm{CDCl}_{3}\right): \delta 170.08,164.25,159.97,151.08$, 137.20, 134.54, 134.06, 132.25, 126.56, 122.67, 122.37, 120.25, 112.25, 77.55, 77.30, 77.04, 76.79, 56.07, 36.34; HR-MS (ESI): $m / z$ calcd for $\mathrm{C}_{19} \mathrm{H}_{16} \mathrm{NaO}_{5}\left([\mathrm{M}+\mathrm{Na}]^{+}\right) 347.0889$, found 347.0891 .

4-[4-(3-Methoxylbenzoyloxy)phenyl]-2-methylenebutyrolactone (4n) White crystals; mp: $185.7-186.2{ }^{\circ} \mathrm{C}$; 44\% yield; ${ }^{1} \mathrm{H}-\mathrm{NMR}\left(500 \mathrm{MHz}, \mathrm{CDCl}_{3}\right): 87.85(\mathrm{~d}, \mathrm{~J}=7.7 \mathrm{~Hz}, 1 \mathrm{H}, \mathrm{ArH}), 7.74(\mathrm{~s}, 4 \mathrm{H}, \mathrm{ArH}), 6.38(\mathrm{~s}, 1 \mathrm{H}$, $\mathrm{C}=\mathrm{CHH}), 5.76(\mathrm{~s}, 1 \mathrm{H}, \mathrm{C}=\mathrm{CHH}), 5.66-5.56(\mathrm{~m}, 1 \mathrm{H}, \mathrm{OCH}), 5.44(\mathrm{dd}, J=10.7,5.2 \mathrm{~Hz}, 3 \mathrm{H}, \mathrm{ArH}), 4.35(\mathrm{~s}$, $\left.3 \mathrm{H}, \mathrm{ArOCH}_{3}\right), 4.11\left(\mathrm{dd}, J=17.0,9.5 \mathrm{~Hz}, 1 \mathrm{H}, \mathrm{CHHC}=\mathrm{CH}_{2}\right), 3.47\left(\mathrm{dd}, J=17.1,8.1 \mathrm{~Hz}, 1 \mathrm{H}, \mathrm{CH} H \mathrm{C}=\mathrm{CH}_{2}\right)$; ${ }^{13} \mathrm{C}-\mathrm{NMR}\left(125 \mathrm{MHz}, \mathrm{CDCl}_{3}\right): \delta 170.03,164.28,159.77,129.67,126.76,122.64,122.10,120.32,114.60$, 
78.69, 77.28, 77.03, 76.78, 55.56, 40.04, 36.41, 29.72, 15.00. HR-MS (ESI): $m / z$ calcd for $\mathrm{C}_{19} \mathrm{H}_{16} \mathrm{NaO}_{5}$ $\left([\mathrm{M}+\mathrm{Na}]^{+}\right) 347.0889$, found 347.0891 .

4-[4-(4-Methoxylbenzoyloxy)phenyl]-2-methylenebutyrolactone (4o) White crystals; mp: $184.5-185.2{ }^{\circ} \mathrm{C}$; $51 \%$ yield; ${ }^{1} \mathrm{H}-\mathrm{NMR}\left(500 \mathrm{MHz}, \mathrm{CDCl}_{3}\right): \delta 8.28-8.00(\mathrm{~m}, 2 \mathrm{H}, \mathrm{ArH}), 7.53-7.30(\mathrm{~m}, 2 \mathrm{H}, \mathrm{ArH}), 7.28-7.14(\mathrm{~m}$, 2H, ArH), 7.02-6.95 (m, 2H, ArH), $6.32(\mathrm{t}, J=2.8 \mathrm{~Hz}, 1 \mathrm{H}, \mathrm{C}=\mathrm{CHH}), 5.71(\mathrm{t}, J=2.5 \mathrm{~Hz}, 1 \mathrm{H}, \mathrm{C}=\mathrm{CHH})$, 5.58-5.41 (m, 1H, OCH), $3.90\left(\mathrm{~s}, 3 \mathrm{H}, \mathrm{ArOCH}_{3}\right), 3.49-3.33\left(\mathrm{~m}, 1 \mathrm{H}, \mathrm{CHHC}=\mathrm{CH}_{2}\right), 2.94(\mathrm{ddd}, J=14.2,6.3$, $\left.3.1 \mathrm{~Hz}, 1 \mathrm{H}, \mathrm{CHHC}=\mathrm{CH}_{2}\right){ }^{13} \mathrm{C}-\mathrm{NMR}\left(125 \mathrm{MHz}, \mathrm{CDCl}_{3}\right): \delta 170.08,164.83,164.05,159.97,151.16,137.23$, 134.05, 132.36, 126.64, 122.70, 122.33, 121.55, 113.92, 77.46, 77.06, 76.74, 55.56, 36.32. HR-MS (ESI): $\mathrm{m} / \mathrm{z}$ calcd for $\mathrm{C}_{19} \mathrm{H}_{16} \mathrm{NaO}_{5}\left([\mathrm{M}+\mathrm{Na}]^{+}\right)$347.0889, found 347.0891.

4-[4-(Propionyloxy)phenyl]-2-methylenebutyrolactone (4p) Colourless oil; $68 \%$ yield; ${ }^{1} \mathrm{H}-\mathrm{NMR}(500 \mathrm{MHz}$, $\left.\mathrm{CDCl}_{3}\right): \delta 6.35(\mathrm{t}, J=2.8 \mathrm{~Hz}, 1 \mathrm{H}, \mathrm{C}=\mathrm{CHH}), 5.74(\mathrm{t}, J=2.4 \mathrm{~Hz}, 1 \mathrm{H}, \mathrm{C}=\mathrm{CHH}), 5.63-5.46(\mathrm{~m}, 1 \mathrm{H}$, $\mathrm{OCH}), 5.39\left(\mathrm{dd}, J=10.7,5.2 \mathrm{~Hz}, 3 \mathrm{H}, \mathrm{CH}_{3} \mathrm{CH}_{2}\right), 3.44\left(\mathrm{dd}, J=17.1,8.1 \mathrm{~Hz}, 1 \mathrm{H}, \mathrm{CHHC}=\mathrm{CH}_{2}\right), 3.03-2.90$ $\left(\mathrm{m}, 1 \mathrm{H}, \mathrm{CHHC}=\mathrm{CH}_{2}\right), 1.67\left(\mathrm{~s}, 2 \mathrm{H}, \mathrm{CH}_{3} \mathrm{CH}_{2}\right) ;{ }^{13} \mathrm{C}-\mathrm{NMR}\left(125 \mathrm{MHz}, \mathrm{CDCl}_{3}\right): \delta 178.99,172.87,150.84$, $136.53,126.63,122.64,78.68,77.39,77.06,76.81,39.98,36.33,27.75,14.97$. HR-MS (ESI): $m / z$ calcd for $\mathrm{C}_{14} \mathrm{H}_{14} \mathrm{NaO}_{4}\left([\mathrm{M}+\mathrm{Na}]^{+}\right)$269.0784, found 269.0786.

[4-(4-Hydroxy-3-methoxycinnamoyloxy)phenyl]-2-methylenebutyrolactone (4q) Yellow oil; 45\% yield; ${ }^{1} \mathrm{H}-\mathrm{NMR}\left(400 \mathrm{MHz}, \mathrm{CDCl}_{3}\right): \delta 7.80(\mathrm{~d}, J=15.9 \mathrm{~Hz}, 1 \mathrm{H}, \mathrm{ArOH}), 7.36(\mathrm{~d}, J=8.6 \mathrm{~Hz}, 2 \mathrm{H}, \mathrm{ArH}), 7.21(\mathrm{dd}$, $J=21.2,12.6 \mathrm{~Hz}, 2 \mathrm{H}, \mathrm{ArH}), 7.16-7.05(\mathrm{~m}, 2 \mathrm{H}, \mathrm{CH}=\mathrm{CH}), 6.95(\mathrm{~d}, J=8.2 \mathrm{~Hz}, 1 \mathrm{H}, \mathrm{ArH}), 6.47(\mathrm{~d}, J=15.9 \mathrm{~Hz}$, $1 \mathrm{H}, \mathrm{ArH}), 6.32(\mathrm{t}, J=2.8 \mathrm{~Hz}, 1 \mathrm{H}, \mathrm{C}=\mathrm{CHH}), 6.10(\mathrm{~s}, 1 \mathrm{H}, \mathrm{ArH}), 5.71(\mathrm{t}, J=2.5 \mathrm{~Hz}, 1 \mathrm{H}, \mathrm{C}=\mathrm{CHH}), 5.58-5.44$ $(\mathrm{m}, 1 \mathrm{H}, \mathrm{OCH}), 4.02-3.82\left(\mathrm{~m}, 3 \mathrm{H}, \mathrm{ArOCH}_{3}\right), 3.49-3.29\left(\mathrm{~m}, 1 \mathrm{H}, \mathrm{CHHC}=\mathrm{CH}_{2}\right), 2.93(\mathrm{ddt}, J=12.2,6.0$, $\left.2.9 \mathrm{~Hz}, 1 \mathrm{H}, \mathrm{CHHC}=\mathrm{CH}_{2}\right) ;{ }^{13} \mathrm{C}-\mathrm{NMR}\left(125 \mathrm{MHz}, \mathrm{CDCl}_{3}\right): \delta 170.02,165.56,151.01,148.60,147.01,137.172$, 134.06, 126.63, 123.51, 122.18, 114.92, 114.22, 109.66, 76.72, 56.01, 49.16, 36.28, 33.94, 30.90, 29.69, 25.62 . HR-MS (ESI): $m / z$ calcd for $\mathrm{C}_{21} \mathrm{H}_{18} \mathrm{NaO}_{6}\left([\mathrm{M}+\mathrm{Na}]^{+}\right)$389.0997, found 389.0995 .

4-[4-(Cinnamoyloxy)phenyl]-2-methylenebutyrolactone (4r) Yellow oil; 43\% yield; ${ }^{1} \mathrm{H}-\mathrm{NMR}(400 \mathrm{MHz}$, $\left.\mathrm{CDCl}_{3}\right): \delta 7.88(\mathrm{~d}, J=16.0 \mathrm{~Hz}, 1 \mathrm{H}, \mathrm{ArH}), 7.64-7.53(\mathrm{~m}, 2 \mathrm{H}, \mathrm{ArH}), 7.47-7.40(\mathrm{~m}, 2 \mathrm{H}, \mathrm{ArH}), 7.39-7.32$ $(\mathrm{m}, 2 \mathrm{H}, \mathrm{ArH}), 7.28-7.16(\mathrm{~m}, 2 \mathrm{H}, \mathrm{CH}=\mathrm{CH}), 6.63(\mathrm{~d}, J=16.0 \mathrm{~Hz}, 1 \mathrm{H}, \mathrm{ArH}), 6.32(\mathrm{t}, J=2.8 \mathrm{~Hz}, 1 \mathrm{H}$, $\mathrm{C}=\mathrm{CHH}), 5.71(\mathrm{t}, J=2.5 \mathrm{~Hz}, 1 \mathrm{H}, \mathrm{C}=\mathrm{CHH}), 5.63-5.46(\mathrm{~m}, 1 \mathrm{H}, \mathrm{OCH}), 3.41(\mathrm{ddt}, J=17.1,8.0,2.4 \mathrm{~Hz}$, $\left.1 \mathrm{H}, \mathrm{CHHC}=\mathrm{CH}_{2}\right), 2.93\left(\mathrm{ddt}, J=9.4,6.0,2.9 \mathrm{~Hz}, 1 \mathrm{H}, \mathrm{CHHC}=\mathrm{CH}_{2}\right) ;{ }^{13} \mathrm{C}-\mathrm{NMR}\left(100 \mathrm{MHz}, \mathrm{CDCl}_{3}\right)$ : $\delta 170.06,165.31,150.88,146.99,137.31,134.05,130.86,129.05,128.37,126.65,122.72,122.16,116.99,77.44$, 77.06, 76.74, 36.30, 33.94, 30.91, 29.63. HR-MS (ESI): $m / z$ calcd for $\mathrm{C}_{20} \mathrm{H}_{16} \mathrm{NaO}_{4}\left([\mathrm{M}+\mathrm{Na}]^{+}\right.$) 343.0940, found 343.0941 .

4-[2-(3-Chlorobenzoyloxy)phenyl]-2-methylenebutyrolactone (5a) White solid; mp: 201.3-201.8 ${ }^{\circ} \mathrm{C} ; 54 \%$ yield; ${ }^{1} \mathrm{H}-\mathrm{NMR}\left(500 \mathrm{MHz}, \mathrm{CDCl}_{3}\right): \delta 8.16(\mathrm{t}, J=1.8 \mathrm{~Hz}, 1 \mathrm{H}, \mathrm{ArH}), 8.08(\mathrm{~d}, J=7.8 \mathrm{~Hz}, 1 \mathrm{H}, \mathrm{ArH}), 7.71-7.59$ $(\mathrm{m}, 1 \mathrm{H}, \operatorname{ArH}), 7.53-7.45(\mathrm{~m}, 2 \mathrm{H}, \mathrm{ArH}), 7.43(\mathrm{dt}, J=7.8,3.9 \mathrm{~Hz}, 1 \mathrm{H}, \mathrm{ArH}), 7.34(\mathrm{dd}, J=9.4,4.9 \mathrm{~Hz}, 1 \mathrm{H}$, $\operatorname{ArH}), 7.21(\mathrm{dd}, J=8.0,0.7 \mathrm{~Hz}, 1 \mathrm{H}, \mathrm{ArH}), 6.24(\mathrm{t}, J=2.9 \mathrm{~Hz}, 1 \mathrm{H}, \mathrm{C}=\mathrm{CHH}), 5.68(\mathrm{dd}, J=8.4,6.2 \mathrm{~Hz}, 1 \mathrm{H}$, $\mathrm{C}=\mathrm{CHH}), 5.63(\mathrm{t}, J=2.5 \mathrm{~Hz}, 1 \mathrm{H}, \mathrm{OCH}), 3.32\left(\mathrm{ddt}, J=17.4,8.4,2.6 \mathrm{~Hz}, 1 \mathrm{H}, \mathrm{CHHC}=\mathrm{CH}_{2}\right), 2.90(\mathrm{ddt}$, $\left.J=17.4,5.9,2.9 \mathrm{~Hz}, 1 \mathrm{H}, \mathrm{CHHC}=\mathrm{CH}_{2}\right) ;{ }^{13} \mathrm{C}-\mathrm{NMR}\left(125 \mathrm{MHz}, \mathrm{CDCl}_{3}\right): \delta 169.96,163.75,147.46,135.04$, $134.19,133.51,132.32,130.46,129.67,128.34,126.85,126.40,123.09,122.85,77.31,77.06,76.80,35.20$; HR-MS (ESI): $m / z$ calcd for $\mathrm{C}_{18} \mathrm{H}_{14} \mathrm{ClO}_{4}\left([\mathrm{M}+\mathrm{Na}]^{+}\right)$325.0574, found 325.0575.

4-[2-(4-Chlorobenzoyloxy)phenyl]-2-methylenebutyrolactone (5b) White solid; mp: 208.7-209.3 ${ }^{\circ} \mathrm{C} ; 48 \%$ yield; ${ }^{1} \mathrm{H}-\mathrm{NMR}\left(400 \mathrm{MHz}, \mathrm{CDCl}_{3}\right): \delta 8.17-8.07(\mathrm{~m}, 2 \mathrm{H}, \mathrm{ArH}), 7.59-7.45(\mathrm{~m}, 4 \mathrm{H}, \mathrm{ArH}), 7.26(\mathrm{~s}, 2 \mathrm{H}, \mathrm{ArH})$, $6.22(\mathrm{~s}, 1 \mathrm{H}, \mathrm{C}=\mathrm{CHH}), 5.67(\mathrm{dd}, J=8.4,6.1 \mathrm{~Hz}, 1 \mathrm{H}, \mathrm{OCH}), 5.61(\mathrm{~s}, 1 \mathrm{H}, \mathrm{C}=\mathrm{CHH}), 3.30(\mathrm{ddt}, J=17.4$, $\left.8.4,2.6 \mathrm{~Hz}, 1 \mathrm{H}, \mathrm{CHHC}=\mathrm{CH}_{2}\right), 2.90\left(\mathrm{ddt}, J=17.4,5.9,2.9 \mathrm{~Hz}, 1 \mathrm{H}, \mathrm{CHHC}=\mathrm{CH}_{2}\right) ;{ }^{13} \mathrm{C}-\mathrm{NMR}(125 \mathrm{MHz}$, $\left.\mathrm{CDCl}_{3}\right): \delta 168.96,165.75,146.45,137.04,134.29,131.58,129.66,129.25,128.81,128.26,126.76,126.40$, 123.09, 122.97, 77.35, 77.03, 76.72, 30.87. HR-MS (ESI): $m / z$ calcd for $\mathrm{C}_{18} \mathrm{H}_{14} \mathrm{ClO}_{4}\left([\mathrm{M}+\mathrm{Na}]^{+}\right) 325.0572$, found 325.0575 . 
4-[2-(2-Bromobenzoyloxy)phenyl]-2-methylenebutyrolactone (5c) White crystal; mp: 204.6-205.1 ${ }^{\circ} \mathrm{C} ; 43 \%$ yield; ${ }^{1} \mathrm{H}-\mathrm{NMR}\left(500 \mathrm{MHz}, \mathrm{CDCl}_{3}\right): \delta 8.05(\mathrm{dd}, J=7.5,1.9 \mathrm{~Hz}, 1 \mathrm{H}, \mathrm{ArH}), 7.79(\mathrm{dd}, J=7.7,1.2 \mathrm{~Hz}, 1 \mathrm{H}$, $\operatorname{ArH}), 7.56-7.16(\mathrm{~m}, 6 \mathrm{H}, \mathrm{ArH}), 6.25(\mathrm{t}, J=2.8 \mathrm{~Hz}, 1 \mathrm{H}, \mathrm{C}=\mathrm{CHH}), 5.76(\mathrm{dd}, J=8.3,6.2 \mathrm{~Hz}, 1 \mathrm{H}, \mathrm{OCH})$, $5.66(\mathrm{t}, J=2.5 \mathrm{~Hz}, 1 \mathrm{H}, \mathrm{C}=\mathrm{CHH}), 3.60-3.22\left(\mathrm{~m}, 1 \mathrm{H}, \mathrm{CHHC}=\mathrm{CH}_{2}\right), 2.93(\mathrm{ddt}, J=17.4,5.9,2.8 \mathrm{~Hz}, 1 \mathrm{H}$, $\left.\mathrm{CHHC}=\mathrm{CH}_{2}\right) ;{ }^{13} \mathrm{C}-\mathrm{NMR}\left(125 \mathrm{MHz}, \mathrm{CDCl}_{3}\right): \delta 164.19,147.43,134.88,132.39,131.97,130.59,129.59$, 127.57, 126.81, 126.29, 122.88, 122.69, 122.42, 77.28, 77.03, 76.78, 73.60, 35.33.HR-MS (ESI): $m / z$ calcd for $\mathrm{C}_{18} \mathrm{H}_{14} \mathrm{BrO}_{4}\left([\mathrm{M}+\mathrm{H}]^{+}\right)$373.0070, found 373.0072.

4-[2-(3-Bromobenzoyloxy) phenyl]-2-methylenebutyrolactone (5d) White crystals; mp: 189.7-190.4 ${ }^{\circ} \mathrm{C} ; 45 \%$ yield; ${ }^{1} \mathrm{H}-\mathrm{NMR}\left(500 \mathrm{MHz}, \mathrm{CDCl}_{3}\right): \delta 8.34(\mathrm{t}, J=1.6 \mathrm{~Hz}, 1 \mathrm{H}, \mathrm{ArH}), 8.14(\mathrm{~d}, J=7.8 \mathrm{~Hz}, 1 \mathrm{H}, \mathrm{ArH})$, 7.91-7.76 (m, 1H, ArH), 7.54-7.40 (m, 3H, ArH), 7.36 (td, J = 7.6, 0.7 Hz, 1H, ArH), 7.23 (dd, J = 8.0, $0.6 \mathrm{~Hz}, 1 \mathrm{H}, \mathrm{ArH}), 6.25(\mathrm{t}, J=2.9 \mathrm{~Hz}, 1 \mathrm{H}, \mathrm{C}=\mathrm{CHH}), 5.69(\mathrm{dd}, J=8.3,6.2 \mathrm{~Hz}, 1 \mathrm{H}, \mathrm{OCH}), 5.65(\mathrm{t}, J=2.5 \mathrm{~Hz}$, $1 \mathrm{H}, \mathrm{C}=\mathrm{CHH}), 3.33\left(\mathrm{ddt}, J=17.4,8.4,2.5 \mathrm{~Hz}, 1 \mathrm{H}, \mathrm{CHHC}=\mathrm{CH}_{2}\right), 2.92(\mathrm{ddt}, J=17.4,5.9,2.8 \mathrm{~Hz}, 1 \mathrm{H}$, $\left.\mathrm{CHHC}=\mathrm{CH}_{2}\right) ;{ }^{13} \mathrm{C}-\mathrm{NMR}\left(125 \mathrm{MHz}, \mathrm{CDCl}_{3}\right): \delta 169.89,163.60,147.50,137.07,133.54,133.12,130.69$, $130.42,129.65,128.77,126.83,126.42,123.15,77.32,77.06,76.81,73.61,35.20$. HR-MS (ESI): $m / z$ calcd for $\mathrm{C}_{18} \mathrm{H}_{14} \mathrm{BrO}_{4}\left([\mathrm{M}+\mathrm{H}]^{+}\right)$373.0070, found 373.0069.

4-[2-(4-Bromobenzoyloxy) phenyl]-2-methylenebutyrolactone (5e) White crystals; mp: $184.7-185.2{ }^{\circ} \mathrm{C} ; 53 \%$ yield; ${ }^{1} \mathrm{H}-\mathrm{NMR}\left(500 \mathrm{MHz}, \mathrm{CDCl}_{3}\right): \delta 8.05(\mathrm{dd}, J=23.8,8.5 \mathrm{~Hz}, 2 \mathrm{H}, \mathrm{ArH}), 7.70(\mathrm{t}, J=11.9 \mathrm{~Hz}, 2 \mathrm{H}, \mathrm{ArH})$, 7.56-7.20 (m, 4H, ArH), $6.25(\mathrm{t}, J=2.8 \mathrm{~Hz}, 1 \mathrm{H}, \mathrm{C}=\mathrm{CHH}), 5.69(\mathrm{dd}, J=8.3,6.2 \mathrm{~Hz}, 1 \mathrm{H}, \mathrm{OCH}), 5.63(\mathrm{t}$, $J=2.4 \mathrm{~Hz}, 1 \mathrm{H}, \mathrm{C}=\mathrm{CHH}), 3.32\left(\mathrm{ddt}, J=17.4,8.4,2.5 \mathrm{~Hz}, 1 \mathrm{H}, \mathrm{CHHC}=\mathrm{CH}_{2}\right), 2.92(\mathrm{ddt}, J=17.4,5.9,2.8 \mathrm{~Hz}$, $\left.1 \mathrm{H}, \mathrm{CHHC}=\mathrm{CH}_{2}\right) ;{ }^{13} \mathrm{C}-\mathrm{NMR}\left(125 \mathrm{MHz}, \mathrm{CDCl}_{3}\right): \delta 169.90,164.22,147.58,133.55,132.27,131.65,130.89$, 130.62, 129.58, 127.66, 126.75, 126.44, 122.93, 77.27, 77.02, 76.76, 73.69, 35.16. HR-MS (ESI): $m / z$ calcd for $\mathrm{C}_{18} \mathrm{H}_{14} \mathrm{BrO}_{4}\left([\mathrm{M}+\mathrm{H}]^{+}\right)$373.0070, found 373.0069.

4-[2-(4-Benzonitrile)phenyl]-2-methylenebutyrolactone (5f) Yellow oil; 65\% yield; ${ }^{1} \mathrm{H}-\mathrm{NMR}(500 \mathrm{MHz}$, $\left.\mathrm{CDCl}_{3}\right): \delta 8.31(\mathrm{~d}, J=8.5 \mathrm{~Hz}, 2 \mathrm{H}, \mathrm{ArH}), 7.86(\mathrm{~d}, J=8.5 \mathrm{~Hz}, 2 \mathrm{H}, \mathrm{ArH}), 7.55-7.43(\mathrm{~m}, 2 \mathrm{H}, \mathrm{ArH}), 7.41-7.35$ $(\mathrm{m}, 1 \mathrm{H}, \mathrm{ArH}), 7.30-7.24(\mathrm{~m}, 1 \mathrm{H}, \mathrm{ArH}), 6.23(\mathrm{t}, J=2.9 \mathrm{~Hz}, 1 \mathrm{H}, \mathrm{C}=\mathrm{CHH}), 5.68(\mathrm{t}, J=7.3 \mathrm{~Hz}, 1 \mathrm{H}, \mathrm{OCH})$, $5.64(\mathrm{t}, J=2.5 \mathrm{~Hz}, 1 \mathrm{H}, \mathrm{C}=\mathrm{CHH}), 3.33\left(\mathrm{ddt}, J=17.4,8.5,2.5 \mathrm{~Hz}, 1 \mathrm{H}, \mathrm{CHHC}=\mathrm{CH}_{2}\right), 3.02-2.93(\mathrm{~m}, 1 \mathrm{H}$, $\left.\mathrm{CHHC}=\mathrm{CH}_{2}\right) ;{ }^{13} \mathrm{C}-\mathrm{NMR}\left(125 \mathrm{MHz}, \mathrm{CDCl}_{3}\right): \delta 163.38,147.52,133.47,132.59,130.68,129.48,127.05$, $126.81,23.12,122.85,120.68,117.59,115.82,77.30,77.04,76.79,75.28,73.86,35.02$. HR-MS (ESI): $m / z$ calcd for $\mathrm{C}_{19} \mathrm{H}_{13} \mathrm{NNaO}_{4}\left([\mathrm{M}+\mathrm{Na}]^{+}\right) 342.0736$, found 342.0741 .

4-(2-Benzoyloxyphenyl)-2-methylenebutyrolactone (5g) White solid; mp: $166.3-167.0{ }^{\circ} \mathrm{C} ; 57 \%$ yield; ${ }^{1} \mathrm{H}-\mathrm{NMR}\left(500 \mathrm{MHz}, \mathrm{CDCl}_{3}\right): \delta 8.22(\mathrm{~d}, J=7.3 \mathrm{~Hz}, 2 \mathrm{H}, \mathrm{ArH}), 7.71(\mathrm{t}, J=7.5 \mathrm{~Hz}, 1 \mathrm{H}, \mathrm{ArH}), 7.57$ $(\mathrm{t}, J=7.8 \mathrm{~Hz}, 2 \mathrm{H}, \operatorname{ArH}), 7.49(\mathrm{t}, J=7.4 \mathrm{~Hz}, 1 \mathrm{H}, \operatorname{ArH}), 7.47-7.42(\mathrm{~m}, 1 \mathrm{H}, \operatorname{ArH}), 7.35(\mathrm{dd}, J=11.1,4.0 \mathrm{~Hz}$, $1 \mathrm{H}, \operatorname{ArH}), 7.25(\mathrm{~d}, J=8.1 \mathrm{~Hz}, 1 \mathrm{H}, \mathrm{ArH}), 6.24(\mathrm{t}, J=2.8 \mathrm{~Hz}, 1 \mathrm{H}, \mathrm{C}=\mathrm{CHH}), 5.73(\mathrm{dd}, J=8.2,6.3 \mathrm{~Hz}$, $1 \mathrm{H}, \mathrm{OCH}), 5.63(\mathrm{t}, J=2.4 \mathrm{~Hz}, 1 \mathrm{H}, \mathrm{C}=\mathrm{CHH}), 3.34\left(\mathrm{ddt}, J=17.4,8.4,2.5 \mathrm{~Hz}, 1 \mathrm{H}, \mathrm{CHHC}=\mathrm{CH}_{2}\right), 2.92$ $\left(\mathrm{ddt}, J=17.4,5.9,2.8 \mathrm{~Hz}, 1 \mathrm{H}, \mathrm{CHHC}=\mathrm{CH}_{2}\right) ;{ }^{13} \mathrm{C}-\mathrm{NMR}\left(125 \mathrm{MHz}, \mathrm{CDCl}_{3}\right): \delta 133.76,130.21,128.64$, $126.72,122.12,78.70,77.28,77.03,76.77,40.04,36.41,29.72,15.00$. HR-MS (ESI): $m / z$ calcd for $\mathrm{C}_{18} \mathrm{H}_{15} \mathrm{O}_{4}$ $\left([\mathrm{M}+\mathrm{H}]^{+}\right)$295.0964, found 295.0964 .

4-[2-(2-Methylbenzoyloxy)phenyl]-2-methylenebutyrolactone (5h) White crystals; $\mathrm{mp}: 172.8-173.4{ }^{\circ} \mathrm{C} ; 47 \%$ yield; ${ }^{1} \mathrm{H}-\mathrm{NMR}\left(400 \mathrm{MHz}, \mathrm{CDCl}_{3}\right): \delta 8.21-8.12(\mathrm{~m}, 1 \mathrm{H}, \mathrm{ArH}), 7.55-7.49(\mathrm{~m}, 1 \mathrm{H}, \mathrm{ArH}), 7.49-7.39(\mathrm{~m}, 2 \mathrm{H}$, $\mathrm{ArH}), 7.38-7.28(\mathrm{~m}, 3 \mathrm{H}, \mathrm{ArH}), 7.26-7.19(\mathrm{~m}, 1 \mathrm{H}, \mathrm{ArH}), 6.22(\mathrm{t}, J=2.9 \mathrm{~Hz}, 1 \mathrm{H}, \mathrm{C}=\mathrm{CHH}), 5.70(\mathrm{dd}, J=8.3$, $6.1 \mathrm{~Hz}, 1 \mathrm{H}, \mathrm{OCH}), 5.61(\mathrm{t}, J=2.5 \mathrm{~Hz}, 1 \mathrm{H}, \mathrm{C}=\mathrm{CH}), 3.32\left(\mathrm{ddt}, J=17.4,8.4,2.6 \mathrm{~Hz}, 1 \mathrm{H}, \mathrm{CHHC}=\mathrm{CH}_{2}\right)$, $2.90\left(\mathrm{ddt}, J=17.4,5.9,2.9 \mathrm{~Hz}, 1 \mathrm{H}, \mathrm{CHHC}=\mathrm{CH}_{2}\right), 2.68\left(\mathrm{~s}, 3 \mathrm{H}, \mathrm{ArCH}_{3}\right) ;{ }^{13} \mathrm{C}-\mathrm{NMR}\left(125 \mathrm{MHz}, \mathrm{CDCl}_{3}\right)$ : $\delta 170.05,165.29,147.67,141.92,133.66,133.33,132.55,131.16,129.52,127.60,126.52,126.17,122.96$, 77.40, 77.08, 76.77, 73.66, 35.30, 22.08.HR-MS (ESI): $m / z$ calcd for $\mathrm{C}_{19} \mathrm{H}_{16} \mathrm{NaO}_{4}\left([\mathrm{M}+\mathrm{Na}]^{+}\right) 331.0940$, found 337.0940 .

4-[2-(3-Methylbenzoyloxy)phenyl]-2-methylenebutyrolactone (5i) White crystals; $\mathrm{mp}: 179.3-179.9{ }^{\circ} \mathrm{C} ; 45 \%$ yield; ${ }^{1} \mathrm{H}-\mathrm{NMR}\left(500 \mathrm{MHz}, \mathrm{CDCl}_{3}\right): \delta 7.99(\mathrm{~d}, J=8.7 \mathrm{~Hz}, 2 \mathrm{H}, \mathrm{ArH}), 7.48(\mathrm{t}, J=8.0 \mathrm{~Hz}, 2 \mathrm{H}, \mathrm{ArH}), 7.45-7.39$ $(\mathrm{m}, 2 \mathrm{H}, \mathrm{ArH}), 7.32(\mathrm{t}, J=7.6 \mathrm{~Hz}, 1 \mathrm{H}, \mathrm{ArH}), 7.21(\mathrm{~d}, J=8.0 \mathrm{~Hz}, 1 \mathrm{H}, \mathrm{ArH}), 6.22(\mathrm{t}, J=2.9 \mathrm{~Hz}, 1 \mathrm{H}, \mathrm{C}=\mathrm{CHH})$, 
$5.70(\mathrm{dd}, J=8.3,6.2 \mathrm{~Hz}, 1 \mathrm{H}, \mathrm{OCH}), 5.60(\mathrm{t}, J=2.5 \mathrm{~Hz}, 1 \mathrm{H}, \mathrm{C}=\mathrm{CH} H), 3.31(\mathrm{ddt}, J=17.4,8.4,2.5 \mathrm{~Hz}$, $\left.1 \mathrm{H}, \mathrm{CHHC}=\mathrm{CH}_{2}\right), 2.89\left(\mathrm{ddt}, J=17.4,5.9,2.8 \mathrm{~Hz}, 1 \mathrm{H}, \mathrm{CHHC}=\mathrm{CH}_{2}\right), 2.46\left(\mathrm{~s}, 3 \mathrm{H}, \mathrm{ArCH}_{3}\right) ;{ }^{13} \mathrm{C}-\mathrm{NMR}$ $\left(125 \mathrm{MHz}, \mathrm{CDCl}_{3}\right): \delta 170.06,165.06,147.69,138.77,134.93,133.65,132.48,130.76,129.52,128.69,127.36$, $126.56,126.16,122.93,77.30,77.05,76.79,73.66,35.28,21.32$. HR-MS (ESI): $m / z$ calcd for $\mathrm{C}_{19} \mathrm{H}_{16} \mathrm{NaO}_{4}$ $\left([\mathrm{M}+\mathrm{Na}]^{+}\right) 337.0940$, found 337.0941.

4-[2-(4-Methylbenzoyloxy)phenyl]-2-methylenebutyrolactone (5j) White crystals; mp: $181.2-181.6{ }^{\circ} \mathrm{C} ; 46 \%$ yield; ${ }^{1} \mathrm{H}-\mathrm{NMR}\left(400 \mathrm{MHz}, \mathrm{CDCl}_{3}\right): \delta 8.08(\mathrm{~d}, J=8.2 \mathrm{~Hz}, 2 \mathrm{H}, \mathrm{ArH}), 7.49-7.38(\mathrm{~m}, 2 \mathrm{H}, \mathrm{ArH}), 7.36-7.28(\mathrm{~m}$, $3 \mathrm{H}, \mathrm{ArH}), 7.24-7.19(\mathrm{~m}, 1 \mathrm{H}, \mathrm{ArH}), 6.22(\mathrm{t}, J=2.9 \mathrm{~Hz}, 1 \mathrm{H}, \mathrm{C}=\mathrm{CHH}), 5.70(\mathrm{dd}, J=8.3,6.1 \mathrm{~Hz}, 1 \mathrm{H}, \mathrm{OCH})$, $5.60(\mathrm{t}, J=2.5 \mathrm{~Hz}, 1 \mathrm{H}, \mathrm{C}=\mathrm{CHH}), 3.31\left(\mathrm{ddt}, J=17.4,8.4,2.6 \mathrm{~Hz}, 1 \mathrm{H}, \mathrm{CHHC}=\mathrm{CH}_{2}\right), 2.89(\mathrm{ddt}, J=17.4$, $\left.5.9,2.9 \mathrm{~Hz}, 1 \mathrm{H}, \mathrm{CHHC}=\mathrm{CH}_{2}\right), 2.47\left(\mathrm{~s}, 3 \mathrm{H}, \mathrm{ArCH}_{3}\right) ;{ }^{13} \mathrm{C}-\mathrm{NMR}\left(125 \mathrm{MHz}, \mathrm{CDCl}_{3}\right): \delta 170.26,163.06$, 149.69,145.15, 138.77, 133.65, 132.49, 130.29, 129.53, 128.49, 126.51, 126.05, 122.95, 77.35, 77.03, 76.72, 73.71, 35.28, 21.83. HR-MS (ESI): $m / z$ calcd for $\mathrm{C}_{19} \mathrm{H}_{16} \mathrm{NaO}_{4}\left([\mathrm{M}+\mathrm{Na}]^{+}\right)$331.0940, found 331.0937.

4-[2-(2-Methoxylbenzoyloxy)phenyl]-2-methylenebutyrolactone (5k) White crystals; mp: $177.8-178.6{ }^{\circ} \mathrm{C}$; $51 \%$ yield; ${ }^{1} \mathrm{H}-\mathrm{NMR}\left(500 \mathrm{MHz}, \mathrm{CDCl}_{3}\right): \delta 8.00(\mathrm{dd}, J=7.7,1.6 \mathrm{~Hz}, 1 \mathrm{H}, \mathrm{ArH}), 7.59(\mathrm{td}, J=8.5,1.7 \mathrm{~Hz}$, $1 \mathrm{H}, \mathrm{ArH}), 7.41(\mathrm{ddd}, J=15.7,9.2,4.6 \mathrm{~Hz}, 2 \mathrm{H}, \mathrm{ArH}), 7.33-7.19(\mathrm{~m}, 2 \mathrm{H}, \mathrm{ArH}), 7.07(\mathrm{dd}, J=12.2,5.2 \mathrm{~Hz}$, $2 \mathrm{H}, \mathrm{ArH}), 6.24(\mathrm{t}, J=2.9 \mathrm{~Hz}, 1 \mathrm{H}, \mathrm{C}=\mathrm{CHH}), 5.79(\mathrm{dd}, J=8.2,6.2 \mathrm{~Hz}, 1 \mathrm{H}, \mathrm{OCH}), 5.61(\mathrm{t}, J=2.5 \mathrm{~Hz}, 1 \mathrm{H}$, $\mathrm{C}=\mathrm{CHH}), 3.95\left(\mathrm{~s}, 3 \mathrm{H}, \mathrm{ArOCH}_{3}\right), 3.36\left(\mathrm{ddt}, J=17.4,8.3,2.5 \mathrm{~Hz}, 1 \mathrm{H}, \mathrm{CHHC}=\mathrm{CH}_{2}\right), 2.87(\mathrm{ddt}, J=17.4,5.9$, $\left.2.9 \mathrm{~Hz}, 1 \mathrm{H}, \mathrm{CHHC}=\mathrm{CH}_{2}\right) ;{ }^{13} \mathrm{C}-\mathrm{NMR}\left(125 \mathrm{MHz}, \mathrm{CDCl}_{3}\right): \delta 170.21,164.40,159.83,147.61,134.84,133.89$, $132.54,129.32,126.40,125.81,122.97,122.72,120.46,118.38,112.25,77.31,77.06,76.80,73.71,56.01,35.45$. HR-MS (ESI): $m / z$ calcd for $\mathrm{C}_{19} \mathrm{H}_{16} \mathrm{NaO}_{5}\left([\mathrm{M}+\mathrm{Na}]^{+}\right)$347.0889, found 347.0889.

4-[2-(3-Methoxylbenzoyloxy)phenyl]-2-methylenebutyrolactone (51) White crystals; $\mathrm{mp}: 180.3-180.8{ }^{\circ} \mathrm{C} ; 50 \%$ yield; ${ }^{1} \mathrm{H}-\mathrm{NMR}\left(500 \mathrm{MHz}, \mathrm{CDCl}_{3}\right): \delta 7.81(\mathrm{~d}, J=7.7 \mathrm{~Hz}, 1 \mathrm{H}, \mathrm{ArH}), 7.76-7.65(\mathrm{~m}, 1 \mathrm{H}, \mathrm{ArH}), 7.55-7.40$ $(\mathrm{m}, 3 \mathrm{H}, \mathrm{ArH}), 7.35(\mathrm{t}, J=7.2 \mathrm{~Hz}, 1 \mathrm{H}, \mathrm{ArH}), 7.30-7.22(\mathrm{~m}, 2 \mathrm{H}, \operatorname{ArH}), 6.25(\mathrm{t}, J=2.9 \mathrm{~Hz}, 1 \mathrm{H}, \mathrm{C}=\mathrm{CHH}), 5.72$ $(\mathrm{dd}, J=8.3,6.2 \mathrm{~Hz}, 1 \mathrm{H}, \mathrm{OCH}), 5.63(\mathrm{t}, J=2.5 \mathrm{~Hz}, 1 \mathrm{H}, \mathrm{C}=\mathrm{CHH}), 3.92\left(\mathrm{~s}, 3 \mathrm{H}, \mathrm{ArOCH}_{3}\right), 3.42-3.22(\mathrm{~m}, 1 \mathrm{H}$, $\left.\mathrm{CHHC}=\mathrm{CH}_{2}\right), 3.02-2.76\left(\mathrm{~m}, 1 \mathrm{H}, \mathrm{CHHC}=\mathrm{CH}_{2}\right) ;{ }^{13} \mathrm{C}-\mathrm{NMR}\left(125 \mathrm{MHz}, \mathrm{CDCl}_{3}\right): \delta 169.99,164.76,159.88$, 147.70, 133.63, 132.44, 129.86, 129.54, 126.60, 126.24, 122.92, 122.56, 120.63, 114.65, 77.28, 77.02, 76.77, 73.69, 55.57, 35.24. HR-MS (ESI): $m / z$ calcd for $\mathrm{C}_{19} \mathrm{H}_{16} \mathrm{NaO}_{5}\left([\mathrm{M}+\mathrm{Na}]^{+}\right) 347.0889$, found 347.0889.

4-[2-(Butyryloxy)phenyl]-2-methylenebutyrolactone (5m) Colourless oil; 78\% yield; ${ }^{1} \mathrm{H}-\mathrm{NMR}(500 \mathrm{MHz}$, $\left.\mathrm{CDCl}_{3}\right): \delta 7.41-7.33(\mathrm{~m}, 2 \mathrm{H}, \mathrm{ArH}), 7.30-7.21(\mathrm{~m}, 1 \mathrm{H}, \mathrm{ArH}), 7.16-7.05(\mathrm{~m}, 1 \mathrm{H}, \mathrm{ArH}), 6.31(\mathrm{t}, J=2.8 \mathrm{~Hz}$, $1 \mathrm{H}, \mathrm{C}=\mathrm{CHH}), 5.68(\mathrm{t}, J=2.4 \mathrm{~Hz}, 1 \mathrm{H}, \mathrm{C}=\mathrm{CHH}), 5.61(\mathrm{dd}, J=8.3,6.3 \mathrm{~Hz}, 1 \mathrm{H}, \mathrm{OCH}), 3.34(\mathrm{ddt}, J=17.4$, 8.4, $\left.2.5 \mathrm{~Hz}, 1 \mathrm{H}, \mathrm{CHHC}=\mathrm{CH}_{2}\right), 2.86\left(\mathrm{ddt}, J=17.4,5.9,2.8 \mathrm{~Hz}, 1 \mathrm{H}, \mathrm{CH} H \mathrm{C}=\mathrm{CH}_{2}\right), 2.61-2.50(\mathrm{~m}, 2 \mathrm{H}$, $\left.\mathrm{CH}_{3} \mathrm{CH}_{2} \mathrm{CH}_{2}\right), 1.78\left(\mathrm{dt}, J=14.8,7.4 \mathrm{~Hz}, 2 \mathrm{H}, \mathrm{CH}_{3} \mathrm{CH}_{2} \mathrm{CH}_{2}\right), 1.05\left(\mathrm{dd}, J=9.0,5.9 \mathrm{~Hz}, 3 \mathrm{H}, \mathrm{CH}_{3} \mathrm{CH}_{2} \mathrm{CH}_{2}\right.$ ); ${ }^{13} \mathrm{C}-\mathrm{NMR}\left(125 \mathrm{MHz}, \mathrm{CDCl}_{3}\right)$ : $\delta$ 171.75, 147.64, 133.87, 131.95, 129.47, 126.31, 77.34, 77.08, 76.83, 73.94, 36.12, 35.23, 18.41, 13.68. HR-MS (ESI): $m / z$ calcd for $\mathrm{C}_{15} \mathrm{H}_{16} \mathrm{NaO}_{4}\left([\mathrm{M}+\mathrm{Na}]^{+}\right)$283.0840, found 283.0841 .

4-[2-(Cinnamoyloxy)phenyl]-2-methylenebutyrolactone (5n) Yellow oil; $48 \%$ yield; ${ }^{1} \mathrm{H}-\mathrm{NMR}(500 \mathrm{MHz}$, $\left.\mathrm{CDCl}_{3}\right): \delta 7.84(\mathrm{~d}, J=15.9 \mathrm{~Hz}, 1 \mathrm{H}, \mathrm{ArH}), 7.49-7.39(\mathrm{~m}, 2 \mathrm{H}, \mathrm{ArH}), 7.32(\mathrm{t}, J=7.5 \mathrm{~Hz}, 1 \mathrm{H}, \mathrm{ArH}), 7.29$ (s, 1H, ArH), 7.24-7.17 (m, 2H, ArH), 7.01-6.97 (m, 1H, ArH), $6.48(\mathrm{~d}, J=15.9 \mathrm{~Hz}, 1 \mathrm{H}, \operatorname{ArH}), 6.30(\mathrm{t}$, $J=2.7 \mathrm{~Hz}, 1 \mathrm{H}, \mathrm{C}=\mathrm{CHH}), 5.71(\mathrm{dd}, J=8.2,6.4 \mathrm{~Hz}, 1 \mathrm{H}, \mathrm{OCH}), 5.66(\mathrm{~d}, J=7.3 \mathrm{~Hz}, 1 \mathrm{H}, \mathrm{C}=\mathrm{CHH}), 4.00(\mathrm{~s}$, $2 \mathrm{H}, \mathrm{CH}=\mathrm{CH}), 3.39\left(\mathrm{dd}, J=17.5,8.5 \mathrm{~Hz}, 1 \mathrm{H}, \mathrm{CHHC}=\mathrm{CH}_{2}\right), 2.99-2.84\left(\mathrm{~m}, 1 \mathrm{H}, \mathrm{CHHC}=\mathrm{CH}_{2}\right) ;{ }^{13} \mathrm{C}-\mathrm{NMR}$ $\left(125 \mathrm{MHz}, \mathrm{CDCl}_{3}\right): \delta 148.74,147.72,129.49,127.04,126.21,123.67,122.95,122.72,114.93,113.54,109.70$, 77.27, 77.01, 76.76, 74.01, 56.04, 35.16, 26.33. HR-MS (ESI): $m / z$ calcd for $\mathrm{C}_{21} \mathrm{H}_{19} \mathrm{O}_{6}\left([\mathrm{M}+\mathrm{H}]^{+}\right) 367.1173$, found 317.1176 .

4-[3-(3-Chlorobenzoyloxy)phenyl]-2-methylenebutyrolactone (6a) White solid; mp: $205.7-206.4{ }^{\circ} \mathrm{C} ; 52 \%$ yield; ${ }^{1} \mathrm{H}-\mathrm{NMR}\left(500 \mathrm{MHz}, \mathrm{CDCl}_{3}\right): \delta 8.20(\mathrm{~s}, 1 \mathrm{H}, \mathrm{ArH}), 8.10(\mathrm{~d}, J=7.7 \mathrm{~Hz}, 1 \mathrm{H}, \mathrm{ArH}), 7.65(\mathrm{dd}, J=8.0$, $1.0 \mathrm{~Hz}, 1 \mathrm{H}, \mathrm{ArH}), 7.55-7.45(\mathrm{~m}, 2 \mathrm{H}, \mathrm{ArH}), 7.30-7.19(\mathrm{~m}, 3 \mathrm{H}, \mathrm{ArH}), 6.35(\mathrm{t}, J=2.8 \mathrm{~Hz}, 1 \mathrm{H}, \mathrm{C}=\mathrm{CHH}), 5.74$ $(\mathrm{t}, J=2.4 \mathrm{~Hz}, 1 \mathrm{H}, \mathrm{C}=\mathrm{CHH}), 5.62-5.54(\mathrm{~m}, 1 \mathrm{H}, \mathrm{OCH}), 3.52-3.41\left(\mathrm{~m}, 1 \mathrm{H}, \mathrm{CHHC}=\mathrm{CH}_{2}\right), 2.97(\mathrm{ddt}, J=12.2$, 6.0, $\left.2.9 \mathrm{~Hz}, 1 \mathrm{H}, \mathrm{CH} H \mathrm{C}=\mathrm{CH}_{2}\right) ;{ }^{13} \mathrm{C}-\mathrm{NMR}\left(125 \mathrm{MHz}, \mathrm{CDCl}_{3}\right): \delta 163.87,151.10,141.83,134.86,133.76$, 
131.04, 130.35, 129.90, 128.31, 122.93, 121.78, 118.66, 77.41, 76.88, 76.76, 36.21, 29.70. HR-MS (ESI): $\mathrm{m} / \mathrm{z}$ calcd for $\mathrm{C}_{18} \mathrm{H}_{13} \mathrm{ClNaO}_{4}\left([\mathrm{M}+\mathrm{Na}]^{+}\right)$351.0394, found 351.0395.

4-[3-(4-Chlorobenzoyloxy)phenyl]-2-methylenebutyrolactone (6b) White solid; mp: $209.8-210.5{ }^{\circ} \mathrm{C} ; 64 \%$ yield; ${ }^{1} \mathrm{H}-\mathrm{NMR}\left(400 \mathrm{MHz}, \mathrm{CDCl}_{3}\right): \delta 8.22-8.03(\mathrm{~m}, 2 \mathrm{H}, \mathrm{ArH}), 7.61-7.36(\mathrm{~m}, 3 \mathrm{H}, \mathrm{ArH}), 7.33-7.14(\mathrm{~m}, 3 \mathrm{H}$, $\operatorname{ArH}), 6.32(\mathrm{t}, J=2.8 \mathrm{~Hz}, 1 \mathrm{H}, \mathrm{C}=\mathrm{CHH}), 5.71(\mathrm{t}, J=2.5 \mathrm{~Hz}, 1 \mathrm{H}, \mathrm{C}=\mathrm{CHH}), 5.56(\mathrm{dd}, J=7.8,6.7 \mathrm{~Hz}, 1 \mathrm{H}$, $\mathrm{OCH}), 3.44\left(\mathrm{ddt}, J=17.1,8.1,2.5 \mathrm{~Hz}, 1 \mathrm{H}, \mathrm{CHHC}=\mathrm{CH}_{2}\right), 2.94\left(\mathrm{ddt}, J=17.1,6.2,2.9 \mathrm{~Hz}, 1 \mathrm{H}, \mathrm{CHHC}=\mathrm{CH}_{2}\right)$; ${ }^{13} \mathrm{C}-\mathrm{NMR}\left(125 \mathrm{MHz}, \mathrm{CDCl}_{3}\right): \delta 164.24,151.14,141.80,140.37,133.73,131.58,130.12,129.05,127.72$, $122.93,121.85,118.72,77.52,76.91,76.74,36.21$. HR-MS (ESI): $m / z$ calcd for $\mathrm{C}_{18} \mathrm{H}_{13} \mathrm{ClNaO}_{4}\left([\mathrm{M}+\mathrm{Na}]^{+}\right)$ 351.0394, found 351.0394 .

4-[3-(2-Bromobenzoyloxy)phenyl]-2-methylenebutyrolactone (6c) White crystals; mp: $175.3-175.8{ }^{\circ} \mathrm{C} ; 56 \%$ yield; ${ }^{1} \mathrm{H}-\mathrm{NMR}\left(500 \mathrm{MHz}, \mathrm{CDCl}_{3}\right): \delta 8.06(\mathrm{dd}, J=7.6,1.7 \mathrm{~Hz}, 1 \mathrm{H}, \mathrm{ArH}), 7.83-7.72(\mathrm{~m}, 1 \mathrm{H}, \mathrm{ArH})$, 7.61-7.42 (m, 2H, ArH), $7.30(\mathrm{~d}, J=10.2 \mathrm{~Hz}, 4 \mathrm{H}, \operatorname{ArH}), 6.38(\mathrm{t}, J=2.8 \mathrm{~Hz}, 1 \mathrm{H}, \mathrm{C}=\mathrm{CHH}), 5.76(\mathrm{dd}$, $J=6.3,3.9 \mathrm{~Hz}, 1 \mathrm{H}, \mathrm{C}=\mathrm{CHH}), 5.67-5.40(\mathrm{~m}, 1 \mathrm{H}, \mathrm{OCH}), 3.62-3.30\left(\mathrm{~m}, 1 \mathrm{H}, \mathrm{CHHC}=\mathrm{CH}_{2}\right), 3.05-2.88(\mathrm{~m}$, $\left.1 \mathrm{H}, \mathrm{CHHC}=\mathrm{CH}_{2}\right) ;{ }^{13} \mathrm{C}-\mathrm{NMR}\left(125 \mathrm{MHz}, \mathrm{CDCl}_{3}\right): \delta 134.74,133.35,130.12,127.40,126.70,122.91,118.69$, 77.28, 77.02, 76.77, 36.35, 29.71, 19.20. HR-MS (ESI): $m / z$ calcd for $\mathrm{C}_{18} \mathrm{H}_{13} \mathrm{BrNaO}_{4}\left([\mathrm{M}+\mathrm{Na}]^{+}\right) 394.9889$, found 394.9892 .

4-[3-(3-Bromobenzoyloxy) phenyl]-2-methylenebutyrolactone (6d) White crystals; mp: $178.6-178.9{ }^{\circ} \mathrm{C}$; $63 \%$ yield; ${ }^{1} \mathrm{H}-\mathrm{NMR}\left(500 \mathrm{MHz}, \mathrm{CDCl}_{3}\right): \delta 8.31(\mathrm{~d}, J=52.5 \mathrm{~Hz}, 1 \mathrm{H}, \mathrm{ArH}), 8.10(\mathrm{dd}, J=52.3,7.5 \mathrm{~Hz}, 1 \mathrm{H}, \mathrm{ArH})$, 7.84-7.72 (m, 1H, ArH), 7.54-7.34 (m, 2H, ArH), 7.33-7.17 (m, 3H, ArH), $6.36(\mathrm{t}, J=2.8 \mathrm{~Hz}, 1 \mathrm{H}, \mathrm{C}=\mathrm{CHH})$, $5.74(\mathrm{t}, J=2.5 \mathrm{~Hz}, 1 \mathrm{H}, \mathrm{C}=\mathrm{CHH}), 5.66-5.46(\mathrm{~m}, 1 \mathrm{H}, \mathrm{OCH}), 3.60-3.36\left(\mathrm{~m}, 1 \mathrm{H}, \mathrm{CHHC}=\mathrm{CH}_{2}\right), 2.97$ (ddt, $\left.J=17.1,6.1,2.9 \mathrm{~Hz}, 1 \mathrm{H}, \mathrm{CHHC}=\mathrm{CH}_{2}\right) ;{ }^{13} \mathrm{C}-\mathrm{NMR}\left(125 \mathrm{MHz}, \mathrm{CDCl}_{3}\right): \delta 136.72,133.14,132.05,131.69$, 130.17, 128.76, 126.91, 126.53, 122.94, 121.78, 118.66, 77.37, 76.87, 76.76, 36.21, 29.72, 15.00. HR-MS (ESI): $m / z$ calcd for $\mathrm{C}_{18} \mathrm{H}_{13} \mathrm{BrNaO}_{4}\left([\mathrm{M}+\mathrm{Na}]^{+}\right)$394.9894, found 394.9890 .

4-[3-(4-Bromobenzoyloxy)phenyl]-2-methylenebutyrolactone (6e) White crystals; mp: 168.6-169.4 ${ }^{\circ} \mathrm{C} ; 41 \%$ yield; ${ }^{1} \mathrm{H}-\mathrm{NMR}\left(500 \mathrm{MHz}, \mathrm{CDCl}_{3}\right): \delta 8.10(\mathrm{~d}, J=8.5 \mathrm{~Hz}, 2 \mathrm{H}, \mathrm{ArH}), 8.00(\mathrm{~d}, J=8.4 \mathrm{~Hz}, 2 \mathrm{H}, \mathrm{ArH}), 7.69$ $(\mathrm{dd}, J=24.8,8.4 \mathrm{~Hz}, 4 \mathrm{H}, \mathrm{ArH}), 6.37(\mathrm{t}, J=2.8 \mathrm{~Hz}, 1 \mathrm{H}, \mathrm{C}=\mathrm{CHH}), 5.76(\mathrm{t}, J=2.4 \mathrm{~Hz}, 1 \mathrm{H}, \mathrm{C}=\mathrm{CHH}), 5.61(\mathrm{~s}$, $1 \mathrm{H}, \mathrm{OCH}), 4.35\left(\mathrm{t}, J=6.8 \mathrm{~Hz}, 1 \mathrm{H}, \mathrm{CHHC}=\mathrm{CH}_{2}\right), 3.48\left(\mathrm{dd}, J=17.0,8.1 \mathrm{~Hz}, 1 \mathrm{H}, \mathrm{CHHC}=\mathrm{CH}_{2}\right) .{ }^{13} \mathrm{C}-\mathrm{NMR}$ $\left(125 \mathrm{MHz}, \mathrm{CDCl}_{3}\right): \delta 150.78,137.95,133.05,131.69,129.05,127.28,126.76,122.75,122.08,78.62,77.28$, 77.03, 76.78, 40.03, 36.36, 15.00. HR-MS (ESI): $m / z$ calcd for $\mathrm{C}_{18} \mathrm{H}_{13} \mathrm{BrNaO}_{4}\left([\mathrm{M}+\mathrm{Na}]^{+}\right)$394.9890, found 394.9889 .

4-(3-Benzoyloxyphenyl)-2-methylenebutyrolactone (6f) White solid; mp: $204.5-204.8{ }^{\circ} \mathrm{C}$; $52 \%$ yield; ${ }^{1} \mathrm{H}-\mathrm{NMR}\left(500 \mathrm{MHz}, \mathrm{CDCl}_{3}\right): \delta 8.22(\mathrm{~d}, J=7.3 \mathrm{~Hz}, 2 \mathrm{H}, \mathrm{ArH}), 7.68(\mathrm{t}, J=7.5 \mathrm{~Hz}, 1 \mathrm{H}, \mathrm{ArH}), 7.49$ $(\mathrm{t}, J=7.8 \mathrm{~Hz}, 1 \mathrm{H}, \mathrm{ArH}), 7.32-7.20(\mathrm{~m}, 5 \mathrm{H}, \mathrm{ArH}), 6.35(\mathrm{t}, J=2.8 \mathrm{~Hz}, 1 \mathrm{H}, \mathrm{C}=\mathrm{CHH}), 5.73(\mathrm{t}, J=2.4 \mathrm{~Hz}$, $1 \mathrm{H}, \mathrm{C}=\mathrm{CH} H), 5.62-5.52(\mathrm{~m}, 1 \mathrm{H}, \mathrm{OCH}), 3.46\left(\mathrm{ddt}, J=17.1,8.1,2.4 \mathrm{~Hz}, 1 \mathrm{H}, \mathrm{CHHC}=\mathrm{CH}_{2}\right), 2.98(\mathrm{ddt}$, $\left.J=9.2,6.0,2.8 \mathrm{~Hz}, 1 \mathrm{H}, \mathrm{CHHC}=\mathrm{CH}_{2}\right) ;{ }^{13} \mathrm{C}-\mathrm{NMR}\left(125 \mathrm{MHz}, \mathrm{CDCl}_{3}\right): \delta 135.76,131.21,128.69,126.77$, $122.62,78.70,77.28,77.03,76.77,42.04,36.51,29.79,15.20$. HR-MS (ESI): $m / z$ calcd for $\mathrm{C}_{18} \mathrm{H}_{14} \mathrm{NaO}_{4}$ $\left([\mathrm{M}+\mathrm{Na}]^{+}\right) 317.0785$, found 317.0784.

4-[3-(2-Methylbenzoyloxy)phenyl]-2-methylenebutyrolactone (6g) White crystals; $\mathrm{mp}$ : $178.3-178.9^{\circ} \mathrm{C} ; 57 \%$ yield; ${ }^{1} \mathrm{H}-\mathrm{NMR}\left(500 \mathrm{MHz}, \mathrm{CDCl}_{3}\right): \delta 8.18(\mathrm{~d}, J=7.8 \mathrm{~Hz}, 1 \mathrm{H}, \mathrm{ArH}), 7.54-7.46(\mathrm{~m}, 2 \mathrm{H}, \mathrm{ArH}), 7.36(\mathrm{t}$, $J=7.7 \mathrm{~Hz}, 2 \mathrm{H}, \mathrm{ArH}), 7.24(\mathrm{dd}, J=13.8,7.7 \mathrm{~Hz}, 3 \mathrm{H}, \mathrm{ArH}), 6.35(\mathrm{t}, J=2.8 \mathrm{~Hz}, 1 \mathrm{H}, \mathrm{C}=\mathrm{CHH}), 5.73(\mathrm{t}$, $J=2.4 \mathrm{~Hz}, 1 \mathrm{H}, \mathrm{C}=\mathrm{CHH}), 5.64-5.51(\mathrm{~m}, 1 \mathrm{H}, \mathrm{OCH}), 3.46\left(\mathrm{ddt}, J=17.1,8.1,2.4 \mathrm{~Hz}, 1 \mathrm{H}, \mathrm{CHHC}=\mathrm{CH}_{2}\right)$, $2.98\left(\mathrm{ddt}, J=17.1,6.1,2.9 \mathrm{~Hz}, 1 \mathrm{H}, \mathrm{CHHC}=\mathrm{CH}_{2}\right), 2.70\left(\mathrm{~s}, 3 \mathrm{H}, \mathrm{ArCH}_{3}\right) ;{ }^{13} \mathrm{C}-\mathrm{NMR}\left(125 \mathrm{MHz}, \mathrm{CDCl}_{3}\right)$ : $\delta$ 165.62, 151.30, 141.68, 141.44, 133.81, 132.91, 132.02, 131.21, 130.02, 128.21, 125.98, 122.71, 122.06, 118.92, 77.26, 77.01, 76.76, 36.23, 21.96. HR-MS (ESI): $m / z$ calcd for $\mathrm{C}_{19} \mathrm{H}_{16} \mathrm{NaO}_{4}\left([\mathrm{M}+\mathrm{Na}]^{+}\right) 331.0940$, found 331.0940 .

4-[3-(3-Methylbenzoyloxy)phenyl]-2-methylenebutyrolactone (6h) White crystals; mp: $177.6-178.2{ }^{\circ} \mathrm{C} ; 68 \%$ yield; ${ }^{1} \mathrm{H}-\mathrm{NMR}\left(500 \mathrm{MHz}, \mathrm{CDCl}_{3}\right): \delta 8.03(\mathrm{~s}, 1 \mathrm{H}, \mathrm{ArH}), 7.46(\mathrm{ddd}, J=15.1,9.9,5.9 \mathrm{~Hz}, 3 \mathrm{H}, \mathrm{ArH})$, 
$7.28(\mathrm{~d}, J=9.6 \mathrm{~Hz}, 4 \mathrm{H}, \mathrm{ArH}), 6.35(\mathrm{t}, J=2.8 \mathrm{~Hz}, 1 \mathrm{H}, \mathrm{C}=\mathrm{CHH}), 5.73(\mathrm{t}, J=2.4 \mathrm{~Hz}, 1 \mathrm{H}, \mathrm{C}=\mathrm{CH} H)$, 5.66-5.52 (m, 1H, OCH), 3.50-3.39 (m, 1H, CHHC $\left.=\mathrm{CH}_{2}\right), 3.03-2.93\left(\mathrm{~m}, 1 \mathrm{H}, \mathrm{CHHC}=\mathrm{CH}_{2}\right), 2.48(\mathrm{~s}, 3 \mathrm{H}$, $\left.\mathrm{ArCH}_{3}\right) ;{ }^{13} \mathrm{C}-\mathrm{NMR}\left(125 \mathrm{MHz}, \mathrm{CDCl}_{3}\right): \delta 170.05,165.28,152.07,136.51,137.36,134.45,134.61,130.71$, $129.69,128.53,127.37,126.67,122.26,77.48,77.28,77.02,76.77,36.32,21.30$. HR-MS (ESI): $m / z$ calcd for $\mathrm{C}_{19} \mathrm{H}_{16} \mathrm{NaO}_{4}\left([\mathrm{M}+\mathrm{Na}]^{+}\right) 331.0942$, found 331.0940.

4-[3-(4-Methylbenzoyloxy)phenyl]-2-methylenebutyrolactone (6i) White crystals; mp: $168.5-168.9{ }^{\circ} \mathrm{C} ; 57 \%$ yield; ${ }^{1} \mathrm{H}-\mathrm{NMR}\left(500 \mathrm{MHz}, \mathrm{CDCl}_{3}\right): \delta 8.10(\mathrm{~d}, J=8.1 \mathrm{~Hz}, 2 \mathrm{H}, \mathrm{ArH}), 7.48(\mathrm{t}, J=7.8 \mathrm{~Hz}, 1 \mathrm{H}, \mathrm{ArH}), 7.34(\mathrm{~d}$, $J=8.0 \mathrm{~Hz}, 1 \mathrm{H}, \operatorname{ArH}), 7.30-7.20(\mathrm{~m}, 4 \mathrm{H}, \mathrm{ArH}), 6.35(\mathrm{t}, J=2.8 \mathrm{~Hz}, 1 \mathrm{H}, \mathrm{C}=\mathrm{CHH}), 5.73(\mathrm{t}, J=2.5 \mathrm{~Hz}, 1 \mathrm{H}$, $\mathrm{C}=\mathrm{CHH}), 5.70-5.40(\mathrm{~m}, 1 \mathrm{H}, \mathrm{OCH}), 3.56-3.36\left(\mathrm{~m}, 1 \mathrm{H}, \mathrm{CHHC}=\mathrm{CH}_{2}\right), 2.98(\mathrm{ddt}, J=17.1,6.0,2.9 \mathrm{~Hz}, 1 \mathrm{H}$, $\left.\mathrm{CHHC}=\mathrm{CH}_{2}\right), 2.34\left(\mathrm{~d}, J=144.3 \mathrm{~Hz}, 3 \mathrm{H}, \mathrm{ArCH}_{3}\right) .{ }^{13} \mathrm{C}-\mathrm{NMR}\left(125 \mathrm{MHz}, \mathrm{CDCl}_{3}\right): \delta 169.99,165.13,151.11$, 144.66, 141.64, 130.24, 130.01, 129.36, 127.37, 126.58, 122.79, 122.63, 122.00, 118.87, 77.27, 77.01, 76.76, 36.22, 21.77. HR-MS (ESI): $m / z$ calcd for $\mathrm{C}_{19} \mathrm{H}_{16} \mathrm{NaO}_{4}\left([\mathrm{M}+\mathrm{Na}]^{+}\right) 331.0940$, found 331.0941.

4-[3-(2-Methoxylbenzoyloxy)phenyl]-2-methylenebutyrolactone (6j) White crystals; mp: $172.3-172.8{ }^{\circ} \mathrm{C} ; 45 \%$ yield; ${ }^{1} \mathrm{H}-\mathrm{NMR}\left(500 \mathrm{MHz}, \mathrm{CDCl}_{3}\right): \delta 8.07-7.99(\mathrm{~m}, 1 \mathrm{H}, \mathrm{ArH}), 7.61-7.56(\mathrm{~m}, 1 \mathrm{H}, \mathrm{ArH}), 7.32-7.20(\mathrm{~m}, 4 \mathrm{H}$, $\operatorname{ArH}), 7.08(\mathrm{t}, J=7.6 \mathrm{~Hz}, 2 \mathrm{H}, \mathrm{ArH}), 6.34(\mathrm{t}, J=2.8 \mathrm{~Hz}, 1 \mathrm{H}, \mathrm{C}=\mathrm{CHH}), 5.73(\mathrm{t}, J=2.4 \mathrm{~Hz}, 1 \mathrm{H}, \mathrm{C}=\mathrm{CH} H)$, 5.62-5.43 (m, 1H, OCH), $3.97\left(\mathrm{~s}, 3 \mathrm{H}, \mathrm{ArOCH}_{3}\right), 3.47-3.38\left(\mathrm{~m}, 1 \mathrm{H}, \mathrm{CHHC}=\mathrm{CH}_{2}\right), 2.97(\mathrm{ddt}, J=17.1,6.1$, $\left.2.9 \mathrm{~Hz}, 1 \mathrm{H}, \mathrm{CHHC}=\mathrm{CH}_{2}\right) .{ }^{13} \mathrm{C}-\mathrm{NMR}\left(125 \mathrm{MHz}, \mathrm{CDCl}_{3}\right): \delta 151.37,141.52,134.54,133.87,132.27,129.92$, 122.76, 122.54, 122.09, 120.27, 118.98, 112.26, 77.30, 77.02, 76.76, 56.07, 49.16, 36.23, 33.95, 25.63, 24.94. HR-MS (ESI): $m / z$ calcd for $\mathrm{C}_{19} \mathrm{H}_{16} \mathrm{NaO}_{5}\left([\mathrm{M}+\mathrm{Na}]^{+}\right)$347.0889, found 347.0890.

4-[3-(3-Methoxybenzoyloxy)phenyl]-2-methylenebutyrolactone (6k) White crystals; mp: $183.7-184.2{ }^{\circ} \mathrm{C}$; $57 \%$ yield; ${ }^{1} \mathrm{H}-\mathrm{NMR}\left(500 \mathrm{MHz}, \mathrm{CDCl}_{3}\right): \delta 7.82(\mathrm{~d}, J=7.7 \mathrm{~Hz}, 1 \mathrm{H}, \mathrm{ArH}), 7.73(\mathrm{~d}, J=7.7 \mathrm{~Hz}, 1 \mathrm{H}, \mathrm{ArH})$, $7.47(\mathrm{dt}, J=18.6,7.8 \mathrm{~Hz}, 2 \mathrm{H}, \operatorname{ArH}), 7.31-7.19(\mathrm{~m}, 4 \mathrm{H}, \operatorname{ArH}), 6.35(\mathrm{t}, J=2.8 \mathrm{~Hz}, 1 \mathrm{H}, \mathrm{C}=\mathrm{CHH}), 5.73(\mathrm{t}$, $J=2.4 \mathrm{~Hz}, 1 \mathrm{H}, \mathrm{C}=\mathrm{CHH}), 5.62-5.55(\mathrm{~m}, 1 \mathrm{H}, \mathrm{OCH}), 3.92\left(\mathrm{~s}, 3 \mathrm{H}, \mathrm{ArOCH}_{3}\right), 3.46(\mathrm{ddt}, J=17.0,8.1,2.4 \mathrm{~Hz}$, $\left.1 \mathrm{H}, \mathrm{CHHC}=\mathrm{CH}_{2}\right), 3.01-2.91\left(\mathrm{~m}, 1 \mathrm{H}, \mathrm{CHHC}=\mathrm{CH}_{2}\right) .{ }^{13} \mathrm{C}-\mathrm{NMR}\left(125 \mathrm{MHz}, \mathrm{CDCl}_{3}\right): \delta 159.75,151.34$, 141.70, 133.78, 130.05, 129.67, 129.49, 122.95-122.49, 121.94, 120.39, 118.80, 114.51, 77.27, 77.01, 76.76, 55.49, 36.21, 29.70.HR-MS (ESI): $m / z$ calcd for $\mathrm{C}_{19} \mathrm{H}_{16} \mathrm{NaO}_{5}\left([\mathrm{M}+\mathrm{Na}]^{+}\right) 347.0889$, found 347.0889.

4-[3-(4-Methoxybenzoyloxy)phenyl]-2-methylenebutyrolactone (61) White crystals; $\mathrm{mp:}$ 182.6-183.3 ${ }^{\circ} \mathrm{C}$; $56 \%$ yield; ${ }^{1} \mathrm{H}-\mathrm{NMR}\left(500 \mathrm{MHz}, \mathrm{CDCl}_{3}\right): \delta 8.23-8.07(\mathrm{~m}, 2 \mathrm{H}, \mathrm{ArH}), 7.45(\mathrm{t}, J=8.0 \mathrm{~Hz}, 1 \mathrm{H}, \mathrm{ArH})$, 7.29-7.14 (m, 3H, ArH), 7.02-6.92 (m, 2H, ArH), $6.32(\mathrm{t}, J=2.8 \mathrm{~Hz}, 1 \mathrm{H}, \mathrm{C}=\mathrm{CHH}), 5.70(\mathrm{t}, J=2.5 \mathrm{~Hz}, 1 \mathrm{H}$, $\mathrm{C}=\mathrm{CHH}), 5.55(\mathrm{dd}, J=7.8,6.8 \mathrm{~Hz}, 1 \mathrm{H}, \mathrm{OCH}), 3.90\left(\mathrm{~s}, 3 \mathrm{H}, \mathrm{ArOCH}_{3}\right), 3.43(\mathrm{ddt}, J=17.1,8.1,2.5 \mathrm{~Hz}, 1 \mathrm{H}$, $\left.\mathrm{CHHC}=\mathrm{CH}_{2}\right), 3.00-2.87\left(\mathrm{~m}, 1 \mathrm{H}, \mathrm{CHHC}=\mathrm{CH}_{2}\right) ;{ }^{13} \mathrm{C}-\mathrm{NMR}\left(125 \mathrm{MHz}, \mathrm{CDCl}_{3}\right): \delta 169.99,164.80,164.06$, 151.44, 141.61, 133.83, 132.35, 130.00, 122.84, 122.60, 122.06, 121.52, 118.92, 113.93, 77.35, 77.06, 76.74, 55.56, 36.21.HR-MS (ESI): $m / z$ calcd for $\mathrm{C}_{19} \mathrm{H}_{16} \mathrm{NaO}_{5}\left([\mathrm{M}+\mathrm{Na}]^{+}\right) 347.0889$, found 347.0892 .

4-(3-Propionyloxyphenyl)-2-methylenebutyrolactone (6m) Colourless oil; $56 \%$ yield; ${ }^{1} \mathrm{H}-\mathrm{NMR}(500 \mathrm{MHz}$, $\left.\mathrm{CDCl}_{3}\right): \delta 7.42(\mathrm{t}, J=8.3 \mathrm{~Hz}, 1 \mathrm{H}, \mathrm{ArH}), 7.29(\mathrm{~s}, 1 \mathrm{H}, \mathrm{ArH}), 7.20(\mathrm{~d}, J=7.8 \mathrm{~Hz}, 1 \mathrm{H}, \operatorname{ArH}), 7.09(\mathrm{~s}, 1 \mathrm{H}$, $\mathrm{ArH}), 6.34(\mathrm{t}, J=2.8 \mathrm{~Hz}, 1 \mathrm{H}, \mathrm{C}=\mathrm{CHH}), 5.72(\mathrm{t}, J=2.4 \mathrm{~Hz}, 1 \mathrm{H}, \mathrm{C}=\mathrm{CHH}), 5.64-5.43(\mathrm{~m}, 1 \mathrm{H}, \mathrm{OCH}), 3.44$ $\left(\mathrm{ddt}, J=17.1,8.1,2.4 \mathrm{~Hz}, 1 \mathrm{H}, \mathrm{CHHC}=\mathrm{CH}_{2}\right), 2.94\left(\mathrm{ddt}, J=17.1,6.0,2.8 \mathrm{~Hz}, 1 \mathrm{H}, \mathrm{CHHC}=\mathrm{CH}_{2}\right), 2.62(\mathrm{q}$, $\left.J=7.5 \mathrm{~Hz}, 2 \mathrm{H}, \mathrm{CH}_{3} \mathrm{CH}_{2}\right), 1.29\left(\mathrm{t}, J=7.5 \mathrm{~Hz}, 3 \mathrm{H}, \mathrm{CH}_{3} \mathrm{CH}_{2}\right) ;{ }^{13} \mathrm{C}-\mathrm{NMR}\left(125 \mathrm{MHz}, \mathrm{CDCl}_{3}\right): \delta 172.81$, 151.14, 141.57, 133.78, 129.92, 122.78, 122.53, 121.75, 118.63, 77.23, 77.01, 76.75, 36.20, 27.73, 9.02. HR-MS (ESI): $m / z$ calcd for $\mathrm{C}_{14} \mathrm{H}_{14} \mathrm{NaO}_{4}\left([\mathrm{M}+\mathrm{Na}]^{+}\right)$269.0784, found 269.0784 .

4-(3-Cinnamoyloxyphenyl)-2-methylenebutyrolactone (6n) Yellow oil; 34\% yield; ${ }^{1} \mathrm{H}-\mathrm{NMR}(400 \mathrm{MHz}$, $\left.\mathrm{CDCl}_{3}\right): \delta 7.87(\mathrm{~d}, J=16.0 \mathrm{~Hz}, 1 \mathrm{H}, \mathrm{ArH}), 7.64-7.55(\mathrm{~m}, 2 \mathrm{H}, \mathrm{CH}=\mathrm{CH}), 7.47-7.38(\mathrm{~m}, 4 \mathrm{H}, \mathrm{ArH}), 7.25-7.10$ $(\mathrm{m}, 3 \mathrm{H}, \mathrm{ArH}), 6.62(\mathrm{~d}, J=16.0 \mathrm{~Hz}, 1 \mathrm{H}, \mathrm{ArH}), 6.31(\mathrm{t}, J=2.8 \mathrm{~Hz}, 1 \mathrm{H}, \mathrm{C}=\mathrm{CHH}), 5.70(\mathrm{t}, J=2.5 \mathrm{~Hz}, 1 \mathrm{H}$, $\mathrm{C}=\mathrm{CHH}), 5.60-5.45(\mathrm{~m}, 1 \mathrm{H}, \mathrm{OCH}), 3.42\left(\mathrm{ddt}, J=17.1,8.1,2.5 \mathrm{~Hz}, 1 \mathrm{H}, \mathrm{CHHC}=\mathrm{CH}_{2}\right), 2.93(\mathrm{ddt}, J=17.1$, 6.0, $\left.2.9 \mathrm{~Hz}, 1 \mathrm{H}, \mathrm{CHHC}=\mathrm{CH}_{2}\right) ;{ }^{13} \mathrm{C}-\mathrm{NMR}\left(100 \mathrm{MHz}, \mathrm{CDCl}_{3}\right): \delta 169.99,165.26,151.17,147.00,141.64$, $134.07,133.83,130.88,130.01,129.06,128.38,122.76,121.88,118.76,116.98,77.56,76.95,76.78,36.19$. HR-MS (ESI): $m / z$ calcd for $\mathrm{C}_{20} \mathrm{H}_{16} \mathrm{NaO}_{4}\left([\mathrm{M}+\mathrm{Na}]^{+}\right) 343.0940$, found 343.0941 . 


\subsubsection{General Synthetic Procedure for Ether Compounds}

$\mathrm{K}_{2} \mathrm{CO}_{3}(13.8 \mathrm{mg}, 10.0 \mathrm{mmol})$ and $\mathrm{Cs}_{2} \mathrm{CO}_{3}(3.2 \mathrm{mg}, 1.0 \mathrm{mmol})$ as catalyst, intermediate compounds 5 or $6(196.0 \mathrm{mg}, 1.1 \mathrm{mmol})$, and acetonitrile $(35.0 \mathrm{~mL})$ were added into a round bottomed flask and refluxed at $78{ }^{\circ} \mathrm{C}$. Then, the appropriate brominated alkane $(1.2 \mathrm{mmol})$ was slowly added into the mixture and stirred for $12 \mathrm{~h}$ at $78^{\circ} \mathrm{C}$. The progress of the reaction was monitored by TLC. After complete conversion, the suspension was filtered and washed with acetonitrile. Finally, the solution was dried with anhydrous $\mathrm{Na}_{2} \mathrm{SO}_{4}$, filtered, and evaporated under vacuum. The obtained crude products were also purified by column chromatography. The ${ }^{1} \mathrm{H}-\mathrm{NMR},{ }^{13} \mathrm{C}-\mathrm{NMR}$, and HR-ESI-MS data are listed below.

4-(2-Butoxyphenyl)-2-methylenebutyrolactone (5o) Yellow oil; $42 \%$ yield; ${ }^{1} \mathrm{H}-\mathrm{NMR}\left(500 \mathrm{MHz}, \mathrm{CDCl}_{3}\right)$ : 8 7.38-7.30 (m, 2H, ArH), 7.04-6.89 (m, 2H, ArH), $6.33(\mathrm{t}, J=2.8 \mathrm{~Hz}, 1 \mathrm{H}, \mathrm{C}=\mathrm{CHH}), 5.77(\mathrm{dd}, J=8.4$, $6.0 \mathrm{~Hz}, 1 \mathrm{H}, \mathrm{OCH}), 5.67(\mathrm{t}, J=2.4 \mathrm{~Hz}, 1 \mathrm{H}, \mathrm{C}=\mathrm{CHH}), 4.13-3.95\left(\mathrm{~m}, 2 \mathrm{H}, \mathrm{CH}_{3} \mathrm{CH}_{2} \mathrm{CH}_{2} \mathrm{CH}_{2} \mathrm{O}\right), 3.45(\mathrm{ddt}$, $\left.J=17.4,8.5,2.6 \mathrm{~Hz}, 1 \mathrm{H}, \mathrm{CHHC}=\mathrm{CH}_{2}\right), 2.92\left(\mathrm{ddt}, J=17.4,5.7,2.8 \mathrm{~Hz}, 1 \mathrm{H}, \mathrm{CHHC}=\mathrm{CH}_{2}\right), 1.86-1.76(\mathrm{~m}$, $\left.2 \mathrm{H}, \mathrm{CH}_{3} \mathrm{CH}_{2} \mathrm{CH}_{2} \mathrm{CH}_{2} \mathrm{O}\right), 1.57-1.47\left(\mathrm{~m}, 2 \mathrm{H}, \mathrm{CH}_{3} \mathrm{CH}_{2} \mathrm{CH}_{2} \mathrm{CH}_{2} \mathrm{O}\right), 1.05-0.98\left(\mathrm{~m}, 3 \mathrm{H}, \mathrm{CH}_{3} \mathrm{CH}_{2} \mathrm{CH}_{2} \mathrm{CH}_{2} \mathrm{O}\right)$; ${ }^{13} \mathrm{C}-\mathrm{NMR}\left(100 \mathrm{MHz}, \mathrm{CDCl}_{3}\right): \delta 155.78,134.92,129.42,126.12,121.82,120.40,111.27,77.29,76.78,75.21$, 67.79, 35.04, 31.28, 30.92, 19.41, 13.83. HR-MS (ESI): $m / z$ calcd for $\mathrm{C}_{15} \mathrm{H}_{18} \mathrm{NaO}_{3}\left([\mathrm{M}+\mathrm{Na}]^{+}\right)$269.1148, found 269.1147 .

4-(2-Propoxylphenyl)-2-methylenebutyrolactone (5p) Yellow oil; 38\% yield; ${ }^{1} \mathrm{H}-\mathrm{NMR}\left(500 \mathrm{MHz}, \mathrm{CDCl}_{3}\right)$ : $\delta 7.30(\mathrm{dd}, J=13.1,5.4 \mathrm{~Hz}, 1 \mathrm{H}, \mathrm{ArH}), 6.90(\mathrm{dd}, J=12.5,10.8 \mathrm{~Hz}, 3 \mathrm{H}, \mathrm{ArH}), 6.33(\mathrm{t}, J=2.8 \mathrm{~Hz}, 1 \mathrm{H}, \mathrm{C}=\mathrm{CHH})$, $5.71(\mathrm{t}, J=2.4 \mathrm{~Hz}, 1 \mathrm{H}, \mathrm{C}=\mathrm{CHH}), 5.58-5.41(\mathrm{~m}, 1 \mathrm{H}, \mathrm{OCH}), 3.94\left(\mathrm{t}, J=6.5 \mathrm{~Hz}, 2 \mathrm{H}, \mathrm{CH}_{3} \mathrm{CH}_{2} \mathrm{CH}_{2} \mathrm{O}\right), 3.41$ $\left(\mathrm{ddt}, J=17.1,8.1,2.4 \mathrm{~Hz}, 1 \mathrm{H}, \mathrm{CHHC}=\mathrm{CH}_{2}\right), 2.93\left(\mathrm{ddt}, J=17.1,6.1,2.9 \mathrm{~Hz}, 1 \mathrm{H}, \mathrm{CHHC}=\mathrm{CH}_{2}\right), 1.90-1.78$ $\left(\mathrm{m}, 2 \mathrm{H}, \mathrm{CH}_{3} \mathrm{CH}_{2} \mathrm{CH}_{2} \mathrm{O}\right), 1.12-0.97\left(\mathrm{~m}, 3 \mathrm{H}, \mathrm{CH}_{3} \mathrm{CH}_{2} \mathrm{CH}_{2} \mathrm{O}\right) ;{ }^{13} \mathrm{C}-\mathrm{NMR}\left(125 \mathrm{MHz}, \mathrm{CDCl}_{3}\right): \delta$ 170.14, $159.58,141.41,134.20,129.93,122.43,117.30,114.49,111.51,77.82,77.28,77.03,76.77,69.61,22.57,10.51$. HR-MS (ESI): $m / z$ calcd for $\mathrm{C}_{14} \mathrm{H}_{16} \mathrm{NaO}_{3}\left([\mathrm{M}+\mathrm{Na}]^{+}\right)$255.0991, found 255.0992.

4-(2-Isopropoxylphenyl)-2-methylenebutyrolactone (5q) Yellow oil; $47 \%$ yield; ${ }^{1} \mathrm{H}-\mathrm{NMR}\left(500 \mathrm{MHz}, \mathrm{CDCl}_{3}\right)$ : $\delta 7.33(\mathrm{dd}, J=12.7,6.6 \mathrm{~Hz}, 2 \mathrm{H}, \mathrm{ArH}), 6.96(\mathrm{dt}, J=12.8,5.9 \mathrm{~Hz}, 2 \mathrm{H}, \mathrm{ArH}), 6.32(\mathrm{t}, J=2.9 \mathrm{~Hz}, 1 \mathrm{H}, \mathrm{C}=\mathrm{CHH})$, $5.73(\mathrm{dd}, J=8.4,5.9 \mathrm{~Hz}, 1 \mathrm{H}, \mathrm{OCH}), 5.67(\mathrm{t}, J=2.4 \mathrm{~Hz}, 1 \mathrm{H}, \mathrm{C}=\mathrm{CHH}), 4.67(\mathrm{dt}, J=12.1,6.0 \mathrm{~Hz}, 1 \mathrm{H}$, $\left.\left(\mathrm{CH}_{3}\right)_{2} \mathrm{CHO}\right), 3.45\left(\mathrm{ddt}, J=17.4,8.5,2.6 \mathrm{~Hz}, 1 \mathrm{H}, \mathrm{CHHC}=\mathrm{CH}_{2}\right), 2.91(\mathrm{ddt}, J=17.5,5.7,2.8 \mathrm{~Hz}, 1 \mathrm{H}$, $\left.\mathrm{CHHC}=\mathrm{CH}_{2}\right), 1.38\left(\mathrm{dd}, J=8.8,6.1 \mathrm{~Hz}, 6 \mathrm{H},\left(\mathrm{CH}_{3}\right)_{2} \mathrm{CHO}\right) ;{ }^{13} \mathrm{C}-\mathrm{NMR}\left(125 \mathrm{MHz}, \mathrm{CDCl}_{3}\right): \delta 170.74,154.58$, 135.17, 129.35, 129.06, 126.55, 121.63, 120.19, 112.42, 77.29, 77.04, 76.78, 75.52, 69.95, 34.95, 29.72, 22.01. HR-MS (ESI): $m / z$ calcd for $\mathrm{C}_{14} \mathrm{H}_{16} \mathrm{NaO}_{3}\left([\mathrm{M}+\mathrm{Na}]^{+}\right)$255.0991, found 255.0990.

4-(2-Ethoxyphenyl)-2-methylenebutyrolactone (5r) Yellow oil; $46 \%$ yield; ${ }^{1} \mathrm{H}-\mathrm{NMR}\left(400 \mathrm{MHz}, \mathrm{CDCl}_{3}\right)$ : $\delta 7.31-7.25(\mathrm{~m}, 3 \mathrm{H}, \mathrm{ArH}), 6.95(\mathrm{td}, J=7.5,0.8 \mathrm{~Hz}, 1 \mathrm{H}, \mathrm{ArH}), 6.28(\mathrm{t}, J=2.9 \mathrm{~Hz}, 1 \mathrm{H}, \mathrm{C}=\mathrm{CHH}), 5.71(\mathrm{dd}$, $J=8.5,5.8 \mathrm{~Hz}, 1 \mathrm{H}, \mathrm{OCH}), 5.63(\mathrm{t}, J=2.5 \mathrm{~Hz}, 1 \mathrm{H}, \mathrm{C}=\mathrm{CHH}), 4.06\left(\mathrm{qd}, J=7.0,2.6 \mathrm{~Hz}, 2 \mathrm{H}, \mathrm{CH}_{3} \mathrm{CH}_{2} \mathrm{O}\right)$, $3.42\left(\mathrm{dd}, J=17.4,8.5 \mathrm{~Hz}, 1 \mathrm{H}, \mathrm{CHHC}=\mathrm{CH}_{2}\right), 2.95-2.77\left(\mathrm{~m}, 1 \mathrm{H}, \mathrm{CHHC}=\mathrm{CH}_{2}\right), 1.40(\mathrm{t}, J=7.0 \mathrm{~Hz}$, $\left.3 \mathrm{H}, \mathrm{CH}_{3} \mathrm{CH}_{2} \mathrm{O}\right) .{ }^{13} \mathrm{C}-\mathrm{NMR}\left(125 \mathrm{MHz}, \mathrm{CDCl}_{3}\right): \delta 129.48,126.34,121.70,120.42,111.34,77.29,77.03$, 76.71, 75.44, 63.64, 34.90, 14.73. HR-MS (ESI): $m / z$ calcd for $\mathrm{C}_{13} \mathrm{H}_{14} \mathrm{NaO}_{3}\left([\mathrm{M}+\mathrm{Na}]^{+}\right) 241.0835$, found 241.0834 .

4-(3-Butoxyphenyl)-2-methylenebutyrolactone (6o) Yellow oil; $47 \%$ yield; ${ }^{1} \mathrm{H}-\mathrm{NMR}$ (500 $\mathrm{MHz}, \mathrm{CDCl}_{3}$ ): $\delta 7.32(\mathrm{dd}, J=13.2,5.4 \mathrm{~Hz}, 2 \mathrm{H}, \mathrm{ArH}), 6.91(\mathrm{~d}, J=9.0 \mathrm{~Hz}, 2 \mathrm{H}, \mathrm{ArH}), 6.35(\mathrm{t}, J=2.8 \mathrm{~Hz}, 1 \mathrm{H}, \mathrm{C}=\mathrm{CHH}), 5.73(\mathrm{t}$, $J=2.4 \mathrm{~Hz}, 1 \mathrm{H}, \mathrm{C}=\mathrm{CHH}), 5.63-5.40(\mathrm{~m}, 1 \mathrm{H}, \mathrm{OCH}), 4.01\left(\mathrm{t}, J=6.5 \mathrm{~Hz}, 2 \mathrm{H}, \mathrm{CH}_{3} \mathrm{CH}_{2} \mathrm{CH}_{2} \mathrm{CH}_{2} \mathrm{O}\right), 3.43(\mathrm{ddt}$, $\left.J=17.0,8.0,2.4 \mathrm{~Hz}, 1 \mathrm{H}, \mathrm{CHHC}=\mathrm{CH}_{2}\right), 2.95\left(\mathrm{ddt}, J=17.1,6.1,2.9 \mathrm{~Hz}, 1 \mathrm{H}, \mathrm{CHHC}=\mathrm{CH}_{2}\right), 1.86-1.74(\mathrm{~m}, 2 \mathrm{H}$, $\mathrm{CH}_{3} \mathrm{CH}_{2} \mathrm{CH}_{2} \mathrm{CH}_{2} \mathrm{O}$ ), 1.58-1.47 (m, 2H, $\mathrm{CH}_{3} \mathrm{CH}_{2} \mathrm{CH}_{2} \mathrm{CH}_{2} \mathrm{O}$ ), 1.09-0.96 (m, 3H, $\mathrm{CH}_{3} \mathrm{CH}_{2} \mathrm{CH}_{2} \mathrm{CH}_{2} \mathrm{O}$ ); ${ }^{13} \mathrm{C}-\mathrm{NMR}\left(100 \mathrm{MHz}, \mathrm{CDCl}_{3}\right): \delta 155.78,134.92,129.42,126.12,121.82,120.40,111.27,77.29,76.78,75.21$, $67.79,35.04,31.28,30.92,19.41,13.83$. HR-MS (ESI): $m / z$ calcd for $\mathrm{C}_{15} \mathrm{H}_{18} \mathrm{NaO}_{3}\left([\mathrm{M}+\mathrm{Na}]^{+}\right) 269.1148$, found 269.1147 . 
4-(3-Propoxylphenyl)-2-methylenebutyrolactone (6p) Yellow oil; 54\% yield; ${ }^{1} \mathrm{H}-\mathrm{NMR}\left(500 \mathrm{MHz}, \mathrm{CDCl}_{3}\right)$ : $\delta 7.30(\mathrm{dd}, J=13.1,5.4 \mathrm{~Hz}, 1 \mathrm{H}, \mathrm{ArH}), 6.90(\mathrm{dd}, J=12.5,10.8 \mathrm{~Hz}, 3 \mathrm{H}, \mathrm{ArH}), 6.33(\mathrm{t}, J=2.8 \mathrm{~Hz}, 1 \mathrm{H}, \mathrm{C}=\mathrm{CHH})$, $5.71(\mathrm{t}, J=2.4 \mathrm{~Hz}, 1 \mathrm{H}, \mathrm{C}=\mathrm{CHH}), 5.58-5.41(\mathrm{~m}, 1 \mathrm{H}, \mathrm{OCH}), 3.94\left(\mathrm{t}, J=6.5 \mathrm{~Hz}, 2 \mathrm{H}, \mathrm{CH}_{3} \mathrm{CH}_{2} \mathrm{CH}_{2} \mathrm{O}\right), 3.41$ $\left(\mathrm{ddt}, J=17.1,8.1,2.4 \mathrm{~Hz}, 1 \mathrm{H}, \mathrm{CHHC}=\mathrm{CH}_{2}\right), 2.93\left(\mathrm{ddt}, J=17.1,6.1,2.9 \mathrm{~Hz}, 1 \mathrm{H}, \mathrm{CH} H \mathrm{C}=\mathrm{CH}_{2}\right), 1.90-1.78$ $\left(\mathrm{m}, 2 \mathrm{H}, \mathrm{CH}_{3} \mathrm{CH}_{2} \mathrm{CH}_{2} \mathrm{O}\right), 1.12-0.97\left(\mathrm{~m}, 3 \mathrm{H}, \mathrm{CH}_{3} \mathrm{CH}_{2} \mathrm{CH}_{2} \mathrm{O}\right) ;{ }^{13} \mathrm{C}-\mathrm{NMR}\left(125 \mathrm{MHz}, \mathrm{CDCl}_{3}\right): \delta 170.14$, 159.58, 141.41, 134.20, 129.93, 122.43, 117.30, 114.49, 111.51, 77.82, 77.28, 77.03, 76.77, 69.61, 22.57, 10.51. HR-MS (ESI): $m / z$ calcd for $\mathrm{C}_{14} \mathrm{H}_{16} \mathrm{NaO}_{3}\left([\mathrm{M}+\mathrm{Na}]^{+}\right)$255.0991, found 255.0992.

\subsection{Fungicidal Activity Bioassay}

\subsubsection{Preparation of Spore Suspension}

The fungal pathogens C. lagenarium and B. cinerea was provided by the Agricultural Culture Collection of China (Yangling, Shaanxi, China). C. lagenarium was cultured for 2 weeks at $25 \pm 1^{\circ} \mathrm{C}$ on potato dextrose agar (PDA) while $B$. cinerea was cultured at $20^{\circ} \mathrm{C}$ on the same medium after being retrieved from the storage tube. Plates were flooded with sterile distilled water, and then conidia were scraped with a glass rod. Mycelial debris was removed by filtration. The spores were harvested and suspended in sterile distilled water containing $0.1 \%(v / v)$ Tween 20 . The concentration of the spore suspension was adjusted to $1.0 \times 10^{6}$ spores $/ \mathrm{mL}$ with sterilized distilled water following [21,39].

\subsubsection{Spore Germination Assay}

The tested samples $(10.0 \mathrm{mg})$ dissolved in acetone $(0.1 \mathrm{~mL})$ were diluted with sterile distilled water to prepare $10.0 \mathrm{~mL}$ stock solution, which was further diluted to prepare test solutions in which the final concentration of acetone was $<1 \%(v / v)$. A series of concentrations of tested samples and one control ( $1 \%$ acetone with sterile distilled water) were separately tested for spore germination of $C$. lagenarium or B. cinerea. The samples were inoculated with spore suspension of C. lagenarium or B. cinerea containing $1.0 \times 10^{6}$ spores $/ \mathrm{mL}$. Aliquots of $10 \mu \mathrm{L}$ of prepared spore suspension were placed on separate glass slides in triplicate. Slides containing the spores were incubated in a moisture chamber at $25^{\circ} \mathrm{C}$ for $6 \sim 8 \mathrm{~h}$. Each slide was then observed under the microscope for spore germination. Spores were considered to have germinated if the length of the germ tube was at least half the length of the spore. Afterward, spore germination was stopped by applying a drop of lactophenol-cotton blue to the inoculation sites on plates. The numbers of generated spores were counted under a microscope (Olympus BX61, Tokyo, Japan), and the percentage of germinated spores was calculated. Chlorothalonil was used as the positive control [21,39].

\subsection{Building and Validation of the QSAR Model}

Firstly, the optimal conformers of the title compounds with the lowest energy were computed at the DFT/6-31G (d) level using the Gaussian 03W package of programs [40]. Then, the calculated results were changed into a form compatible with CODESSA 2.7.15 using Ampac 9.1.3 [41,42]. Finally, all of the molecular descriptors involved in these compounds were calculated by CODESSA 2.7.15. In order to find out which structural features play an important role in the fungicidal activity against C. lagenarium, the heuristic method analysis was selected to generate the QSAR model. In this model, the statistical criteria were indicated by the squared correction coefficient $\left(R^{2}\right)$, the squared standard error of the estimates $\left(S^{2}\right)$, and the Fisher significance ratio $(F)$. The tested $\mathrm{IC}_{50}$ values were converted into the corresponding $\log \mathrm{IC}_{50}$ values and used as dependent variables in the QSAR studies. The quality of the final model was determined using both an internal validation and the "leave-one-out" cross-validation methods [43].

\section{Conclusions}

In summary, forty-six ester and six ether derivatives containing $\alpha$-methylene- $\gamma$-butyrolactone moieties were synthesized, and their fungicidal activities against C. lagenarium and B. cinerea was 
investigated. Halogen atom-containing derivatives showed better activity than others, especially compounds $\mathbf{6 a}, \mathbf{d}$ which exhibited excellent fungicidal activity against C. lagenarium. Both SAR and QSAR studies indicated that the structural characteristics had an important influence on the fungicidal activity, and electron withdrawing substituents on the $\alpha$-methylene- $\gamma$-butyrolactone derivatives had a positive effect on the fungicidal activity. It was notable that the present set of compounds consisted of racemic mixtures; it will be an interesting task for further studies to test the most active compounds in optically pure form. The level of fungicidal activity and cytotoxic activity observed with $\alpha$-methylene- $\gamma$-butyrolactone derivatives provide great impetus for further work on the design of high-activity and non-toxic crop-protection agents.

Acknowledgments: We greatly appreciate the funding support for this research provided by the National Natural Science Foundation of China (Grant No. 31471800, 31272074). We also thank Du-qiang Luo for the HR-MS spectral data and The Fourth Military Medical University (Xi'an, China) for the cytotoxicity testing results.

Author Contributions: Yongling $\mathrm{Wu}$ designed and carried out the experimental and wrote the paper; Delong Wang and Yanqing Gao assisted in prepared the manuscript; Juntao Feng and Xing Zhang supervised the whole experiment and provided technical guidance. All authors have read and approved the final manuscript.

Conflicts of Interest: The authors declare no conflict of interest.

\section{References}

1. Shimizu, M.; Yazawa, S.; Ushijima, Y. A promising strain of endophytic Streptomyces sp. for biological control of cucumber anthracnose. J. Gen. Plant Pathol. 2009, 75, 27-36. [CrossRef]

2. Haverkort, A.; Boonekamp, P.; Hutten, R.; Jacobsen, E.; Lotz, L.; Kessel, G.; Visser, R.; van der Vossen, E. Societal costs of late blight in potato and prospects of durable resistance through cisgenic modification. Potato Res. 2008, 51, 47-57. [CrossRef]

3. Brase, S.; Encinas, A.; Keck, J.; Nising, C.F. Chemistry and biology of mycotoxins and relatedfungal metabolites. Chem. Rev. 2009, 109, 3903-3990. [CrossRef] [PubMed]

4. Wilson, R.A.; Talbot, N.J. Fungal physiology-A future perspective. Microbiology 2009, 155, 3810-3815. [CrossRef] [PubMed]

5. Kuan, C.P.; Wu, M.T.; Huang, H.C.; Chang, H. Rapid detection of Colletotrichum lagenarium, causal agent of anthracnose of cucurbitaceous crops, by PCR and real-time PCR. J. Phytopathol. 2011, 159, 276-282. [CrossRef]

6. Williamson, B.; Tudzynski, B.; Tudzynski, P.; van Kan, J.A.L. Botrytis cinerea: The cause of grey mould disease. Mol. Plant Pathol. 2007, 8, 561-580. [CrossRef] [PubMed]

7. Fisher, M.C.; Henk, D.A.; Briggs, C.J.; Brownstein, J.S.; Madoff, L.C.; McCraw, S.L.; Gurr, S.J. Emerging fungal threats to animal, plant and ecosystem health. Nature 2012, 484, 186-194. [CrossRef] [PubMed]

8. Chen, Y.; Dai, G. Antifungal activity of plant extracts against Colletotrichum lagenarium, the causal agent of anthracnose in cucumber. J. Sci. Food Agric. 2012, 92, 1937-1943. [CrossRef] [PubMed]

9. Dodds, P.N.; Rathjen, J.P. Towards an integrated view of plant pathogen interactions. Nat. Rev. Genet. 2010, 11, 539-548. [CrossRef] [PubMed]

10. Han, C.; Barrios, F.J.; Mark, V.R.; David, A.C. Semisynthetic Derivatives of Sesquiterpene Lactones by Palladium-Catalyzed Arylation of the $\alpha$-Methylene- $\gamma$-lactone Substructure. J. Org. Chem. 2009, 74, 7176-7179. [CrossRef] [PubMed]

11. Ravinder, R.; Laura, J.A.; Le, T.; Christopher, D.T.; Amy, R.H. Cross Metathesis of $\alpha$-Methylene Lactones II: $\gamma$ - and $\delta$-Lactones. Org. Lett. 2007, 9, 1699-1701.

12. Yusuke, M.; Masaki, T. Construction of spiro-Fused 2-oxindole/ $\alpha$-methylene- $\gamma$-Butyrolactone Systems with extremely high enantioselectivity via Indium-Catalyzed amide allylation of $\mathrm{N}$ methyl isatin. Org. Lett. 2013, 15, 6182-6185.

13. Irakusne, L.; Santiago, R.; Javier, I.; Florenci, V. Highly Stereoselective Epoxidation of $\alpha$-Methyl- $\gamma$-hydroxy$\alpha, \beta$-unsaturated Esters: Rationalization and Synthetic Applications. J. Org. Chem. 2007, 72, 6614-6617.

14. Antonio, G.G.; Margarita, H.S.; Juan, I.P. Synthesis and Antiproliferative Activityof a New Compound Containing an $\alpha$-Methylene- $\gamma$-Lactone Group. J. Med. Chem. 2002, 45, 2358-2361. 
15. Romeo, R.; Pier, G.B.; Mojgan, A.T.; Jaime, Bermejo; Francisco, E.; Monica, B.; Roberto, G. Design, Synthesis, and Biological Evaluation of Hybrid Molecules Containing $\alpha$-Methylene- $\gamma$-Butyrolactones and $\alpha$-Bromoacryloyl Moieties. J. Med. Chem. 2005, 48, 7906-7910.

16. Miyazawa, M.; Shimabayashi, H.; Hayashi, S.; Hashimoto, S.; Nakamura, S.; Kosaka, H.; Kameoka, H. Synthesis and Biological Activity of $\alpha$-Methylene- $\gamma$-lactones as New Aroma Chemicals. J. Agric. Food Chem. 2000, 48, 5406-5410. [CrossRef] [PubMed]

17. Feng, J.T.; Zhang, Y.M.; Wang, J.R.; Zhang, X. Synthesis and antifungal activities of carabrone derivatives. Chin. J. Pestic. Sci. 2007, 9, 185-188. [CrossRef] [PubMed]

18. Feng, J.T.; Ma, Z.Q.; Wang, J.R.; Wang, Z.H.; Su, Z.S.; Li, G.Z.; Zhang, X. Carabrane Type Sesquiterpene Lactone Compound with Sterilization Activity Separated from Carpesium macrocephalum Franch.et Sav and Its Application. China Patent ZL 200,610,104,867, 25 June 2009.

19. Feng, J.T.; Ma, Z.Q.; Li, J.; He, J.; Xu, H.; Zhang, X. Synthesis and antifungal activity of carabrone derivatives. Molecules 2010, 15, 6485-6492. [CrossRef] [PubMed]

20. Feng, J.T.; Wang, H.; Ren, S.X.; He, J.; Liu, Y.; Zhang, X. Synthesis and Antifungal Activities of Carabrol Ester Derivatives. J. Agric. Food Chem. 2012, 60, 3817-3823. [CrossRef] [PubMed]

21. Feng, J.T.; Wang, D.L.; Wu, Y.L.; Yan, H.; Zhang, X. New antifungal scaffold derived from a natural pharmacophore: Synthesis of $\alpha$-methylene- $\gamma$-butyrolactone derivatives and their antifungal activity against Colletotrichum lagenarium. Bioorg. Med. Chem. Lett. 2013, 23, 4393-4397.

22. Gao, Y.; Li, J.; Song, Z.; Song, J.; Shang, S.; Xiao, G.; Wan, Z.; Rao, X. Turning renewable resources into value-added products: Development of rosin-based insecticide candidates. Ind. Crop. Prod. 2015, 76, 660-671. [CrossRef]

23. García, I.; Fall, Y.; Gómez, G.; González-Díaz, H. First computational chemistry multi-target model for anti-Alzheimer, anti-parasitic, anti-fungi, and anti-bacterial activity of GSK-3 inhibitors in vitro, in vivo, and in different cellular lines. Mol. Divers. 2011, 15, 561-567. [CrossRef] [PubMed]

24. Prado-Prado, F.J.; Borges, F.; Perez-Montoto, L.G.; González-Díaz, H. Multi-target spectral moment: QSAR for antifungal drugs vs. different fungi species. Eur. J. Med. Chem. 2009, 44, 4051-4056. [CrossRef] [PubMed]

25. Choudhury, P.K.; Foubelo, F.; Yus, M. Direct indium-promoted preparation of $\alpha$-methylene- $\gamma$-lactones from 2-(bromomethyl) acrylic acid and carbonyl compounds. Tetrahedron 1999, 55, 10779-10788. [CrossRef]

26. Song, J.; Wang, Z.; Findlater, A.; Han, Z.; Jiang, Z.; Chen, J.; Zheng, W.; Hyde, S. Terpenoid mosquito repellents: A combined DFT and QSAR study. Bioorg. Med. Chem. Lett. 2013, 23, 1245-1248. [CrossRef] [PubMed]

27. Wang, Z.; Song, J.; Chen, J.; Song, Z.; Shang, S.; Jiang, Z.; Han, Z. QSAR study of mosquito repellents from terpenoid with a six-member-ring. Bioorg. Med. Chem. Lett. 2008, 18, 2854-2859. [CrossRef] [PubMed]

28. Liao, S.; Song, J.; Wang, Z.; Chen, J.; Fan, G.; Song, Z.; Shang, S.; Chen, S.; Wang, P. Molecular interactions between terpenoid mosquito repellents and human-secreted attractants. Bioorg. Med. Chem. Lett. 2014, 24, 773-779. [CrossRef] [PubMed]

29. Li, J.; Gao, Y.; Shang, S.; Rao, X.J.; Wang, Z. Synthesis and quantitative structure-activity relationship (QSAR) studies of novel rosin-based diamide insecticides. RSC Adv. 2014, 4, 58190-58199. [CrossRef]

30. Li, J.; Xiao, G.; Shang, S.; Rao, X. A QSAR Study of the Acrylpimaric Acid Derivatives as the Inhibitors of NCI-H460. Lett. Drug Des. Discov. 2014, 11, 59-66. [CrossRef]

31. Karelson, M.; Lobanov, V.S.; Katritzky, A.R. Quantum-Chemical Descriptors in QSAR/QSPR Studies. Chem. Rev. 1996, 96, 1027-1043. [CrossRef] [PubMed]

32. Thanikaivelan, P.; Subramanian, V.; Rao, J.R.; Nair, B.U. Application of quantum chemical descriptor in quantitative structure activity and structure property relationship. Chem. Phys. Lett. 2000, 323, 59-70. [CrossRef]

33. Ellis, G.W.L.; Tavares, D.F.; Rauk, A. The mechanism of an intramolecular Michael addition: A MNDO study. Can. J. Chem. 1985, 63, 3510-3515. [CrossRef]

34. Lavallee, J.F.; Berthiaume, G.; Deslongchamps, P. Intramolecular Michael addition of cyclic $\beta$-ketoester on conjugated acetylenic ketone. Tetrahedron Lett. 1986, 27, 5455-5458. [CrossRef]

35. Kalani, K.; Yadav, D.; Khan, F.; Srivastava, S.; Suri, N. Pharmacophore, QSAR, and ADME based semisynthesis and in vitro evaluation of ursolic acid analogs for anticancer activity. J. Mol. Model. 2012, 18, 3389-3413. [CrossRef] [PubMed] 
36. Roy, P.P.; Kovarich, S.; Gramatica, P. QSAR Model Reproducibility and Applicability: A Case Study of Rate Constants of Hydroxyl Radical Reaction Models Applied to Polybrominated Diphenyl Ethers and (Benzo-)Triazoles. J. Comput. Chem. 2011, 32, 2386-2396. [CrossRef] [PubMed]

37. Schmidt, T.J.; Nour, A.M.M.; Khalid, S.A.; Kaiser, M.; Brun, R. Quantitative Structure-Antiprotozoal Activity Relationships of Sesquiterpene Lactones. Molecules 2009, 14, 2062-2076. [CrossRef] [PubMed]

38. Heilmann, J.; Waseschaa, M.R.; Schmidt, T.J. The Influence of Glutathione and Cysteine Levels on the Cytotoxicity of Helenanolide Type Sesquiterpene Lactones Against KB Cells. Bioorg. Med. Chem. 2001, 9, 2189-2194. [CrossRef]

39. Li, S.K.; Ji, Z.Q.; Zhang, J.W.; Guo, Z.Y.; Wu, W.J. Synthesis of 1-Acyl-3-isopropenylbenzimidazolone Derivatives and Their Activity against Botrytis cinerea. J. Agric. Food Chem. 2010, 58, 2668-2672. [CrossRef] [PubMed]

40. Frisch, M.J.; Trucks, G.W.; Schlegel, H.B.; Scuseria, G.E.; Robb, M.A.; Cheeseman, J.R.; Montgomery, J.A.; Vreven, T.; Kudin, K.N.; Burant, J.C.; et al. Gaussian 03; Gaussian, Inc.: Wallingford, CT, USA, 2004.

41. Katritsky, A.; Karelson, M.; Lobanov, V.S.; Dennington, R.; Keith, T.A.; Keith, R.D.A.T. Codessa 2.7.15; Semichem, Inc.: Shawnee, KS, USA, 2004.

42. Dewar, M.J.S.; Holder, A.J.; Roy, I.; Dennington, D.; Liotard, D.A.; Truhlar, D.G.; Keith, T.A.; Millam, J.M.; Harris, C.D. AMPAC 9.3.1; Semichem, Inc.: Shawnee, KS, USA, 2004.

43. Li, J.; Tian, X.; Gao, Y.; Shang, S.; Feng, J.; Zhang, X. A value-added use of volatile turpentine: Antifungal activity and QSAR study of $\beta$-pinene derivatives against three agricultural fungi. RSC Adv. 2015, 5, 66947-66955. [CrossRef]

Sample Availability: Samples of the compounds $4 \mathbf{a}-\mathbf{r}, \mathbf{5 a}-\mathbf{r}$ and $\mathbf{6 a}-\mathbf{p}$ are available from the authors.

(C) 2016 by the authors; licensee MDPI, Basel, Switzerland. This article is an open access article distributed under the terms and conditions of the Creative Commons by Attribution (CC-BY) license (http://creativecommons.org/licenses/by/4.0/). 